\title{
Development and Evaluation of an Economic Model for a Libyan Oil Field Development with an EPSA Agreement
}

\author{
Mohamed S BenZeglam
}

Follow this and additional works at: https://researchrepository.wvu.edu/etd

\section{Recommended Citation}

BenZeglam, Mohamed S, "Development and Evaluation of an Economic Model for a Libyan Oil Field Development with an EPSA Agreement" (2018). Graduate Theses, Dissertations, and Problem Reports. 7162.

https://researchrepository.wvu.edu/etd/7162

This Thesis is protected by copyright and/or related rights. It has been brought to you by the The Research Repository @WVU with permission from the rights-holder(s). You are free to use this Thesis in any way that is permitted by the copyright and related rights legislation that applies to your use. For other uses you must obtain permission from the rights-holder(s) directly, unless additional rights are indicated by a Creative Commons license in the record and/ or on the work itself. This Thesis has been accepted for inclusion in WVU Graduate Theses, Dissertations, and Problem Reports collection by an authorized administrator of The Research Repository @ WVU. For more information, please contact researchrepository@mail.wvu.edu. 
Development and Evaluation of an Economic Model for a Libyan Oil Field Development with an EPSA Agreement

\author{
Mohamed S. BenZeglam \\ Thesis submitted \\ to the Benjamin M. Statler College of Engineering and Mineral Resources \\ at West Virginia University \\ in partial fulfillment of the requirements for the degree of \\ Master of Science in \\ Petroleum and Natural Gas Engineering
}

Ilkin Bilgesu, Ph.D., Chair

Samuel Ameri, M.S.

Kashy Aminian, Ph.D.

Department of Petroleum and Natural Gas Engineering

Morgantown, West Virginia

2018

Keywords: economics, oil production, Monte Carlo, reservoir variables

Copyright 2018 Mohamed BenZeglam 


\section{Abstract \\ Development and Evaluation of an Economic Model for a Libyan Oil Field Development with an EPSA Agreement}

Mohamed BenZeglam

Economic evaluation of any project is an essential part of the process of studying available investment opportunities and supporting decision-making, by using special methodology and scientific analysis to select best options. It is a decision-making tool. The evaluation of petroleum projects has general features which are similar to those in other industries. To be able to carry out a detailed economic evaluation study on an upstream petroleum project it is essential to be familiar with the applied petroleum fiscal regime.

An International Oil Company (IOC) operating in Libya has recently made a significant undersaturated oil discovery inside one of its designated concession areas within the Sirte Basin in the northern part of the Sahara Desert. The company is considering to develop this discovery under the existing Exploration \& Production Sharing Agreement (EPSA-IV) with the Libyan National Oil Corporation (NOC). This agreement is a special case of the widely applied Production Sharing Contracts (PSC).

An economic model is developed with a set of basic (rough) data obtained from the company through NOC. NOC wants to determine the feasibility of developing this discovery based on the available data through the construction of an economic model. However, NOC does not have such a model. As a result, this study focuses on the construction of an economic model that incorporates the EPSA-IV terms and conditions to be used for evaluating the economics of development projects under this agreement. Further, the study determines the impact of variations in input parameters. The results indicate that the project will be profitable. 


\section{Dedication}

"to my parents, my sisters, my wife, and my daughter" 


\section{Acknowledgement}

I would like to express my sincere gratitude to Dr. Ilkin Bilgesu Department of Petroleum Engineering at West Virginia University, for giving me the opportunity to do my Master's Project on this study. He has provided me with the support and encouragement through the past years while taking my post graduate courses.

I would also like to thank Prof. Samuel Ameri, Dr. Kashy Aminian, and other staff members for approving the title of my project and for their encouragement while working on this thesis.

I also thank members of the National Oil Corporation who provided me with the necessary data on the recent discovery and expressed their need to carry out this economic evaluation study and to acquire an economic model based on EPSA-IV agreement to enable them to evaluate similar future projects.

Finally, I would like to express my sincere appreciation to the Faculty of Petroleum Engineering at the University of Tripoli for granting me a full academic scholarship to obtain my Master's Degree. 


\section{Table of Content}

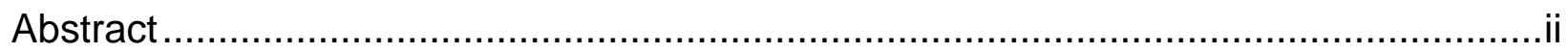

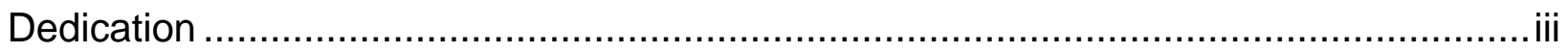

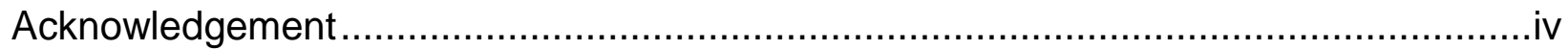

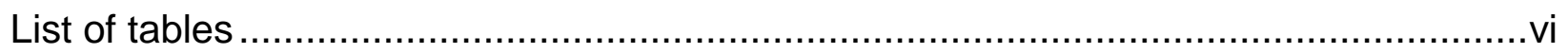

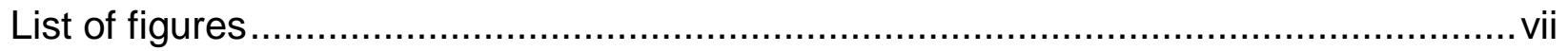

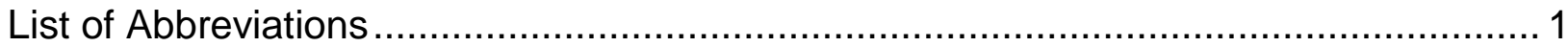

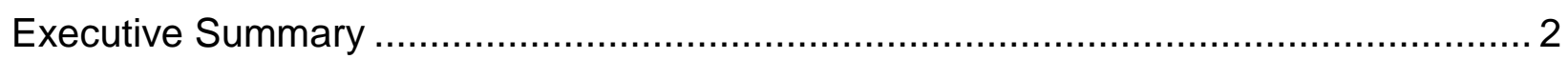

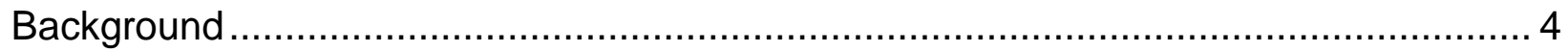

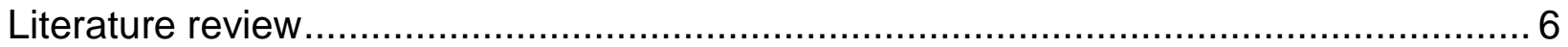

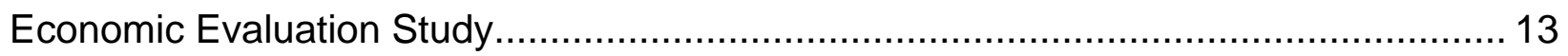

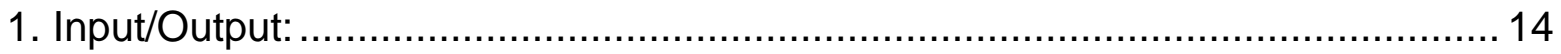

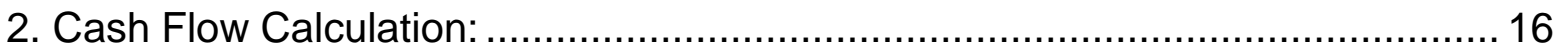

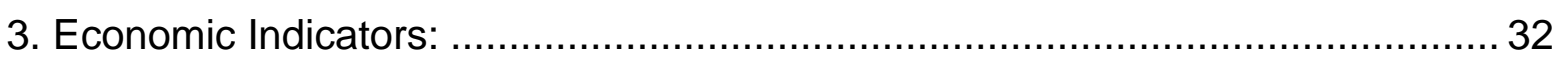

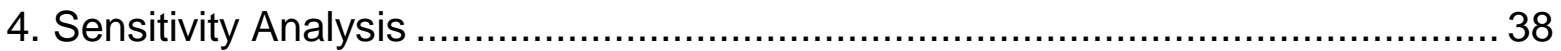

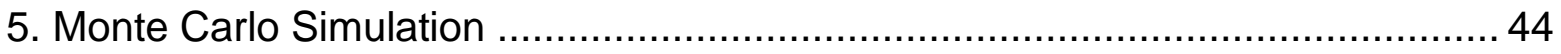

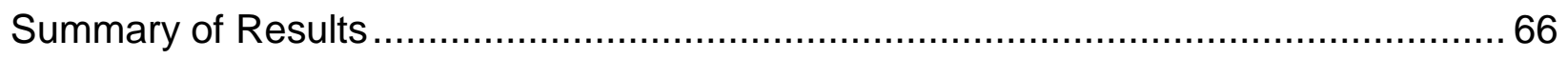

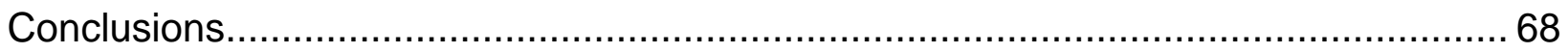

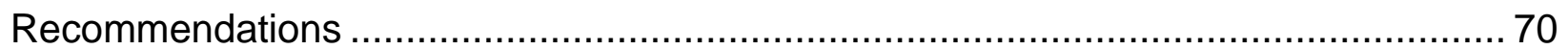

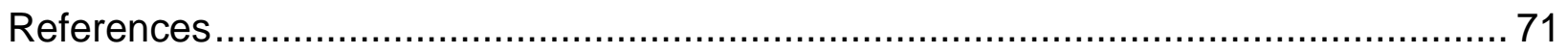

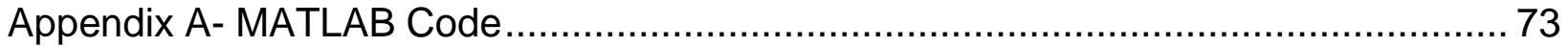

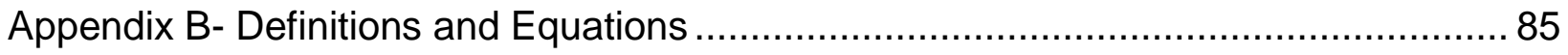




\section{List of tables}

Table1 : Economic indicators for the project and each party ................................... 2

Table2 : Monte Carlo Simulation Worst/Best-Case scenario........................................... 3

Table3 : "A" Factor (Index Factor) ..................................................................... 10

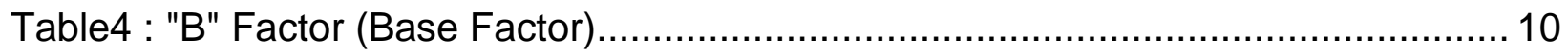

Table5 : Calculated annual production rate, price and revenue for each product ......... 17

Table6 : The expected cumulative production after 20 years of production .................. 18

Table7 : The annual capital and operating expenditures ........................................... 19

Table8 : Expected cumulative capital and operating expenditures after 20 years ......... 20

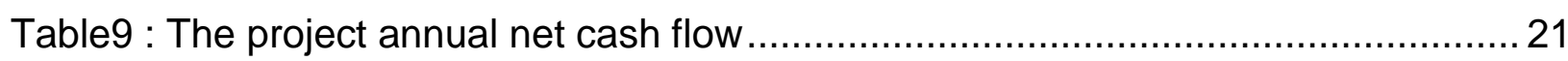

Table10 : The second party abandonment provision:................................................ 23

Table11 : The second party cost recovery profile...................................................... 24

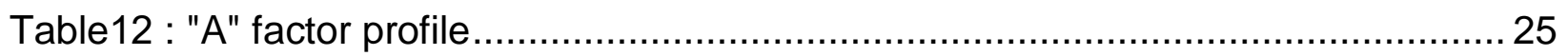

Table13 : "B" Factor and the combined factor profiles ................................................ 26

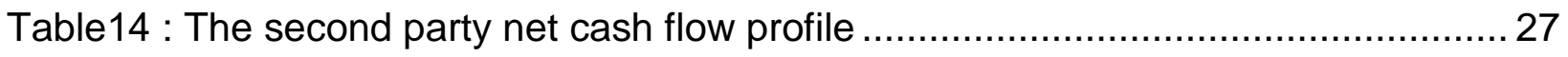

Table15 : First party net cash flow calculation using method 1 ................................... 29

Table16 : First party net cash flow calculation using method 2 ................................. 30

Table17 : The economic indicators for the project and for each party .......................... 34

Table18 : Production cost per barrel equivalent calculations for each party based on

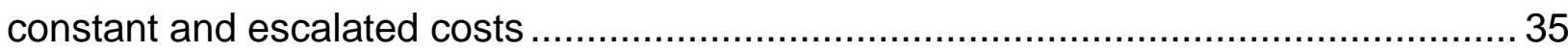

Table19 : The average constant and nominal costs per barrel equivalent for the project

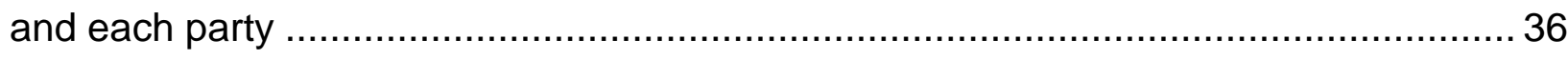

Table20 : The calculated NPV's and IRR's for the project and for each party for each

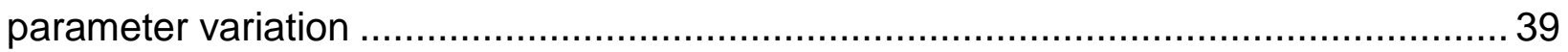

Table21 : Economic Indicator for the Project (MATLAB vs Spreadsheet) ..................... 44

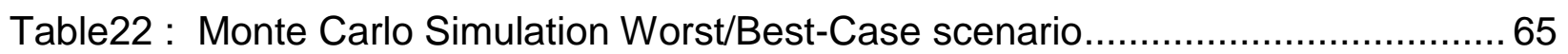

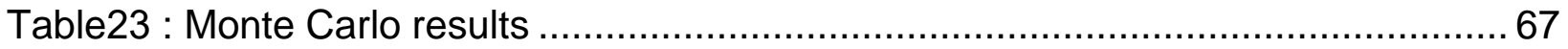

Table24 : Decline curves (Model, Exponential and Linear Decline) .............................. 84

Table25 : Decline curves (Model, Harmonic and Hyperbolic Decline) ........................... 84 


\section{List of figures}

Figure 1: Cost and production share of each party according to EPSA-IV ................... 11

Figure 2: Costs and revenues share among the two parties ........................................ 11

Figure 3: Input data as displayed in the Input / Output section.................................... 15

Figure 4: The annual oil, gas and condensate prodution rates.................................. 18

Figure 5: The annual capital and operating expenditures......................................... 20

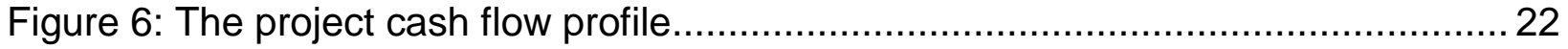

Figure 7: The project net cash flow profile for each party .......................................... 31

Figure 8: The project NCF allocation for each party ............................................... 31

Figure 9: The Internal Rate of Return for the project and for each party..................... 33

Figure 10: The payback time for the project and for each party ................................ 33

Figure 11: Production cost per barrel equivalent profile for the project and for each party

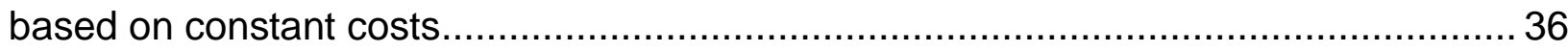

Figure 12: Production cost per barrel equivalent profile for the project and for each party

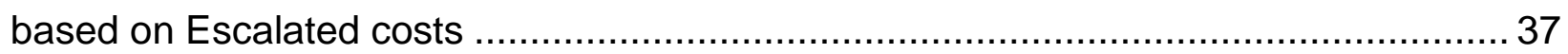

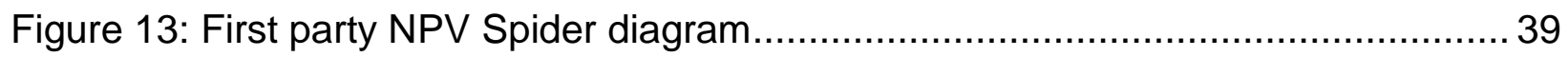

Figure 14: Second party NPV Spider diagram ...................................................... 40

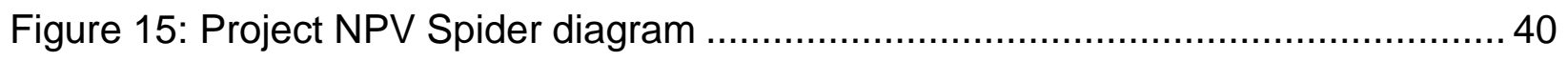

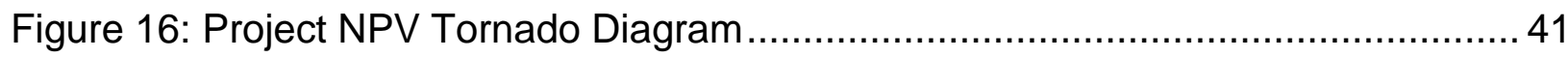

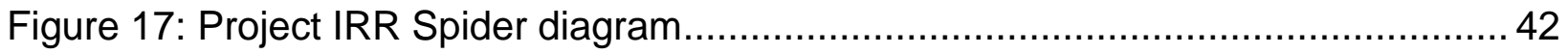

Figure 18: First Party IRR Spider diagram ........................................................ 42

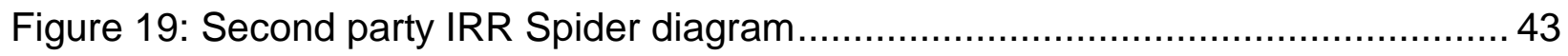

Figure 20: Second Party IRR Tornado Diagram ...................................................... 43

Figure 21: Production Forecast using Different Decline Curve.................................. 45

Figure 22: Production Forecast using Different Decline Curve (Semi-Log) ................... 46

Figure23 : Distribution of Production Rate and NPV Distribution Functions .................. 47

Figure24 : Net Present Value vs Production Rate .................................................. 48

Figure 25: Distribution of Oil Price and NPV Distribution Functions ............................. 49

Figure 26: Net Present Value vs Oil Price .............................................................. 49

Figure 27: Distribution of Gas Price and NPV Distribution Functions ...........................5 50 


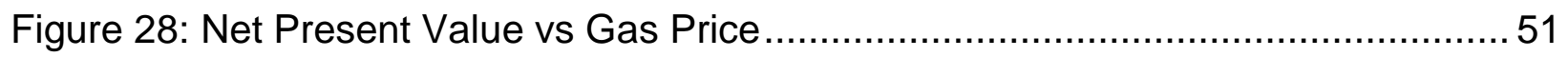

Figure 29: Distribution of Condensate Price and NPV Distribution Functions ............... 52

Figure 30: Net Present Value vs Condensate Price …............................................ 52

Figure 31: Distribution of Number of Wells and NPV Distribution Functions ................. 53

Figure 32: Net Present Value vs Number of Wells .................................................... 54

Figure 33: Distribution of Cost Contingency and NPV Distribution Functions ............... 55

Figure 34: Net Present Value vs Cost Contingency ................................................ 55

Figure 35: Distribution of Gas Oil Ratio and NPV Distribution Functions ......................56

Figure 36: Net Present Value vs Gas Oil Ratio ....................................................... 57

Figure 37: Discount Rate and NPV Distribution Functions ...................................... 58

Figure 38: Net Present Value vs Discount Rate ....................................................... 58

Figure 39: Inflation Rate and NPV Distribution Functions ....................................... 59

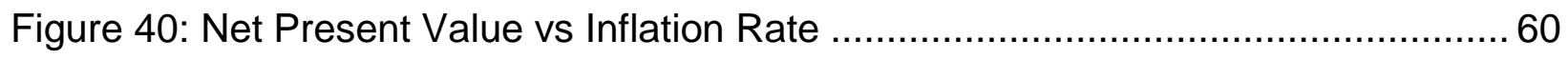

Figure 41: NPV Probability and Cumulative Distribution Functions (All Key Parameters

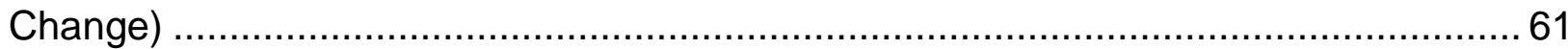

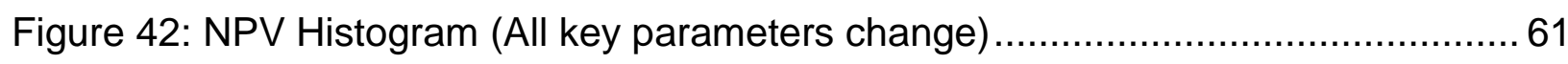

Figure 43: NCF Histogram (All key parameters change) ............................................62

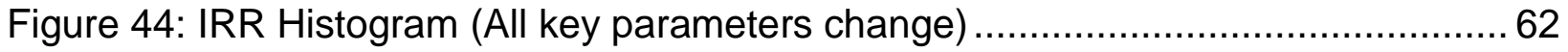

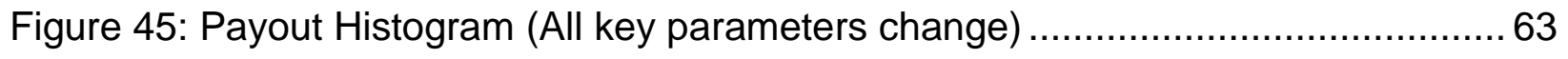

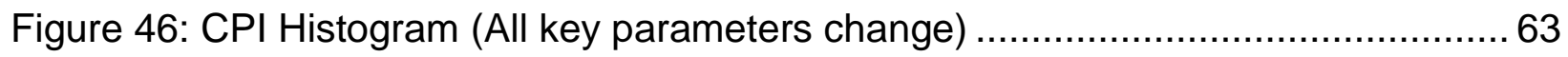

Figure 47: ME value Histogram (All key parameters change) ..................................... 64

Figure 48: ME Time Histogram (All key parameters change) ...................................... 64 


\section{List of Abbre}

\section{viations}

$\begin{array}{ll}\text { BOE } & \text { Barrels of Oil Equivalent } \\ \text { CAPEX } & \text { Capital Cost, \$ } \\ \text { CCF } & \text { Cumulative (Net) Cash Flow, \$ } \\ \text { CPI } & \text { Capital Productivity Index } \\ \text { DEPSA } & \text { Development and Production Sharing Agreement } \\ \text { EPSA } & \text { Exploration and Production Sharing Agreement } \\ \text { IOC } & \text { International Oil Companies } \\ \text { IRR } & \text { Internal Rate of Return } \\ \text { M } & 1,000 \\ \text { ME } & \text { Maximum Exposure } \\ \text { MM } & 1,000,000 \\ n & \text { Year } \\ \text { NCF } & \text { Net Cash Flow, \& } \\ \text { NOC } & \text { National Oil Company } \\ \text { NPV } & \text { Net Present Value, \$ } \\ \text { OPEX } & \text { Operational Expenses, \$ } \\ \text { PSC } & \text { Production Sharing Contract } \\ \text { PO } & \text { Profit Oil } \\ \text { ROI } & \text { Return on Investment } \\ \text { SCF } & \text { Standard Cubic Feet } \\ \text { STB } & \text { Million US Dollars } \\ \text { \$ } & \\ \text { \$MM } & \end{array}$




\section{Executive Summary}

The Libyan NOC wishes to acquire a spreadsheet economic model to be able to study the feasibility of oil development projects under the EPSA-IV agreement, including a recent discovery made by an IOC in the Sirte Basin.

This study consists of developing an economic model to study the feasibility of oil development projects under the EPSA-IV agreement for the Libyan NOC, including a recent discovery made by an $\mathrm{IOC}$ in the Sirte Basin.

A set of basic (rough) data of this discovery has been obtained from the IOC through NOC. A spreadsheet economic model was built to accommodate this data and to carry out a detailed economic evaluation study to determine the viability of developing this discovery, for the project as a whole and for each involved party, namely NOC ( $1^{\text {st }}$ Party) and IOC (2 $2^{\text {nd }}$ Party).

The study included calculating cash flow profile, determining the economic indicators and analyzing the sensitivity of key indicators to varying certain parameters.

The following table summarizes the economic indicators for the project as a whole and for each party according to EPSA-IV terms and conditions for an assumed production life of 20 years.

Table1 : Economic indicators for the project and each party

\begin{tabular}{|c|c|c|c|c|}
\hline Economic Indicator & Project & 1st Party & 2nd Party & Units \\
\hline Net Cash Flow (NCF) & 24,197 & 22,275 & 1,923 & $\$ M M$ \\
\hline Net Present Value (NPV) & 7,141 & 6,787 & 354 & \$MM \\
\hline Internal Rate of Return (IRR) & $55.5 \%$ & $76.4 \%$ & $18.5 \%$ & \\
\hline Payback Period (Payout) & 4.83 & 4.49 & 6.86 & Years \\
\hline Capital Productivity Index (CPI) & 5.84 & 10.47 & 0.61 & $\$ / \$$ \\
\hline Cumulative Production & 367 & 327 & 40 & MMBOE \\
\hline Cost per Barrel Equivalent (Constant) & 8.12 & 6.18 & 24.02 & \$/BOE \\
\hline Cost per Barrel Equivalent (Escalated) & 9.86 & 7.71 & 27.46 & \$/BOE \\
\hline
\end{tabular}

Each of these indicators confirms the economic viability of developing this discovery for each party. The sensitivity analysis indicated that the project economics is highly sensitive 
to the production rate, selling prices and the assumed discount rate, while less sensitive to the capital and operating expenses.

Monte Carlo simulation results confirm the project profitability with worst-case scenario of 3,000 \$MM, and best scenario of 12,000 \$MM. Additionally, the rest of the economic indicators show the project remain feasible in all cases.

The following table summarizes the results obtained from conducting the Monte Carlo simulation by showing the best and worst possible scenario using the selected probability distributions for each key parameter.

Table2 : Monte Carlo Simulation Worst/Best-Case scenario

\begin{tabular}{|l|c|c|l|c|c|l|c|c|}
\hline \multicolumn{9}{|c|}{ Monte Carlo Simulation } \\
\hline \multicolumn{3}{|c|}{ Worst-Case } & \multicolumn{3}{c|}{ Base-Case } & \multicolumn{3}{c|}{ Best-Case } \\
\hline NCF & 11,200 & \$MM & NCF & 24,197 & \$MM & NCF & 38,000 & \$MM \\
NPV & 3,000 & \$MM & NPV & 7,141 & \$MM & NPV & 12,000 & \$MM \\
IRR & 33 & $\%$ & IRR & 55.5 & $\%$ & IRR & 77 & $\%$ \\
Payout & 5.8 & Years & Payout & 4.83 & Years & Payout & 4.5 & Years \\
CPI & 2 & \$/\$ & CPI & 5.84 & \$ \$ & CPI & 10.9 & \$ \$ \\
ME Value & $-1,890$ & \$MM & ME Value & $-1,462$ & \$MM & ME Value & $-1,100$ & \$MM \\
Year of ME & 2022 & & Year of ME & 2022 & & Year of ME & 2022 & \\
\hline
\end{tabular}




\section{Background}

Libya gained its independence in 1951. Its economy was dependent on simple trades in addition to the rents derived from US and UK military bases operating on the Libyan soil. In the 1960's Libya became a major oil producer after the discovery of giant oil fields. However, its economy ever since has been dependent almost entirely on the oil \& gas revenues. A number of IOCs, such as Esso, Occidental, Texaco, British Petroleum, Total, Agip and others were actively operating under the concession agreement that was in effect then. They were granted concession blocks at the Sirte Basin and made giant oil discoveries. These discoveries were quickly developed and produced. Under the terms of this agreement the IOCs were granted the right to explore, produce and market the minerals located on the country's various blocks or concession areas. They were granted full control, including technical and commercial control, over all aspects of the oil and gas production. The government intake was then $16.67 \%$ royalties and $65 \%$ production tax.

During the 1970's a partial nationalization came into effect where the government issued a decree acquiring $51 \%$ of most of the IOC's assets. Under this decree the government started paying $51 \%$ of the operating costs and receiving $51 \%$ of the revenues. The companies were still paying the government royalties and taxes on its remaining revenues. The National Oil Corporation was then established representing the government in receiving its share of the petroleum revenues.

As a result of this decree many operating companies suffered from low profits and decided to withdraw from the country. Their assets were bought by the government and a number of local companies were established to continue their operations. In addition, oil embargo was imposed and the country's economy severely suffered from lack of expertise and funds. Consequently, the country's exploration activities were declined rapidly and its oil reserves were being depleted without adding new discoveries. The Libyan oil industry dramatically suffered from lack of fund and technology.

NOC then decided to encourage foreign companies to return under a Production Sharing Contracts (PSC) regime. Under the PSC, NOC is relieved from bearing the risk of finding new discoveries while benefiting from the technology brought by the international oil 
companies. It introduced the Exploration and Production Sharing Agreement (EPSA) which is a special case of the PSC. In 1979 the introduction of EPSA-I was enacted. Libya continued to issue new versions of EPSA hoping to attract more investors in the oil industry. EPSA-II was introduced in the 1980's followed by EPSA-III in 1990's, and finally EPSA-IV in 2005. The main difference between EPSA-IV and the previous versions is that under EPSA-IV for IOC to win the bid it should accept the lowest share of profits. A number of major companies such as Exxon-Mobil, Occidental, Shell and others won EPSA-IV bids and were granted open blocks to carry out exploration activities.

Under the EPSA-IV agreement the IOC is responsible for all exploration activities such as seismic surveys, wildcat and appraisal well drilling during a fixed period (normally five years). If no commercial discovery is found the company leaves without any compensation from NOC. However, in case of a commercial discovery the capital and operating costs of the field development project are shared between both parties and the company receives a portion of the total production to recover its past costs (including exploration) plus adequate profit. Under this agreement the IOC is exempted from taxes, custom duties and rental fees. So, the EPSA-IV agreement was attractive to both IOC and NOC.

Under the EPSA-IV agreement the IOC does not grant ownership of the oil as in the case of the concession agreement. It acts as a contractor and only grants the right to receive a share of the production. However, it bears the risk of exploration costs. As a result, the company must insure that its income is consistent with the risk. With regards to the government the introduction of the EPSA-IV agreement was attractive. In addition to receiving an adequate profit it benefits from attracting foreign investments, job creation, technology transfer and the development of infrastructure. So, at the end it is a win-win situation.

At the turn of the century a number of companies failed to find commercial discoveries and had to withdraw while others were fortunate enough to find significant discoveries. They submitted development plans to obtain NOC's approval for projects commerciality. Once granted they developed these discoveries jointly with NOC and started production under EPSA-IV terms and conditions. 


\section{Literature review}

\section{Petroleum Economic Evaluation:}

Economic evaluation of any project is an essential part of the process of studying available investment opportunities and supporting decision-making, by using special methodology and scientific analysis to select best options. It is a decision-making tool. The evaluation of petroleum projects has general features which are similar to those in other industries. However, there are special and distinguished issues, essentially linked to the nature and conditions of petroleum projects that require special skills and experiences (Yas, 2010). The upstream petroleum projects are characterized by:

- High Risk in finding hydrocarbon resources

- High Degree of Uncertainty in predicting future prices/costs/production rate/reserves.

- Capital Intensive due to huge amounts spent for exploration and to produce sufficient oil reserves.

- Long Period between start of Project until Profit

- Limited Production Period (Contract)

- High Technology.

- High Reward/Return

To be able to carry out a detailed economic evaluation study on an upstream petroleum project it is essential to be familiar with the applied petroleum fiscal regime.

\section{Petroleum Fiscal Regime:}

The petroleum fiscal regime is a set of laws, regulations and agreements which govern the economic benefits derived from the upstream petroleum projects (Johnston, 1994). The regime dictates how the costs and the profits will be shared among the involved parties; the National Oil Corporation and the International Oil Company.

Because each country has distinctive legislation, there are theoretically just as many different fiscal regimes as there are countries in the world with petroleum resources, but 
the regimes can still be categorized based on their common characteristics. So there is no ideal Fiscal Regime or One-Regime-Fits-All.

Within fiscal regimes where the government owns the mineral rights, the governments have generally selected one of two types of licensing systems: a concession agreement or a contractual (production sharing) agreement.

\section{Concession Agreement:}

All oil companies within the Libyan Oil Industry were operating under the concession agreement which was in effect since the 1960's. Under the concession agreement, IOCs were granted the right to explore, produce and market the minerals located on one of the country's various blocks or concession areas. A concession agreement granted the IOC full control, including technical and commercial control, over all aspects of the oil and gas production for a limited time (Karbal, 2015). The economic evaluation of the Libyan upstream projects under the concession agreement is relatively simple and does not require a rigorous software.

By the 1980's following the economic downturn of the Libyan Oil Industry which resulted from the withdrawal of many IOC's and the imposed US embargo, NOC decided to encourage foreign investments by introducing the Exploration and Production Sharing Agreement (EPSA) which is a special case of the Production Sharing Contracts.

\section{Production Sharing Contracts (PSCs)}

Production sharing contracts are a common type of contract signed between NOC and IOC. Today they dominate most of the oil companies in the Middle East and Central Asia. In production sharing contracts, the NOC awards the execution of exploration and production activities to IOC which bears the mineral and financial risk of the initiative and explores, develops and ultimately produces the field as required. When successful, IOC is permitted to use the money from produced oil to recover capital and operational expenditures, known as "cost recovery". The remaining money is known as "profit oil", 
and is split between the government and the company in accordance with the EPSA terms and conditions.

However, the split of the profit between NOC and IOC is relatively complex as IOC share of the profit oil follows a sliding scale. As a result, IOC's make the decision to invest in a certain petroleum project based on economic models. These models are constructed as spreadsheets prepared by internal economists in the company or by external experts. As a result, each petroleum company has developed its own economics model (Shereih, 2015).

\section{EPSA-IV}

Compared to the Concession Agreement, the EPSA-IV which is the latest version of the EPSA agreement was preferred by both parties. In 2008, NOC decided to convert all IOC contracts from concession to special version of EPSA-IV agreements called Development and Production Sharing Agreement (DEPSA) (Palmer, 2016). On 17 July 2008, NOC continued their policy of redefining contracts in line with the new rubric by renegotiating the contract for an international consortium operated by Spain's Repsol, in partnership with France's Total, Austria's OMV and Norway's Saga Petroleum. In 2011, NOC continued negotiating a DEPSA with the Waha Group, consisting of US oil majors Marathon, ConocoPhillips and Hess ("EPSA IV," n.d). However, these negotiations were suspended due to the political unrest following the Arab Spring. Currently NOC is back negotiating with Germany's Wintershall to convert its existing Concession Agreement to DEPSA.

NOC has been responsible for negotiating new EPSA-IV agreements with prospective IOC's. Because of the complexity of the agreement, it has been relying on IOC's to present their project economics and sometimes verify it with the help of a third party economic consultant.

\section{Recent Discovery}

A few years ago an IOC signed an EPSA-IV agreement with NOC whereby an open block at the Sirte Basin was granted. It then carried out an extensive exploration activity 
including a seismic survey, wild cats and appraisal wells drilling before declaring an oil discovery. It is currently in the process of preparing a comprehensive development plan to obtain NOC's approval of the commerciality of the discovery. Some data was received from NOC and used in determining the economics of developing this discovery for each party under the existing EPSA-IV terms and conditions.

It has always been the case that NOC would like to be able to run its own economic evaluation on all EPSA-IV projects. A number of economics software's are being acquired by NOC and other petroleum companies in Libya to determine upstream project profitability including Schlumberger's Merak PEEP. However, these softwares can carry out standard economic analyses including production forecasting and portfolio management but they cannot simulate the complexity of the cost recovery, sliding scale factors and the abandonment provision calculations detailed in the agreement. These softwares are currently used by NOC and most of the local oil companies on relatively simple projects and for training purposes. As a result, it is decided to conduct this study for the development of an economic spreadsheet model specially designed for EPSA-IV projects and further use it for determining the profitability of this new EPSA-IV project.

\section{EPSA-IV Description}

The EPSA-IV agreement clearly dictates how the costs and the production will be shared among the parties. In terms of costs, $100 \%$ of the exploration costs, $50 \%$ of the capital costs and $15 \%$ of the operating costs are to be paid by IOC. NOC will pay the remaining costs. In the case of production, $15 \%$ of the production will be entitled to IOC (as a cost stop) to recover its past costs including the exploration and the development capital and operating costs (cost recovery). Once its past costs are recovered its remaining entitled production (called profit oil) will be shared with NOC. IOC share of profit oil will follow a sliding scale intended to limit its withdrawal. This sliding scale is a function of two factors; namely the Index or "A" Factor and the Base or "B" Factor. The "A" Factor is calculated based on the ratio "R" of IOC's cumulative revenue divided by its cumulative costs as of the previous year. The higher the ratio "R", indicating that IOC is receiving additional revenue, the lower the "A" Factor. The Base or "B" Factor is a function of the total fluid production rate (oil and condensate). The production rate is divided into segments. A 
specific "B" factor is assigned to each segment so that the higher the rate the lower the overall "B" factor.

The following tables describe these factors (NOC v. IOC, 2006), and the allocation of the costs and revenues of each party:

Table3 : "A" Factor (Index Factor)

\begin{tabular}{|c|c|}
\hline \multicolumn{2}{|c|}{ "A" Factor (Index Factor) } \\
Is a function of R = Company's (Cum Revenue / Cum Costs \\
\hline "R" Ratio & "A" Factor \\
\hline$\leq 1.0$ & $90 \%$ \\
\hline$>1.0$ to $\leq 3.0$ & $70 \%$ \\
\hline$>3.0$ to $\leq 4.0$ & $50 \%$ \\
\hline$>4.0$ & $30 \%$ \\
\hline
\end{tabular}

Table4 : "B" Factor (Base Factor)

\begin{tabular}{|c|c|}
\hline $\begin{array}{l}\text { "B" Facto } \\
\text { Is a function of Project's }\end{array}$ & $\begin{array}{l}\text { 3ase" Factor) } \\
\text { y Production }\end{array}$ \\
\hline Oil Prod. Rate (MBD) & "Base" Factor per Segment \\
\hline$\leq 20$ & $100 \%$ \\
\hline$>20-\leq 30$ & $80 \%$ \\
\hline$>30-\leq 60$ & $50 \%$ \\
\hline$>60-\leq 85$ & $30 \%$ \\
\hline$>85$ & $20 \%$ \\
\hline
\end{tabular}

The following Figure-1 describe the cost and production shares of each party according to EPSA-IV: 
IOC Paid all Exploration Costs

IOC Pays $50 \%$ of Capex

NOC Pays $50 \%$ of Capex

IOC Pays $15 \%$ of Opex

NOC Pays $85 \%$ of Opex

IOC Entitled to $15 \%$ of Gross Revenue to recover its costs. The remaining is the Profit Oil

IOC Cost Recovery = Past Exploration + Its Capex Including Abandonment Provision + Its Opex

IOC Revenue $=$ Cost Recovery + Its Share of Profit Oil

NOC Revenue $=85 \%$ of project revenue + Remaining Profit Oil + IOC Abandonment Provision

\begin{tabular}{|c|c|}
\hline \multicolumn{2}{|c|}{ NOC Share } \\
\hline \multicolumn{2}{|c|}{$85 \%$} \\
\hline Coc Entitlement \\
\hline
\end{tabular}

IOC NCF $=$ Cost Recovery + Its Share of PO - Its Share of (Capex + Opex + Abandonment Provision $)$ NOC NCF = Its Revenue Share + Remaining PO + Company Aband. - Its Share of Capex \& Opex \& Aband. NOC NCF $=$ Project NCF - IOC NCF

NOC NCF $=($ Gross Revenue - Total Capex - Total Opex $)-$ IOC NCF

Figure 1: Cost and production share of each party according to EPSA-IV

The following flow chart (Figure-2) describes how costs and revenues are shared among the two parties:

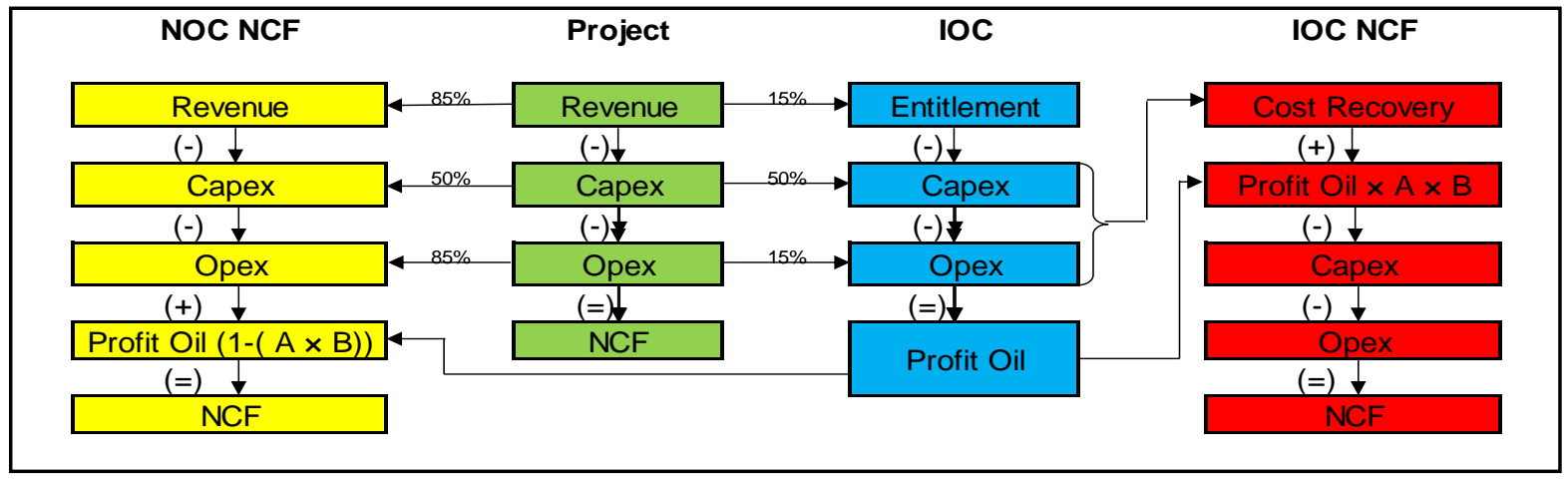

Figure 2: Costs and revenues share among the two parties 


\section{Economic Model Development:}

In order to carry out a detailed economic evaluation on IOC discovery, an economic model was built using Spreadsheet (Excel). The model is capable of performing the following functions:

1. Calculation of basic input parameters based on the acquired data. These parameters will consist of oil, gas and condensate production forecasts, capital and operating expenditure profiles for an assumed production life of 20 years.

2. Carry out a detailed nominal cash flow analysis of the entire project regardless of the parties involved. This analysis included the calculation of the annual revenue, capital and operating expenditure profiles after applying an assumed cost contingency and an annual inflation rate. The annual net cash flow profile resulted from deducting the annual costs from the annual revenues.

3. Determination of the project's key economic indicators such as Net Present Value, Internal Rate of Return, Payback Period, Capital Productivity Index and Maximum Exposure using an assumed discount rate.

4. Based on the EPSA-IV terms and conditions, detailed cash flow calculation for each party applying a sliding scale for the IOC to control its production withdrawal. This sliding scale is consisted of two factors; the "A" and the "B" Factors as defined earlier. The cash flow calculation for the revenue, cost recovery and profit oil followed by the calculation of the Net Cash Flow of each party.

5. Determination of each party key economic indicators.

6. Carry out sensitivity analysis to determine the effect of varying some input parameters on key economic indicators. This analysis is carried out for the entire project and for each party. It included the construction of the spider and tornado diagrams. Important information are obtained from the spider diagram such as breakeven data. 


\section{Economic Evaluation Study}

The economic study consists of the following sections:

1. Input/Output

2. Cash flow calculations

3. Economic Indicators

4. Sensitivity Analysis 


\section{Input/Output:}

This section lists the input data of the project as received from NOC. Then it displays the results of the study.

In case this model is to be used for other projects that may have a different set of data then this section could be modified to accommodate new data. In many cases, NOC receives refined data that could be directly inserted in the cash flow section.

Figure-3 shows the input data as displayed in the Input / Output section (Input Output Sheet). Note that the data on the shaded cells indicate variables. So in case any of this data is changed the resulting output data will change automatically. 


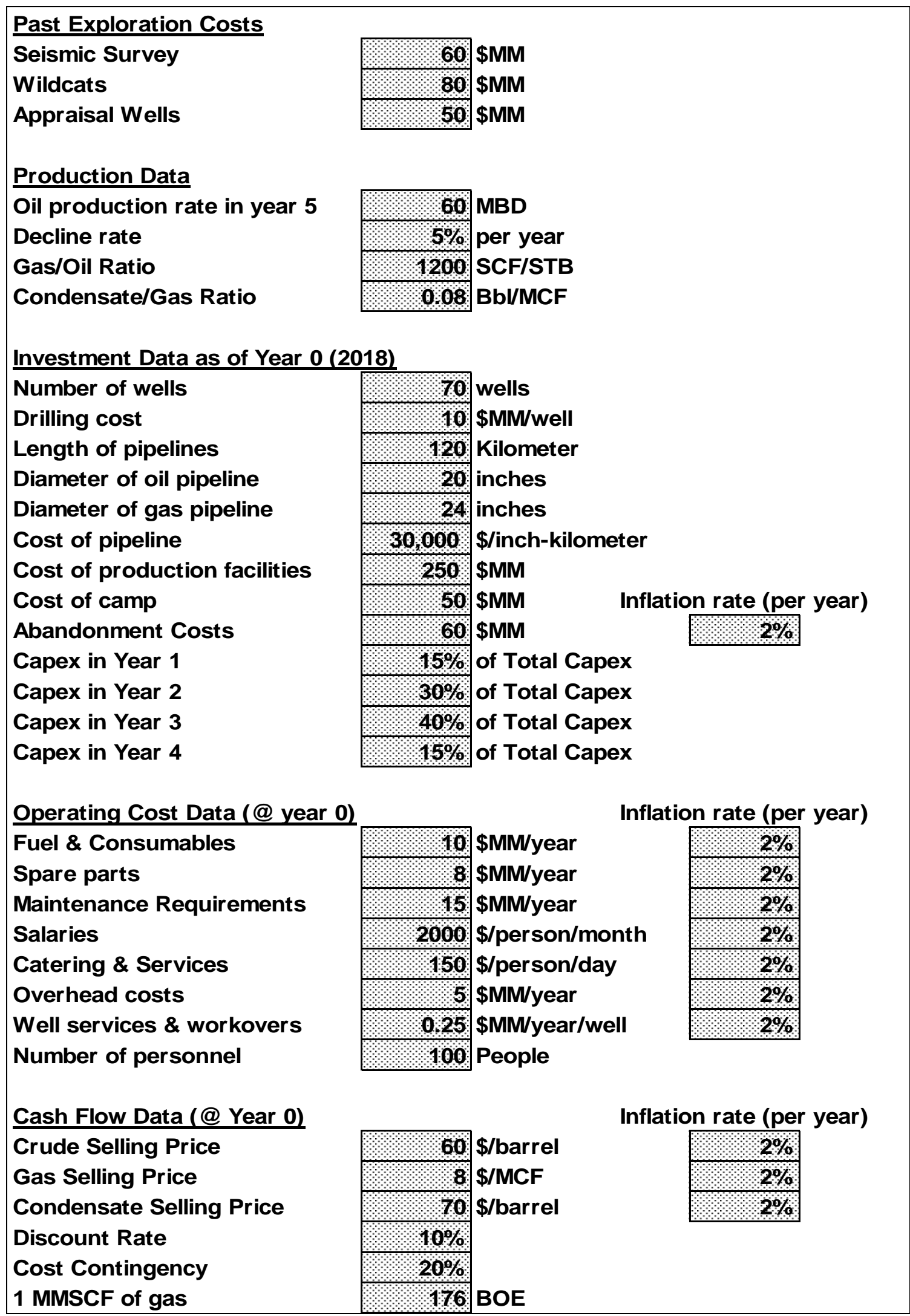

Figure 3: Input data as displayed in the Input / Output section 


\section{Cash Flow Calculation:}

\section{Calculation of Main Parameters:}

A detailed cash flow calculation was performed to determine the stream of Net Cash Flow (NCF) for the project and for each party (Cash Flow Sheet).

Table- 5 summarizes the calculated annual production rate, price and revenue for each product. The year column starts at year 2018 (year 0) and continues to year 2042 (year 24). It is assumed that the project will be executed starting year 1 for 4 years, and production will start in year 5 for 20 years. Abandonment of the project will take place in year 25 . The year number $(n)$ indicates the number of years after starting the project. All calculated terms in each column are defined in Appendix B. 
Table5 : Calculated annual production rate, price and revenue for each product

\begin{tabular}{|c|c|c|c|c|c|c|c|c|c|c|c|}
\hline & & \multicolumn{3}{|c|}{ Annual Production } & \multicolumn{3}{|c|}{ Price } & \multicolumn{4}{|c|}{ Revenue } \\
\hline \multicolumn{2}{|c|}{ Year } & $\begin{array}{c}\text { Oil } \\
\text { MMB }\end{array}$ & $\begin{array}{l}\text { Gas } \\
\text { BCF }\end{array}$ & $\begin{array}{l}\text { Cond. } \\
\text { MMB }\end{array}$ & $\begin{array}{c}\text { Oil } \\
\$ / \text { bbl. }\end{array}$ & $\begin{array}{c}\text { Gas } \\
\$ / M C F\end{array}$ & $\begin{array}{l}\text { Cond. } \\
\text { \$/bbl. }\end{array}$ & $\begin{array}{c}\text { Oil } \\
\$ M M\end{array}$ & $\begin{array}{c}\text { Gas } \\
\$ M M\end{array}$ & $\begin{array}{l}\text { Cond. } \\
\$ M M\end{array}$ & $\begin{array}{l}\text { Total } \\
\$ M M\end{array}$ \\
\hline 2018 & 0 & & & & & & & & & & \\
\hline 2019 & 1 & & & & & & & & & & \\
\hline 2020 & 2 & & & & & & & & & & \\
\hline 2021 & 3 & & & & & & & & & & \\
\hline 2022 & 4 & & & & & & & & & & \\
\hline 2023 & 5 & 21.9 & 26.3 & 2.1 & 66.24 & 8.83 & 77.29 & 1,451 & 232 & 162 & 1,845 \\
\hline 2024 & 6 & 20.8 & 25.0 & 2.0 & 67.57 & 9.01 & 78.83 & 1,406 & 225 & 157 & 1,788 \\
\hline 2025 & 7 & 19.8 & 23.7 & 1.9 & 68.92 & 9.19 & 80.41 & 1,362 & 218 & 153 & 1,733 \\
\hline 2026 & 8 & 18.8 & 22.5 & 1.8 & 70.30 & 9.37 & 82.02 & 1,320 & 211 & 148 & 1,679 \\
\hline 2027 & 9 & 17.8 & 21.4 & 1.7 & 71.71 & 9.56 & 83.66 & 1,279 & 205 & 143 & 1,627 \\
\hline 2028 & 10 & 16.9 & 20.3 & 1.6 & 73.14 & 9.75 & 85.33 & 1,239 & 198 & 139 & 1,577 \\
\hline 2029 & 11 & 16.1 & 19.3 & 1.5 & 74.60 & 9.95 & 87.04 & 1,201 & 192 & 135 & 1,528 \\
\hline 2030 & 12 & 15.3 & 18.4 & 1.5 & 76.09 & 10.15 & 88.78 & 1,164 & 186 & 130 & 1,480 \\
\hline 2031 & 13 & 14.5 & 17.4 & 1.4 & 77.62 & 10.35 & 90.55 & 1,128 & 180 & 126 & 1,434 \\
\hline 2032 & 14 & 13.8 & 16.6 & 1.3 & 79.17 & 10.56 & 92.36 & 1,093 & 175 & 122 & 1,390 \\
\hline 2033 & 15 & 13.1 & 15.7 & 1.3 & 80.75 & 10.77 & 94.21 & 1,059 & 169 & 119 & 1,347 \\
\hline 2034 & 16 & 12.5 & 14.9 & 1.2 & 82.37 & 10.98 & 96.09 & 1,026 & 164 & 115 & 1,305 \\
\hline 2035 & 17 & 11.8 & 14.2 & 1.1 & 84.01 & 11.20 & 98.02 & 994 & 159 & 111 & 1,265 \\
\hline 2036 & 18 & 11.2 & 13.5 & 1.1 & 85.69 & 11.43 & 99.98 & 963 & 154 & 108 & 1,225 \\
\hline 2037 & 19 & 10.7 & 12.8 & 1.0 & 87.41 & 11.65 & 101.98 & 934 & 149 & 105 & 1,187 \\
\hline 2038 & 20 & 10.1 & 12.2 & 1.0 & 89.16 & 11.89 & 104.02 & 905 & 145 & 101 & 1,151 \\
\hline 2039 & 21 & 9.6 & 11.6 & 0.9 & 90.94 & 12.13 & 106.10 & 877 & 140 & 98 & 1,115 \\
\hline 2040 & 22 & 9.2 & 11.0 & 0.9 & 92.76 & 12.37 & 108.22 & 849 & 136 & 95 & 1,080 \\
\hline 2041 & 23 & 8.7 & 10.4 & 0.8 & 94.61 & 12.62 & 110.38 & 823 & 132 & 92 & 1,047 \\
\hline 2042 & 24 & 8.3 & 9.9 & 0.8 & 96.51 & 12.87 & 112.59 & 798 & 128 & 89 & 1,014 \\
\hline \multirow[t]{2}{*}{2043} & 25 & & & & & & & & & & \\
\hline & Total & 281 & 337 & 27 & & & & 21,869 & 3,499 & 2,449 & 27,818 \\
\hline
\end{tabular}

The following bar chart (Figure-4) summarizes the annual oil, gas and condensate production rates. 


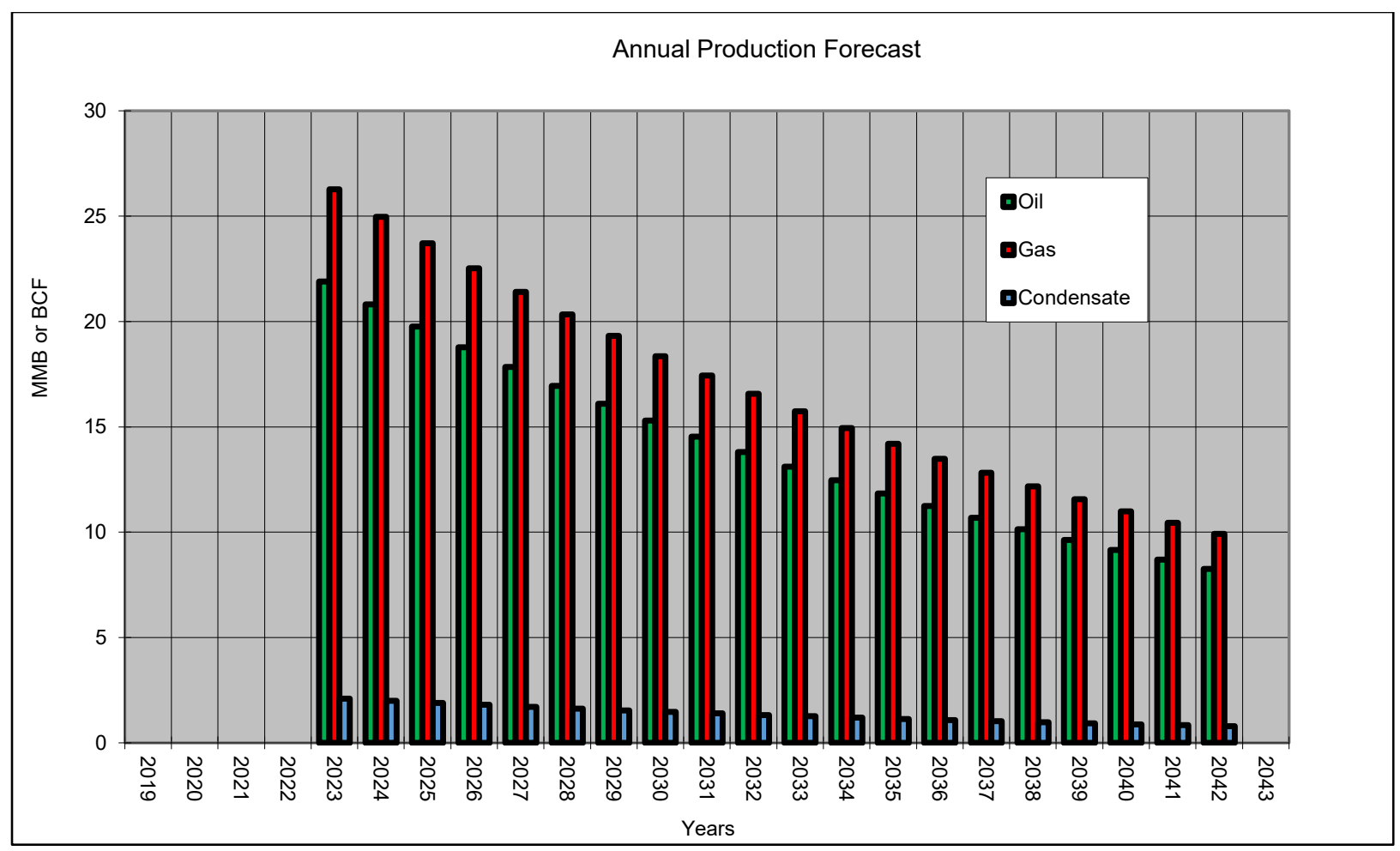

Figure 4: The annual oil, gas and condensate prodution rates

Table- 6 below summarizes the expected cumulative production after 20 years of production.

Table6 : The expected cumulative production after 20 years of production

\begin{tabular}{|c|c|c|c|}
\hline Product & $\begin{array}{c}\text { Oil } \\
\text { (MMB) }\end{array}$ & $\begin{array}{c}\text { Gas } \\
\text { (BCF) }\end{array}$ & $\begin{array}{c}\text { Condensate } \\
\text { (MMB) }\end{array}$ \\
\hline $\begin{array}{c}\text { Cumulative Production } \\
\text { (20 years) }\end{array}$ & 281 & 337 & 27 \\
\hline
\end{tabular}

Table-7 summarizes the annual capital and operating expenditures. Annual capex profile is calculated from assumed data and allocated for each of the first 4 years by incorporating capex percentage allocation for each year. Cost contingency and the inflation rate are then incorporated using equations given in Appendix B. Note that the spreadsheet model can accommodate a different inflation rate for each of the operating cost items as well as the capital cost and the selling price of each of the different products. However, for this study it is assumed to equal $2 \%$ per year for all cost and price items. 
Table7 : The annual capital and operating expenditures

\begin{tabular}{|c|c|c|c|c|c|c|c|c|c|}
\hline \multirow[b]{2}{*}{ Year } & \multirow{2}{*}{$\begin{array}{c}\text { Capex } \\
\text { \$MM }\end{array}$} & \multicolumn{8}{|c|}{ Opex } \\
\hline & & $\begin{array}{l}\text { Fuel } \\
\$ M M\end{array}$ & $\begin{array}{l}\text { Spares } \\
\text { \$MM }\end{array}$ & $\begin{array}{l}\text { Maint. } \\
\text { \$MM }\end{array}$ & $\begin{array}{c}\text { Salaries } \\
\text { \$MM }\end{array}$ & $\begin{array}{l}\text { Serv. } \\
\$ M M\end{array}$ & $\begin{array}{l}\text { O/H } \\
\$ M M\end{array}$ & $\begin{array}{l}\text { Wells } \\
\$ M M\end{array}$ & $\begin{array}{l}\text { Total } \\
\text { \$MM }\end{array}$ \\
\hline \multicolumn{10}{|l|}{2018} \\
\hline 2019 & 213 & & & & & & & & \\
\hline 2020 & 434 & & & & & & & & \\
\hline 2021 & 590 & & & & & & & & \\
\hline 2022 & 226 & & & & & & & & \\
\hline 2023 & & 11.04 & 8.83 & 16.56 & 2.65 & 6.04 & 5.52 & 19.32 & 83.97 \\
\hline 2024 & & 11.26 & 9.01 & 16.89 & 2.70 & 6.17 & 5.63 & 19.71 & 85.64 \\
\hline 2025 & & 11.49 & 9.19 & 17.23 & 2.76 & 6.29 & 5.74 & 20.10 & 87.36 \\
\hline 2026 & & 11.72 & 9.37 & 17.57 & 2.81 & 6.41 & 5.86 & 20.50 & 89.10 \\
\hline 2027 & & 11.95 & 9.56 & 17.93 & 2.87 & 6.54 & 5.98 & 20.91 & 90.89 \\
\hline 2028 & & 12.19 & 9.75 & 18.28 & 2.93 & 6.67 & 6.09 & 21.33 & 92.70 \\
\hline 2029 & & 12.43 & 9.95 & 18.65 & 2.98 & 6.81 & 6.22 & 21.76 & 94.56 \\
\hline 2030 & & 12.68 & 10.15 & 19.02 & 3.04 & 6.94 & 6.34 & 22.19 & 96.45 \\
\hline 2031 & & 12.94 & 10.35 & 19.40 & 3.10 & 7.08 & 6.47 & 22.64 & 98.38 \\
\hline 2032 & & 13.19 & 10.56 & 19.79 & 3.17 & 7.22 & 6.60 & 23.09 & 100.35 \\
\hline 2033 & & 13.46 & 10.77 & 20.19 & 3.23 & 7.37 & 6.73 & 23.55 & 102.35 \\
\hline 2034 & & 13.73 & 10.98 & 20.59 & 3.29 & 7.52 & 6.86 & 24.02 & 104.40 \\
\hline 2035 & & 14.00 & 11.20 & 21.00 & 3.36 & 7.67 & 7.00 & 24.50 & 106.49 \\
\hline 2036 & & 14.28 & 11.43 & 21.42 & 3.43 & 7.82 & 7.14 & 24.99 & 108.62 \\
\hline 2037 & & 14.57 & 11.65 & 21.85 & 3.50 & 7.98 & 7.28 & 25.49 & 110.79 \\
\hline 2038 & & 14.86 & 11.89 & 22.29 & 3.57 & 8.14 & 7.43 & 26.00 & 113.01 \\
\hline 2039 & & 15.16 & 12.13 & 22.73 & 3.64 & 8.30 & 7.58 & 26.52 & 115.27 \\
\hline 2040 & & 15.46 & 12.37 & 23.19 & 3.71 & 8.46 & 7.73 & 27.05 & 117.57 \\
\hline 2041 & & 15.77 & 12.62 & 23.65 & 3.78 & 8.63 & 7.88 & 27.60 & 119.92 \\
\hline 2042 & & 16.08 & 12.87 & 24.13 & 3.86 & 8.81 & 8.04 & 28.15 & 122.32 \\
\hline \multirow[t]{2}{*}{2043} & 118 & & & & & & & & \\
\hline & 1,580 & 268 & 215 & 402 & 64 & 147 & 134 & 469 & 2,040 \\
\hline
\end{tabular}

The following chart (Figure-8) summarizes the annual capital and operating expenditures. 


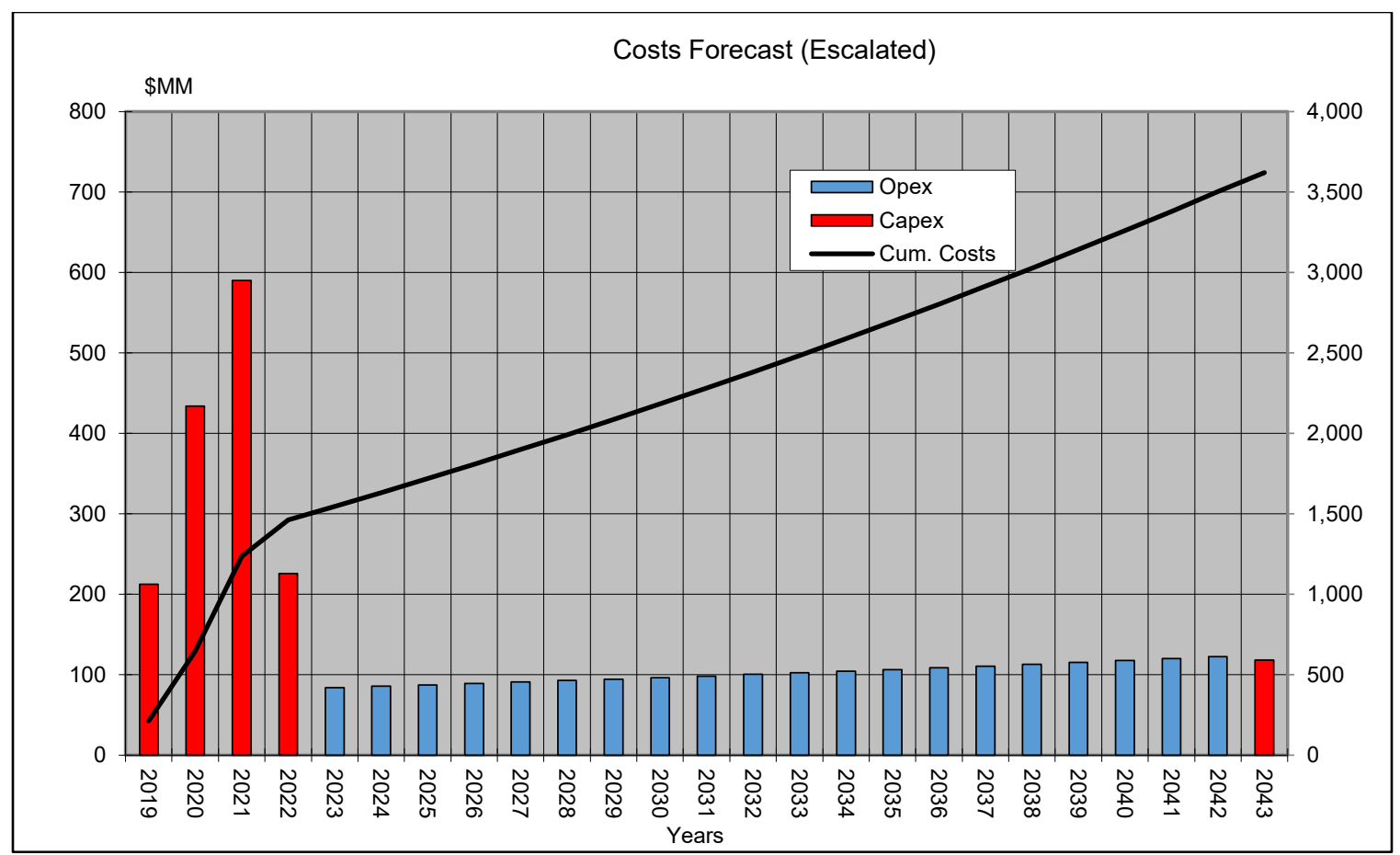

Figure 5: The annual capital and operating expenditures

Table-8 summarizes the expected cumulative capital and operating expenditures after 20 years:

Table8 : Expected cumulative capital and operating expenditures after 20 years

\begin{tabular}{|c|c|c|c|c|}
\hline \multirow{2}{*}{ Costs (\$MM) } & \multicolumn{2}{|c|}{$\begin{array}{c}\text { Constant } \\
\text { (Year 2018 Costs) }\end{array}$} & \multicolumn{2}{c|}{ Escalated Costs } \\
\cline { 2 - 5 } & CAPEX & OPEX & CAPEX & OPEX \\
\hline $\begin{array}{c}\text { Cumulative Cost } \\
\text { (25 years) }\end{array}$ & 1,462 & 1,521 & 1,580 & 2,040 \\
\hline
\end{tabular}

Project annual net cash flow is given in Table- 9 . 
Table9 : The project annual net cash flow

\begin{tabular}{|c|c|c|c|c|c|c|}
\hline \multirow[b]{2}{*}{ Year } & \multicolumn{6}{|c|}{ Total Project Cash Flow } \\
\hline & $\begin{array}{c}\text { Revenue } \\
\$ M M\end{array}$ & $\begin{array}{c}\text { Capex } \\
\$ M M\end{array}$ & $\begin{array}{l}\text { Opex } \\
\$ M M\end{array}$ & $\begin{array}{l}\text { NCF } \\
\$ M M\end{array}$ & $\begin{array}{c}\text { Cum NCF } \\
\$ M M\end{array}$ & $\begin{array}{c}\text { Payback } \\
\text { Years }\end{array}$ \\
\hline \multicolumn{7}{|l|}{2018} \\
\hline 2019 & & 213 & & -213 & -213 & 0.00 \\
\hline 2020 & & 434 & & -434 & -647 & 0.00 \\
\hline 2021 & & 590 & & -590 & $-1,237$ & 0.00 \\
\hline 2022 & & 226 & & -226 & $-1,462$ & 0.00 \\
\hline 2023 & 1,845 & & 84 & 1761 & 299 & 4.83 \\
\hline 2024 & 1,788 & & 86 & 1703 & 2,002 & 0.00 \\
\hline 2025 & 1,733 & & 87 & 1645 & 3,647 & 0.00 \\
\hline 2026 & 1,679 & & 89 & 1590 & 5,237 & 0.00 \\
\hline 2027 & 1,627 & & 91 & 1536 & 6,773 & 0.00 \\
\hline 2028 & 1,577 & & 93 & 1484 & 8,257 & 0.00 \\
\hline 2029 & 1,528 & & 95 & 1433 & 9,690 & 0.00 \\
\hline 2030 & 1,480 & & 96 & 1384 & 11,074 & 0.00 \\
\hline 2031 & 1,434 & & 98 & 1336 & 12,410 & 0.00 \\
\hline 2032 & 1,390 & & 100 & 1290 & 13,699 & 0.00 \\
\hline 2033 & 1,347 & & 102 & 1245 & 14,944 & 0.00 \\
\hline 2034 & 1,305 & & 104 & 1201 & 16,145 & 0.00 \\
\hline 2035 & 1,265 & & 106 & 1158 & 17,303 & 0.00 \\
\hline 2036 & 1,225 & & 109 & 1117 & 18,420 & 0.00 \\
\hline 2037 & 1,187 & & 111 & 1077 & 19,496 & 0.00 \\
\hline 2038 & 1,151 & & 113 & 1038 & 20,534 & 0.00 \\
\hline 2039 & 1,115 & & 115 & 1000 & 21,534 & 0.00 \\
\hline 2040 & 1,080 & & 118 & 963 & 22,496 & 0.00 \\
\hline 2041 & 1,047 & & 120 & 927 & 23,423 & 0.00 \\
\hline 2042 & 1,014 & & 122 & 892 & 24,316 & 0.00 \\
\hline \multirow[t]{2}{*}{2043} & 0 & 118 & 0 & -118 & 24,197 & 0.00 \\
\hline & 27,818 & 1,580 & 2,040 & 24,197 & & 4.83 \\
\hline
\end{tabular}

The project cash flow profile is shown in Figure-6. 


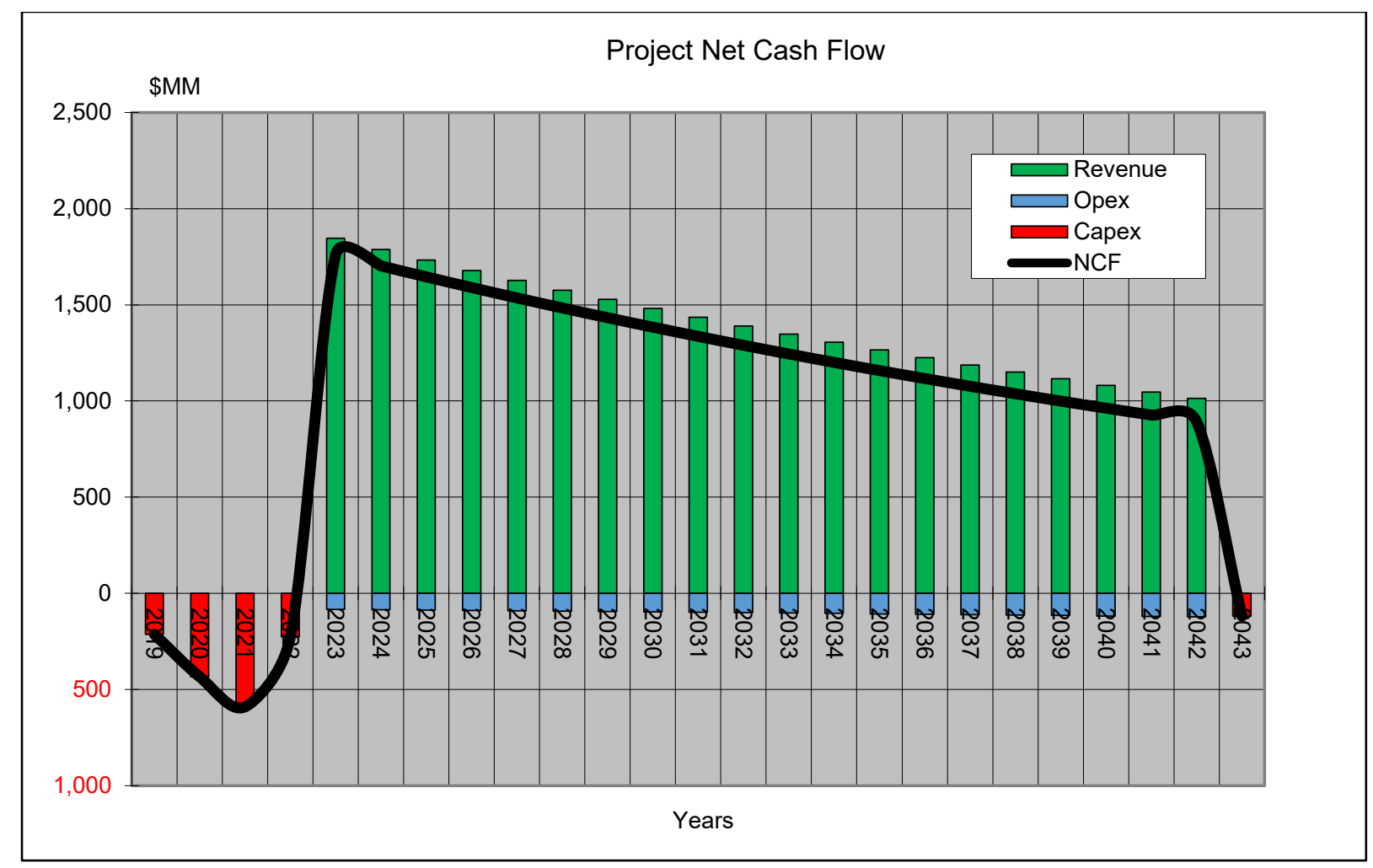

Figure 6: The project cash flow profile

\section{IOC Net Cash Flow:}

NCF is determined for each party according to the EPSA-IV terms and conditions. To determine the second party Net Cash Flow the following parameters have to be calculated:

1. Abandonment Provision

2. Cost Recovery

3. "A" Factor

4. "B" Factor

5. Profit Oil 


\section{Abandonment Provision}

The EPSA-IV agreement defines IOC Abandonment Provision. Since the abandonment cost is a capital item then it should be equally paid by both parties. The IOC share of the abandonment cost is to be deposited in a saving account designated to NOC. This abandonment provision will start when the IOC recovers its past costs and will be calculated based on the Units-of-Production depreciation method. At the end of the contract period NOC has the option either to combine IOC's deposited amount to its share of the abandonment costs and abandonment the project, or it can decide to solely continue production.

Table-10 summarizes the second party abandonment provision:

Table10 : The second party abandonment provision:

\begin{tabular}{|c|c|c|c|c|c|c|c|}
\hline \multirow[b]{2}{*}{ Year } & \multicolumn{7}{|c|}{ Calculating Second Party Abandonment Provision } \\
\hline & $\begin{array}{c}\text { Abandonment } \\
\text { \$MM }\end{array}$ & $\begin{array}{l}\text { Production } \\
\text { MMB }\end{array}$ & $\begin{array}{c}\text { Cum Prod. } \\
\text { MMB }\end{array}$ & $\begin{array}{c}\text { Rem. Res. } \\
\text { MMB }\end{array}$ & $\begin{array}{c}\text { Cum AP } \\
\$ M M\end{array}$ & $\begin{array}{c}\text { AP@Y25 } \\
\text { \$MM }\end{array}$ & $\begin{array}{l}\text { PV of AP } \\
\text { \$MM }\end{array}$ \\
\hline \multicolumn{8}{|l|}{2018} \\
\hline \multicolumn{8}{|l|}{2019} \\
\hline \multicolumn{8}{|l|}{2020} \\
\hline \multicolumn{8}{|l|}{2021} \\
\hline \multicolumn{8}{|l|}{2022} \\
\hline 2023 & & 22 & 22 & 281 & 0.0 & 0.0 & 0.0 \\
\hline 2024 & & 21 & 43 & 259 & 0.0 & 0.0 & 0.0 \\
\hline 2025 & & 20 & 62 & 238 & 0.0 & 0.0 & 0.0 \\
\hline 2026 & & 19 & 81 & 219 & 0.0 & 0.0 & 0.0 \\
\hline 2027 & & 18 & 99 & 200 & 5.3 & 5.3 & 1.1 \\
\hline 2028 & & 17 & 116 & 182 & 10.3 & 5.0 & 1.2 \\
\hline 2029 & & 16 & 132 & 165 & 15.0 & 4.8 & 1.3 \\
\hline 2030 & & 15 & 147 & 149 & 19.6 & 4.5 & 1.3 \\
\hline 2031 & & 15 & 162 & 134 & 23.9 & 4.3 & 1.4 \\
\hline 2032 & & 14 & 176 & 119 & 27.9 & 4.1 & 1.4 \\
\hline 2033 & & 13 & 189 & 105 & 31.8 & 3.9 & 1.5 \\
\hline 2034 & & 12 & 201 & 92 & 35.5 & 3.7 & 1.6 \\
\hline 2035 & & 12 & 213 & 80 & 39.0 & 3.5 & 1.6 \\
\hline 2036 & & 11 & 224 & 68 & 42.3 & 3.3 & 1.7 \\
\hline 2037 & & 11 & 235 & 57 & 45.5 & 3.2 & 1.8 \\
\hline 2038 & & 10 & 245 & 46 & 48.5 & 3.0 & 1.9 \\
\hline 2039 & & 10 & 255 & 36 & 51.3 & 2.9 & 1.9 \\
\hline 2040 & & 9 & 264 & 26 & 54.0 & 2.7 & 2.0 \\
\hline 2041 & & 9 & 273 & 17 & 56.6 & 2.6 & 2.1 \\
\hline 2042 & & 8 & 281 & 8 & 59.1 & 2.4 & 2.2 \\
\hline \multirow[t]{2}{*}{2043} & 59 & & & & & & \\
\hline & 59 & 281 & & & & 59 & 26 \\
\hline
\end{tabular}




\section{Cost Recovery}

The cost recovery is calculated to determine the amount of revenue to be received by the second party to recover its costs; namely the past exploration costs, its share of capex including the abandonment provision and its share of the operating cost. According to EPSA-IV the second party entitled revenue is the cost recovery ceiling. To calculate the cost recovery, the second party cumulative costs and cumulative entitled revenue have to be calculated first. Table-11 summarizes the second party cost recovery profile.

Table11 : The second party cost recovery profile

\begin{tabular}{|c|c|c|c|c|c|c|c|c|}
\hline \multirow[b]{2}{*}{ Year } & \multicolumn{8}{|c|}{ Calculating Cost Recovery } \\
\hline & $\begin{array}{c}\text { Revenue } \\
\text { \$MM }\end{array}$ & $\begin{array}{l}\text { Capex } \\
\$ M M \\
\end{array}$ & $\begin{array}{l}\text { Opex } \\
\text { \$MM }\end{array}$ & $\begin{array}{c}\text { PV of AP } \\
\text { \$MM }\end{array}$ & $\begin{array}{l}\text { Cost } \\
\text { \$MM }\end{array}$ & $\begin{array}{c}\text { Cum Rev } \\
\text { \$MM }\end{array}$ & $\begin{array}{c}\text { Cum Cost } \\
\$ M M\end{array}$ & $\begin{array}{c}\text { Cost Rec. } \\
\text { \$MM }\end{array}$ \\
\hline & & & & & & & 190 & \\
\hline \multicolumn{9}{|l|}{2018} \\
\hline 2019 & & 106 & & & 106 & & 296 & \\
\hline 2020 & & 217 & & & 217 & & 513 & \\
\hline 2021 & & 295 & & & 295 & & 808 & \\
\hline 2022 & & 113 & & & 113 & & 921 & \\
\hline 2023 & 277 & 0 & 13 & 0.0 & 13 & 277 & 934 & 277 \\
\hline 2024 & 268 & 0 & 13 & 0.0 & 13 & 545 & 947 & 268 \\
\hline 2025 & 260 & 0 & 13 & 0.0 & 13 & 805 & 960 & 260 \\
\hline 2026 & 252 & 0 & 13 & 0.0 & 13 & 1,057 & 973 & 168 \\
\hline 2027 & 244 & 0 & 14 & 1.1 & 15 & 1,301 & 988 & 15 \\
\hline 2028 & 236 & 0 & 14 & 1.2 & 15 & 1,537 & 1,003 & 15 \\
\hline 2029 & 229 & 0 & 14 & 1.3 & 15 & 1,766 & 1,018 & 15 \\
\hline 2030 & 222 & 0 & 14 & 1.3 & 16 & 1,989 & 1,034 & 16 \\
\hline 2031 & 215 & 0 & 15 & 1.4 & 16 & 2,204 & 1,050 & 16 \\
\hline 2032 & 208 & 0 & 15 & 1.4 & 16 & 2,412 & 1,067 & 16 \\
\hline 2033 & 202 & 0 & 15 & 1.5 & 17 & 2,614 & 1,084 & 17 \\
\hline 2034 & 196 & 0 & 16 & 1.6 & 17 & 2,810 & 1,101 & 17 \\
\hline 2035 & 190 & 0 & 16 & 1.6 & 18 & 3,000 & 1,118 & 18 \\
\hline 2036 & 184 & 0 & 16 & 1.7 & 18 & 3,183 & 1,136 & 18 \\
\hline 2037 & 178 & 0 & 17 & 1.8 & 18 & 3,362 & 1,155 & 18 \\
\hline 2038 & 173 & 0 & 17 & 1.9 & 19 & 3,534 & 1,174 & 19 \\
\hline 2039 & 167 & 0 & 17 & 1.9 & 19 & 3,701 & 1,193 & 19 \\
\hline 2040 & 162 & 0 & 18 & 2.0 & 20 & 3,863 & 1,213 & 20 \\
\hline 2041 & 157 & 0 & 18 & 2.1 & 20 & 4,021 & 1,233 & 20 \\
\hline 2042 & 152 & 0 & 18 & 2.2 & 21 & 4,173 & 1,253 & 21 \\
\hline \multicolumn{9}{|l|}{2043} \\
\hline & 4,173 & 731 & 306 & 26 & 1,063 & & & 1,253 \\
\hline
\end{tabular}




\section{The Index "A" Factor}

To calculate the Index or "A" Factor it is important to first calculate the "R" ratio which is the ratio of the second party cumulative received revenue over its cumulative costs as of the previous year. The following Table-12 summarizes the "A" Factor profile.

Table12 : "A" factor profile

\begin{tabular}{|c|c|c|c|c|c|c|c|c|c|}
\hline \multirow[b]{3}{*}{ Year } & \multicolumn{9}{|c|}{ Calculating "A" Factor } \\
\hline & \multirow{2}{*}{$\begin{array}{l}\text { Received } \\
\text { Revenue }\end{array}$} & \multirow{2}{*}{$\begin{array}{c}\text { Cum Rev } \\
\$ M M\end{array}$} & \multirow{2}{*}{$\begin{array}{c}\text { Cum Cost } \\
\$ M M\end{array}$} & \multirow{2}{*}{$\begin{array}{c}\mathbf{R} \\
\text { Ratio }\end{array}$} & \multirow{2}{*}{$\begin{array}{c}R<1.0 \\
1.0\end{array}$} & \multirow{2}{*}{$\begin{array}{c}1.0<R<3.0 \\
3.0\end{array}$} & \multirow{2}{*}{$\begin{array}{c}3.0<R<4.0 \\
4.0\end{array}$} & \multirow{2}{*}{$\begin{array}{c}R>4.0 \\
100.0\end{array}$} & \multirow{2}{*}{$\begin{array}{c}\text { "A" } \\
\text { Factor }\end{array}$} \\
\hline & & & & & & & & & \\
\hline & & & 190 & & $90 \%$ & $70 \%$ & $50 \%$ & $30 \%$ & \\
\hline \multicolumn{10}{|l|}{2018} \\
\hline 2019 & & & 296 & & & & & & \\
\hline 2020 & & & 513 & & & & & & \\
\hline 2021 & & & 808 & & & & & & \\
\hline 2022 & & & 921 & & & & & & \\
\hline 2023 & 277 & 277 & 934 & 0.00 & $90 \%$ & $0 \%$ & $0 \%$ & $0 \%$ & $90 \%$ \\
\hline 2024 & 268 & 545 & 947 & 0.30 & $90 \%$ & $0 \%$ & $0 \%$ & $0 \%$ & $90 \%$ \\
\hline 2025 & 260 & 805 & 960 & 0.58 & $90 \%$ & $0 \%$ & $0 \%$ & $0 \%$ & $90 \%$ \\
\hline 2026 & 223 & 1,028 & 973 & 0.84 & $90 \%$ & $0 \%$ & $0 \%$ & $0 \%$ & $90 \%$ \\
\hline 2027 & 134 & 1,162 & 988 & 1.06 & $0 \%$ & $70 \%$ & $0 \%$ & $0 \%$ & $70 \%$ \\
\hline 2028 & 132 & 1,294 & 1,003 & 1.18 & $0 \%$ & $70 \%$ & $0 \%$ & $0 \%$ & $70 \%$ \\
\hline 2029 & 130 & 1,425 & 1,018 & 1.29 & $0 \%$ & $70 \%$ & $0 \%$ & $0 \%$ & $70 \%$ \\
\hline 2030 & 129 & 1,554 & 1,034 & 1.40 & $0 \%$ & $70 \%$ & $0 \%$ & $0 \%$ & $70 \%$ \\
\hline 2031 & 127 & 1,681 & 1,050 & 1.50 & $0 \%$ & $70 \%$ & $0 \%$ & $0 \%$ & $70 \%$ \\
\hline 2032 & 126 & 1,807 & 1,067 & 1.60 & $0 \%$ & $70 \%$ & $0 \%$ & $0 \%$ & $70 \%$ \\
\hline 2033 & 124 & 1,931 & 1,084 & 1.69 & $0 \%$ & $70 \%$ & $0 \%$ & $0 \%$ & $70 \%$ \\
\hline 2034 & 123 & 2,054 & 1,101 & 1.78 & $0 \%$ & $70 \%$ & $0 \%$ & $0 \%$ & $70 \%$ \\
\hline 2035 & 122 & 2,176 & 1,118 & 1.87 & $0 \%$ & $70 \%$ & $0 \%$ & $0 \%$ & $70 \%$ \\
\hline 2036 & 121 & 2,297 & 1,136 & 1.95 & $0 \%$ & $70 \%$ & $0 \%$ & $0 \%$ & $70 \%$ \\
\hline 2037 & 120 & 2,417 & 1,155 & 2.02 & $0 \%$ & $70 \%$ & $0 \%$ & $0 \%$ & $70 \%$ \\
\hline 2038 & 119 & 2,535 & 1,174 & 2.09 & $0 \%$ & $70 \%$ & $0 \%$ & $0 \%$ & $70 \%$ \\
\hline 2039 & 116 & 2,652 & 1,193 & 2.16 & $0 \%$ & $70 \%$ & $0 \%$ & $0 \%$ & $70 \%$ \\
\hline 2040 & 114 & 2,766 & 1,213 & 2.22 & $0 \%$ & $70 \%$ & $0 \%$ & $0 \%$ & $70 \%$ \\
\hline 2041 & 111 & 2,877 & 1,233 & 2.28 & $0 \%$ & $70 \%$ & $0 \%$ & $0 \%$ & $70 \%$ \\
\hline 2042 & 109 & 2,986 & 1,253 & 2.33 & $0 \%$ & $70 \%$ & $0 \%$ & $0 \%$ & $70 \%$ \\
\hline \multicolumn{10}{|l|}{2043} \\
\hline & 2,986 & & & & & & & & \\
\hline
\end{tabular}

From this table the calculated "A" Factor is $70 \%$ once the "R" ratio exceeds 1 . It will remain at this rate till the end of the production life as long as the "R" ratio is between 1 and 3 . 


\section{Base "B" Factor}

The Base "B" Factor is calculated based on the total project fluid production rate (oil + condensate). This production rate is divided into segments and for each segment a designated "B" Factor is applied as per the previously mentioned "B" factor table. The following Table-13 summarizes the "B" Factor and the combined factor profiles.

Table13 : "B" Factor and the combined factor profiles

\begin{tabular}{|c|c|c|c|c|c|c|c|c|}
\hline \multirow[b]{3}{*}{ Year } & \multicolumn{7}{|c|}{ Calculating Base Factor } & \multirow{3}{*}{$\begin{array}{l}\text { Combined } \\
\text { Factor }\end{array}$} \\
\hline & \multirow[t]{2}{*}{ Fluid Prod. } & \multirow{2}{*}{$\begin{array}{c}P<20 \\
20\end{array}$} & \multirow{2}{*}{$\begin{array}{c}20<P<30 \\
30\end{array}$} & \multirow{2}{*}{$\begin{array}{c}30<\mathrm{P}<60 \\
60\end{array}$} & \multirow{2}{*}{$\begin{array}{c}60<P<85 \\
85\end{array}$} & \multirow{2}{*}{$\begin{array}{c}P>85 \\
85\end{array}$} & \multirow{2}{*}{$\begin{array}{l}\text { "Base" } \\
\text { Factor }\end{array}$} & \\
\hline & & & & & & & & \\
\hline & (MBD) & $100 \%$ & $80 \%$ & $50 \%$ & $30 \%$ & $20 \%$ & & \\
\hline \multicolumn{9}{|l|}{2018} \\
\hline \multicolumn{9}{|l|}{2019} \\
\hline \multicolumn{9}{|l|}{2020} \\
\hline \multicolumn{9}{|l|}{2021} \\
\hline \multicolumn{9}{|l|}{2022} \\
\hline 2023 & 65.8 & 20.0 & 10.0 & 30.0 & 5.8 & 0.0 & $68.0 \%$ & $61.2 \%$ \\
\hline 2024 & 62.5 & 20.0 & 10.0 & 30.0 & 2.5 & 0.0 & $70.0 \%$ & $63.0 \%$ \\
\hline 2025 & 59.3 & 20.0 & 10.0 & 29.3 & 0.0 & 0.0 & $71.9 \%$ & $64.7 \%$ \\
\hline 2026 & 56.4 & 20.0 & 10.0 & 26.4 & 0.0 & 0.0 & $73.1 \%$ & $65.8 \%$ \\
\hline 2027 & 53.6 & 20.0 & 10.0 & 23.6 & 0.0 & 0.0 & $74.3 \%$ & $52.0 \%$ \\
\hline 2028 & 50.9 & 20.0 & 10.0 & 20.9 & 0.0 & 0.0 & $75.5 \%$ & $52.9 \%$ \\
\hline 2029 & 48.3 & 20.0 & 10.0 & 18.3 & 0.0 & 0.0 & $76.9 \%$ & $53.8 \%$ \\
\hline 2030 & 45.9 & 20.0 & 10.0 & 15.9 & 0.0 & 0.0 & $78.3 \%$ & $54.8 \%$ \\
\hline 2031 & 43.6 & 20.0 & 10.0 & 13.6 & 0.0 & 0.0 & $79.8 \%$ & $55.9 \%$ \\
\hline 2032 & 41.4 & 20.0 & 10.0 & 11.4 & 0.0 & 0.0 & $81.4 \%$ & $57.0 \%$ \\
\hline 2033 & 39.4 & 20.0 & 10.0 & 9.4 & 0.0 & 0.0 & $83.0 \%$ & $58.1 \%$ \\
\hline 2034 & 37.4 & 20.0 & 10.0 & 7.4 & 0.0 & 0.0 & $84.8 \%$ & $59.3 \%$ \\
\hline 2035 & 35.5 & 20.0 & 10.0 & 5.5 & 0.0 & 0.0 & $86.6 \%$ & $60.6 \%$ \\
\hline 2036 & 33.8 & 20.0 & 10.0 & 3.8 & 0.0 & 0.0 & $88.5 \%$ & $62.0 \%$ \\
\hline 2037 & 32.1 & 20.0 & 10.0 & 2.1 & 0.0 & 0.0 & $90.5 \%$ & $63.4 \%$ \\
\hline 2038 & 30.5 & 20.0 & 10.0 & 0.5 & 0.0 & 0.0 & $92.7 \%$ & $64.9 \%$ \\
\hline 2039 & 28.9 & 20.0 & 8.9 & 0.0 & 0.0 & 0.0 & $93.8 \%$ & $65.7 \%$ \\
\hline 2040 & 27.5 & 20.0 & 7.5 & 0.0 & 0.0 & 0.0 & $94.5 \%$ & $66.2 \%$ \\
\hline 2041 & 26.1 & 20.0 & 6.1 & 0.0 & 0.0 & 0.0 & $95.3 \%$ & $66.7 \%$ \\
\hline 2042 & 24.8 & 20.0 & 4.8 & 0.0 & 0.0 & 0.0 & $96.1 \%$ & $67.3 \%$ \\
\hline 2043 & & & & & & & & \\
\hline
\end{tabular}

From this table the "B" Factor increases as the field production rate declines. Since the "A" Factor remains constant starting year 2027 when the ratio "R" exceeds 1, then the combined ratio will increase from $52 \%$ in year 2027 to $67 \%$ in year 2042 . IOC share of the Profit Oil will be based on this combined ratio. 


\section{Profit Oil}

Note that the second party entitled revenue will all be allocated to its Cost Recovery during the first 4 years of production. After that the remaining entitled revenue will be shared between the two parties based on the calculated combined factor. Table-14 summarizes the second party net cash flow profile.

Table14 : The second party net cash flow profile

\begin{tabular}{|c|c|c|c|c|c|c|c|c|c|c|}
\hline \multirow[b]{3}{*}{ Year } & \multicolumn{10}{|c|}{ Second Party Cash Flow } \\
\hline & \multicolumn{2}{|c|}{ Cost Rec. Profit Oil } & \multirow{2}{*}{\multicolumn{2}{|c|}{$\begin{array}{c}\text { Share of PO Revenue } \\
\$ M M\end{array}$}} & \multirow{2}{*}{$\begin{array}{l}\text { Cost } \\
\text { \$MM }\end{array}$} & \multirow{2}{*}{$\begin{array}{l}\text { NCF } \\
\$ M M\end{array}$} & \multirow{2}{*}{$\begin{array}{l}\text { Cum NCF } \\
\$ M M\end{array}$} & \multirow{2}{*}{$\begin{array}{c}\text { Payback } \\
\text { Years }\end{array}$} & \multicolumn{2}{|c|}{ Max Exposure } \\
\hline & $\$ M M$ & $\$ M M$ & & & & & & & Year & Time \\
\hline \multicolumn{11}{|l|}{2018} \\
\hline 2019 & & & & & 106 & -106 & -106 & 0.00 & 0 & 0 \\
\hline 2020 & & & & & 217 & -217 & -323 & 0.00 & 0 & 0 \\
\hline 2021 & & & & & 295 & -295 & -618 & 0.00 & 0 & 0 \\
\hline 2022 & & & & & 113 & -113 & -731 & 0.00 & 2022 & 4 \\
\hline 2023 & 277 & 0 & 0 & 277 & 13 & 264 & -467 & 0.00 & 0 & 0 \\
\hline 2024 & 268 & 0 & 0 & 268 & 13 & 255 & -212 & 0.00 & 0 & 0 \\
\hline 2025 & 260 & 0 & 0 & 260 & 13 & 247 & 35 & 6.86 & 0 & 0 \\
\hline 2026 & 168 & 84 & 55 & 223 & 13 & 210 & 245 & 0.00 & 0 & 0 \\
\hline 2027 & 15 & 229 & 119 & 134 & 15 & 119 & 364 & 0.00 & 0 & 0 \\
\hline 2028 & 15 & 221 & 117 & 132 & 15 & 117 & 481 & 0.00 & 0 & 0 \\
\hline 2029 & 15 & 214 & 115 & 130 & 15 & 115 & 596 & 0.00 & 0 & 0 \\
\hline 2030 & 16 & 206 & 113 & 129 & 16 & 113 & 709 & 0.00 & 0 & 0 \\
\hline 2031 & 16 & 199 & 111 & 127 & 16 & 111 & 821 & 0.00 & 0 & 0 \\
\hline 2032 & 16 & 192 & 109 & 126 & 16 & 109 & 930 & 0.00 & 0 & 0 \\
\hline 2033 & 17 & 185 & 108 & 124 & 17 & 108 & 1,038 & 0.00 & 0 & 0 \\
\hline 2034 & 17 & 179 & 106 & 123 & 17 & 106 & 1,143 & 0.00 & 0 & 0 \\
\hline 2035 & 18 & 172 & 104 & 122 & 18 & 104 & 1,248 & 0.00 & 0 & 0 \\
\hline 2036 & 18 & 166 & 103 & 121 & 18 & 103 & 1,351 & 0.00 & 0 & 0 \\
\hline 2037 & 18 & 160 & 101 & 120 & 18 & 101 & 1,452 & 0.00 & 0 & 0 \\
\hline 2038 & 19 & 154 & 100 & 119 & 19 & 100 & 1,552 & 0.00 & 0 & 0 \\
\hline 2039 & 19 & 148 & 97 & 116 & 19 & 97 & 1,649 & 0.00 & 0 & 0 \\
\hline 2040 & 20 & 142 & 94 & 114 & 20 & 94 & 1,743 & 0.00 & 0 & 0 \\
\hline 2041 & 20 & 137 & 91 & 111 & 20 & 91 & 1,834 & 0.00 & 0 & 0 \\
\hline 2042 & 21 & 132 & 89 & 109 & 21 & 89 & 1,923 & 0.00 & 0 & 0 \\
\hline \multirow[t]{2}{*}{2043} & & & & & & & 1,923 & 0.00 & 0 & 0 \\
\hline & 1,253 & 2,919 & 1,733 & 2,986 & 1,063 & 1,923 & & 6.86 & 2022 & 4 \\
\hline
\end{tabular}

\section{NOC Net Cash Flow:}

The first party net cash flow profile is calculated using two different methods:

Method 1: 
First party NCF $=$ Cash Inflow - Cash Outflow

First party NCF $=$ Project gross revenue $\times$ Its share + the remaining profit oil +

second party abandonment provision - its share of capex(including abandonment costs) its share of Opex

Method 2:

First party NCF $=$ Project NCF - Second party NCF

The following Table-15 summarizes first party net cash flow calculation using method 1 : 
Table15 : First party net cash flow calculation using method 1

\begin{tabular}{|c|c|c|c|c|c|c|c|c|c|}
\hline \multirow[b]{2}{*}{ Year } & \multirow[b]{2}{*}{$\begin{array}{c}\text { Revenue Share } \\
\text { \$MM } \\
\end{array}$} & \multicolumn{8}{|c|}{ First Party Cash Flow (Method 1) } \\
\hline & & $\begin{array}{c}\text { Remaining PO } \\
\text { \$MM }\end{array}$ & $\begin{array}{l}\text { 2nd Party } \\
\text { Aband. }\end{array}$ & $\begin{array}{c}\text { Revenue } \\
\$ \text { \$MM }\end{array}$ & $\begin{array}{l}\text { Capex } \\
\$ M M\end{array}$ & $\begin{array}{l}\text { Opex } \\
\$ M M\end{array}$ & $\begin{array}{l}\text { NCF } \\
\text { \$MM } \\
\end{array}$ & $\begin{array}{c}\text { Cum NCF } \\
\$ M M\end{array}$ & $\begin{array}{c}\text { Payback } \\
\text { Years } \\
\end{array}$ \\
\hline \multicolumn{10}{|l|}{2018} \\
\hline 2019 & & & & & 106 & & -106 & -106 & 0.00 \\
\hline 2020 & & & & & 217 & & -217 & -323 & 0.00 \\
\hline 2021 & & & & & 295 & & -295 & -618 & 0.00 \\
\hline 2022 & & & & & 113 & & -113 & -731 & 0.00 \\
\hline 2023 & 1,569 & 0 & 0.0 & 1,569 & & 71 & 1,497 & 766 & 4.49 \\
\hline 2024 & 1,520 & 0 & 0.0 & 1,520 & & 73 & 1,447 & 2,213 & 0.00 \\
\hline 2025 & 1,473 & 0 & 0.0 & 1,473 & & 74 & 1,399 & 3,612 & 0.00 \\
\hline 2026 & 1,427 & 29 & 0.0 & 1,456 & & 76 & 1,380 & 4,992 & 0.00 \\
\hline 2027 & 1,383 & 110 & 1.1 & 1,494 & & 77 & 1,417 & 6,409 & 0.00 \\
\hline 2028 & 1,340 & 104 & 1.2 & 1,446 & & 79 & 1,367 & 7,775 & 0.00 \\
\hline 2029 & 1,299 & 99 & 1.3 & 1,398 & & 80 & 1,318 & 9,094 & 0.00 \\
\hline 2030 & 1,258 & 93 & 1.3 & 1,353 & & 82 & 1,271 & 10,364 & 0.00 \\
\hline 2031 & 1,219 & 88 & 1.4 & 1,308 & & 84 & 1,225 & 11,589 & 0.00 \\
\hline 2032 & 1,181 & 83 & 1.4 & 1,266 & & 85 & 1,180 & 12,769 & 0.00 \\
\hline 2033 & 1,145 & 78 & 1.5 & 1,224 & & 87 & 1,137 & 13,906 & 0.00 \\
\hline 2034 & 1,109 & 73 & 1.6 & 1,184 & & 89 & 1,095 & 15,001 & 0.00 \\
\hline 2035 & 1,075 & 68 & 1.6 & 1,144 & & 91 & 1,054 & 16,055 & 0.00 \\
\hline 2036 & 1,042 & 63 & 1.7 & 1,106 & & 92 & 1,014 & 17,069 & 0.00 \\
\hline 2037 & 1,009 & 58 & 1.8 & 1,070 & & 94 & 975 & 18,044 & 0.00 \\
\hline 2038 & 978 & 54 & 1.9 & 1,034 & & 96 & 938 & 18,982 & 0.00 \\
\hline 2039 & 948 & 51 & 1.9 & 1,000 & & 98 & 903 & 19,885 & 0.00 \\
\hline 2040 & 918 & 48 & 2.0 & 969 & & 100 & 869 & 20,753 & 0.00 \\
\hline 2041 & 890 & 46 & 2.1 & 938 & & 102 & 836 & 21,589 & 0.00 \\
\hline 2042 & 862 & 43 & 2.2 & 908 & & 104 & 804 & 22,393 & 0.00 \\
\hline \multirow[t]{2}{*}{2043} & & & & & 118 & & -118 & 22,275 & 0.00 \\
\hline & 23,645 & 1,187 & 26 & 24,858 & 849 & 1,734 & 22,275 & & 4.49 \\
\hline
\end{tabular}

The following Table-16 summarizes first party net cash flow calculation using method 2: 
Table16 : First party net cash flow calculation using method 2

\begin{tabular}{|c|c|c|c|}
\hline \multirow[b]{3}{*}{ Year } & \multicolumn{3}{|c|}{ First Party Cash Flow (Method 2) } \\
\hline & \multicolumn{2}{|c|}{ Project NCF 2nd Party NCF } & \multirow{2}{*}{$\begin{array}{l}\text { NCF } \\
\$ M M\end{array}$} \\
\hline & $\$ M M$ & $\$ M M$ & \\
\hline \multicolumn{4}{|l|}{2018} \\
\hline 2019 & -213 & -106 & -106 \\
\hline 2020 & -434 & -217 & -217 \\
\hline 2021 & -590 & -295 & -295 \\
\hline 2022 & -226 & -113 & -113 \\
\hline 2023 & 1,761 & 264 & 1,497 \\
\hline 2024 & 1,703 & 255 & 1,447 \\
\hline 2025 & 1,645 & 247 & 1,399 \\
\hline 2026 & 1,590 & 210 & 1,380 \\
\hline 2027 & 1,536 & 119 & 1,417 \\
\hline 2028 & 1,484 & 117 & 1,367 \\
\hline 2029 & 1,433 & 115 & 1,318 \\
\hline 2030 & 1,384 & 113 & 1,271 \\
\hline 2031 & 1,336 & 111 & 1,225 \\
\hline 2032 & 1,290 & 109 & 1,180 \\
\hline 2033 & 1,245 & 108 & 1,137 \\
\hline 2034 & 1,201 & 106 & 1,095 \\
\hline 2035 & 1,158 & 104 & 1,054 \\
\hline 2036 & 1,117 & 103 & 1,014 \\
\hline 2037 & 1,077 & 101 & 975 \\
\hline 2038 & 1,038 & 100 & 938 \\
\hline 2039 & 1,000 & 97 & 903 \\
\hline 2040 & 963 & 94 & 869 \\
\hline 2041 & 927 & 91 & 836 \\
\hline 2042 & 892 & 89 & 804 \\
\hline \multirow[t]{2}{*}{2043} & -118 & 0 & -118 \\
\hline & 24,197 & 1,923 & 22,275 \\
\hline
\end{tabular}

The following diagrams in Figure 7 and Figure-8 summarize the project net cash flow profile and NCF allocation for each party. 


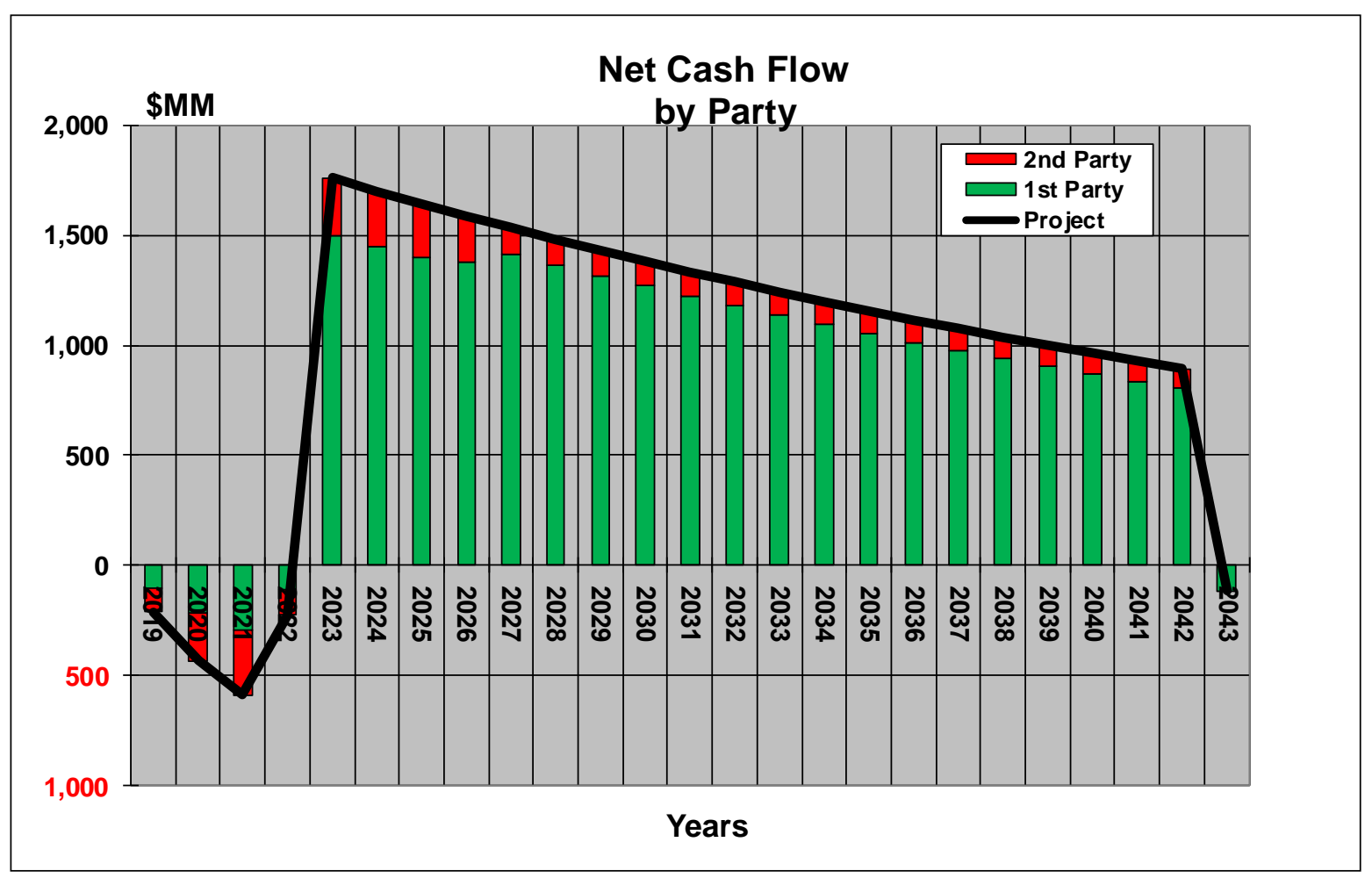

Figure 7: The project net cash flow profile for each party

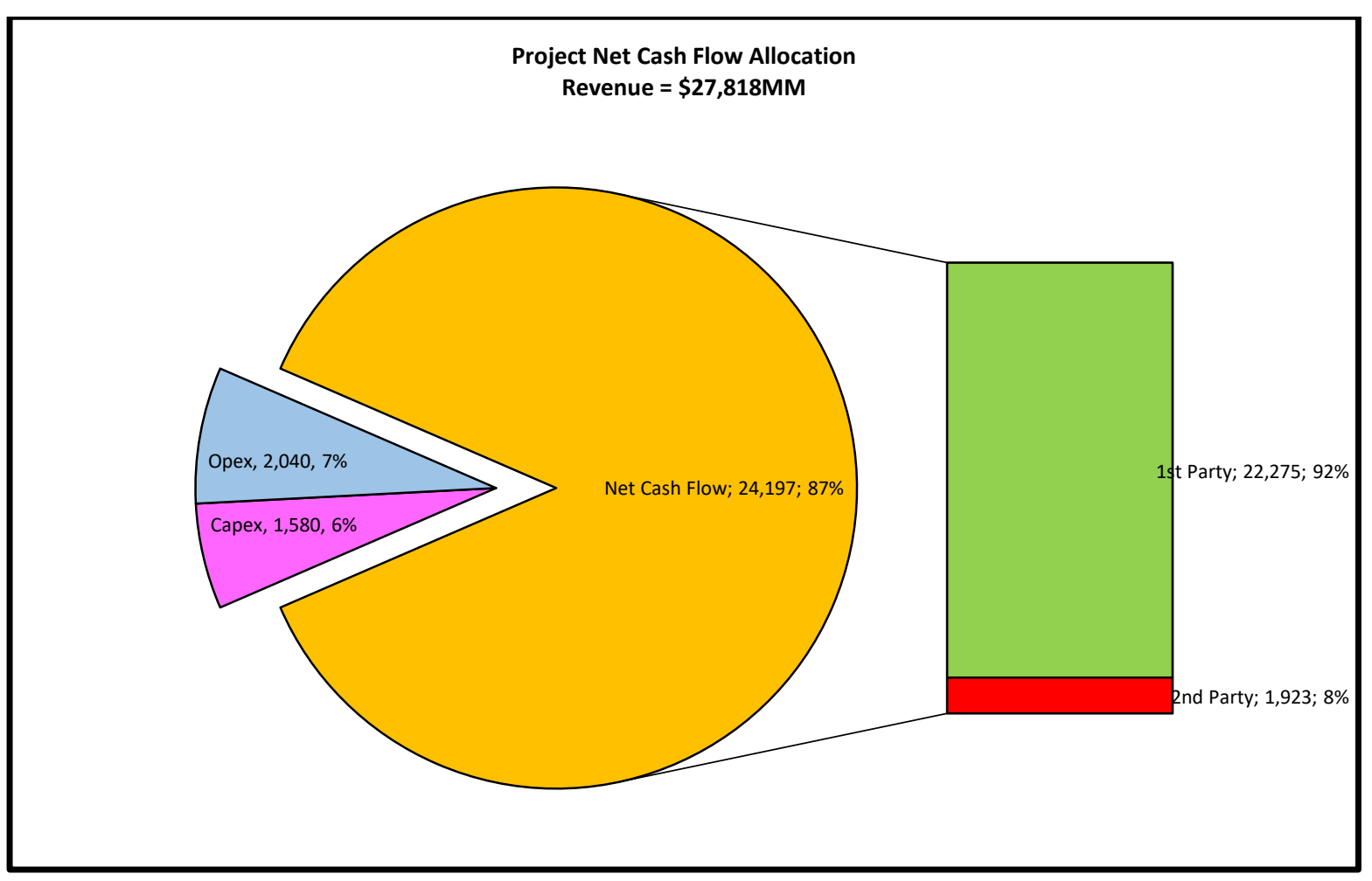

Figure 8: The project NCF allocation for each party 


\section{Economic Indicators:}

A number of key economic indicators were calculated for the entire project and for each party. The following indicators were calculated:

- Net Cash Flow (NCF)

- Net Present Value (NPV)

- Internal Rate of Return (IRR)

- Payback Period (or Payout)

- The Capital Productivity Index (CPI) or Return on Investment (ROI)

- Maximum Exposure (ME)

The definition of indicators are given in Appendix B. The IRR is determined by using a spreadsheet built-in function, by trial \& error or graphically by plotting the NPV versus discount rate. The following Figure-9 demonstrates the IRR for the project and for each party. 


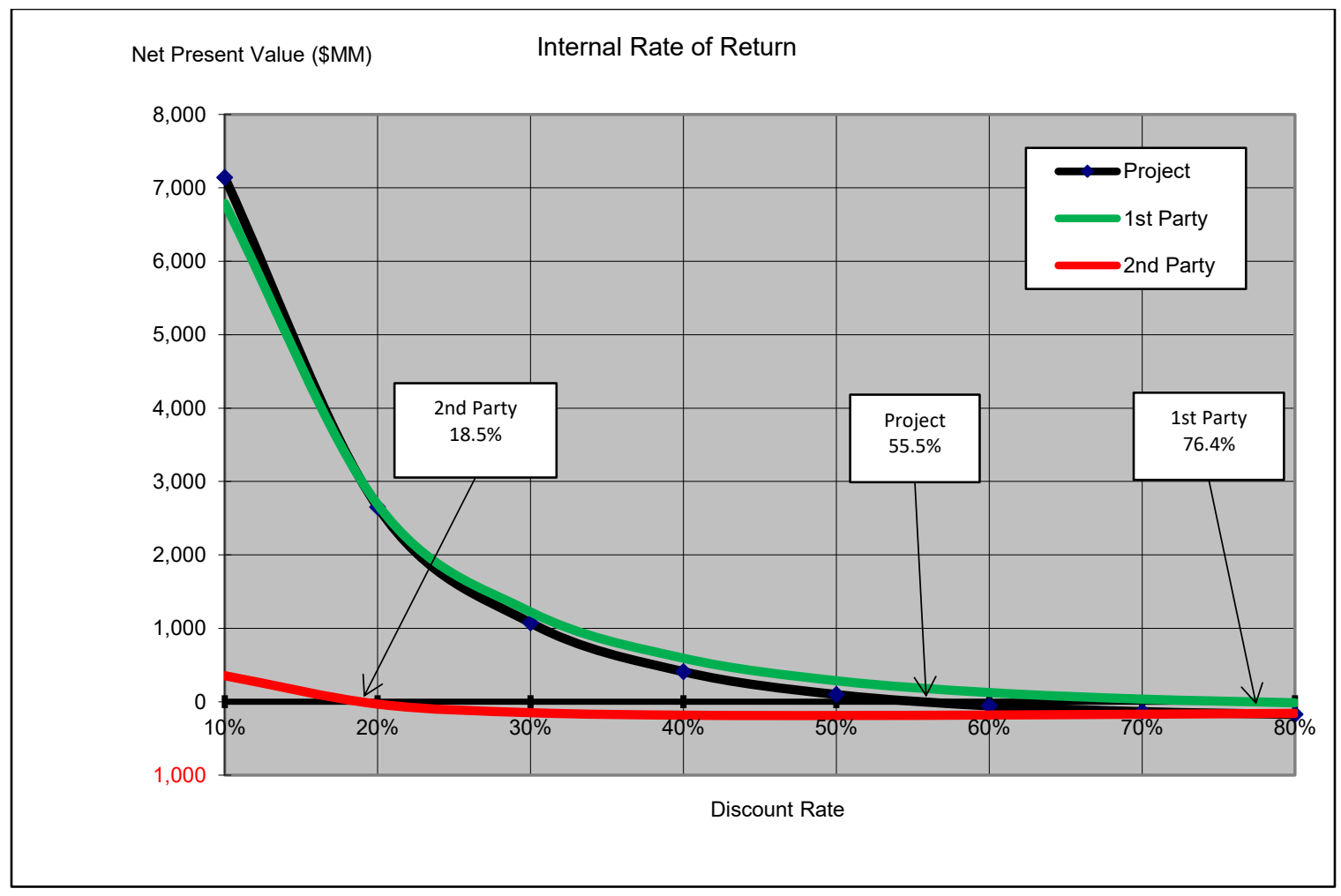

Figure 9: The Internal Rate of Return for the project and for each party.

Figure-10 demonstrates the payback time for the project and for each party:

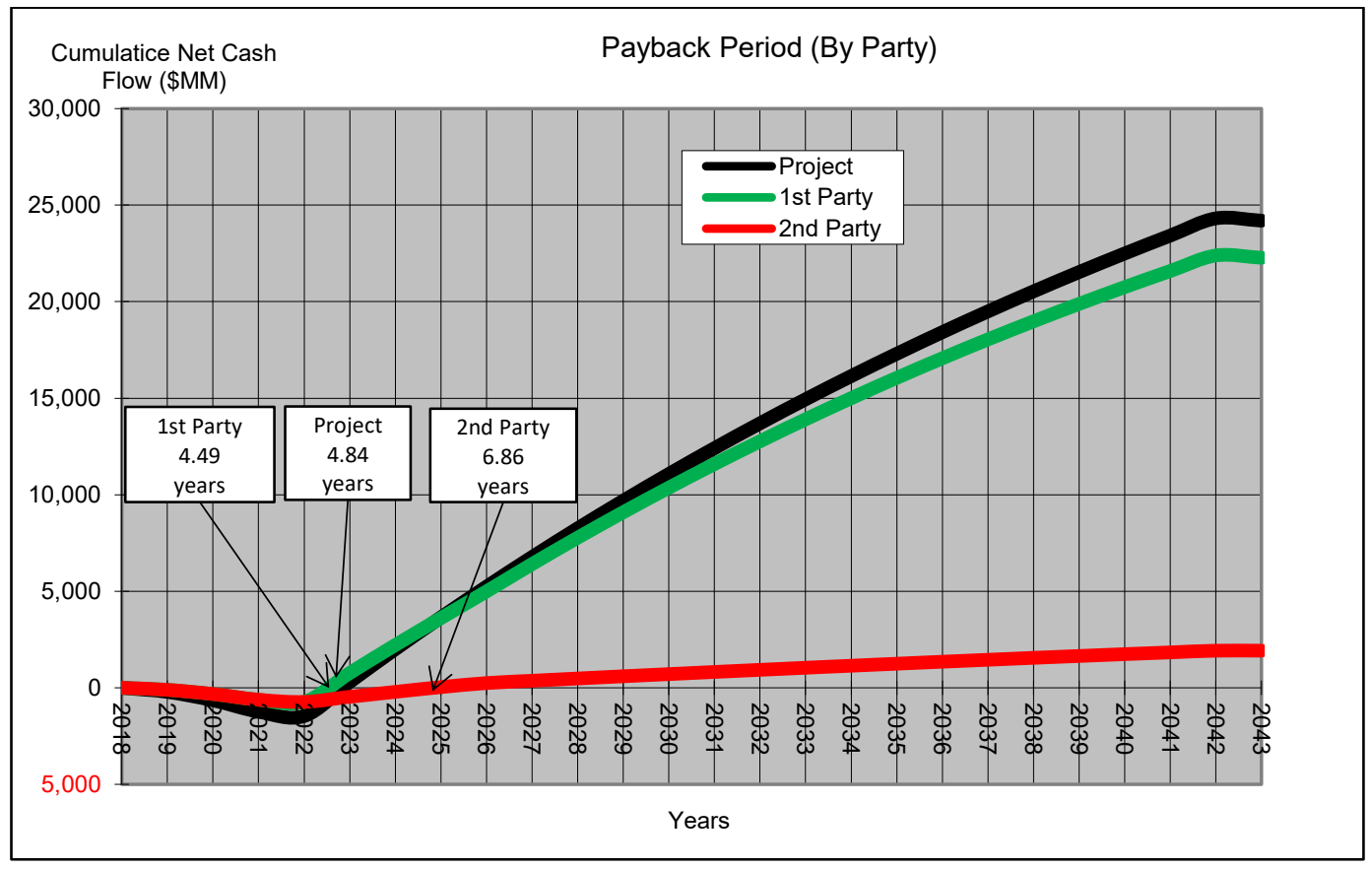

Figure 10: The payback time for the project and for each party 
Economic indicators for the project and for each party are summarized in Table-17.

Table17 : The economic indicators for the project and for each party

\begin{tabular}{|l|c|c|c|c|}
\hline \multicolumn{1}{|c|}{ Economic Indicator } & Project & 1st Party & 2nd Party & Units \\
\hline Net Cash Flow (NCF) & 24,197 & 22,275 & 1,923 & $\mathbf{\$ M M}$ \\
\cline { 2 - 5 } Net Present Value (NPV) & 7,141 & 6,787 & 354 & $\mathbf{\$ M M}$ \\
\cline { 2 - 5 } Internal Rate of Return (IRR) & $55.5 \%$ & $76.4 \%$ & $18.5 \%$ & \\
\cline { 2 - 5 } Payback Period (Payout) & 4.83 & 4.49 & 6.86 & Years \\
\cline { 2 - 5 } Capital Productivity Index (CPI) & 5.84 & 10.47 & 0.61 & $\mathbf{\$} \mathbf{\$}$ \\
\cline { 2 - 6 } Maximum Exposure Value & $-1,462$ & -731 & -731 & $\mathbf{\$ M M}$ \\
\cline { 2 - 5 } Year of ME & 2022 & 2022 & 2022 & \\
\hline
\end{tabular}

The following Tables-18 and Table-19 together with Figure-11 and Figure-12 summarize the average production cost per barrel equivalent $(\$ / B O E)$ and its profile for the project and for each party based on constant (fixed) and escalated costs. 
Table18 : Production cost per barrel equivalent calculations for each party based on constant and escalated costs

\begin{tabular}{|c|c|c|c|c|c|c|}
\hline \multirow[b]{3}{*}{ Year } & \multicolumn{6}{|c|}{ Cost/BOE (\$/BOE) } \\
\hline & \multicolumn{3}{|c|}{ Constant } & \multicolumn{3}{|c|}{ Escalated } \\
\hline & 1st Party & 2nd Party & Project & 1st Party & 2nd Party & Project \\
\hline \multicolumn{7}{|l|}{2018} \\
\hline \multicolumn{7}{|l|}{2019} \\
\hline \multicolumn{7}{|l|}{2020} \\
\hline \multicolumn{7}{|l|}{2021} \\
\hline \multicolumn{7}{|l|}{2022} \\
\hline 2023 & 5.51 & 18.84 & 7.51 & 5.94 & 19.96 & 8.04 \\
\hline 2024 & 5.80 & 19.83 & 7.91 & 6.31 & 21.07 & 8.53 \\
\hline 2025 & 6.11 & 20.88 & 8.32 & 6.71 & 22.25 & 9.04 \\
\hline 2026 & 6.30 & 24.80 & 8.76 & 6.99 & 26.51 & 9.59 \\
\hline 2027 & 6.27 & 42.14 & 9.22 & 7.03 & 45.18 & 10.17 \\
\hline 2028 & 6.61 & 43.57 & 9.71 & 7.49 & 46.86 & 10.79 \\
\hline 2029 & 6.97 & 45.02 & 10.22 & 7.97 & 48.57 & 11.44 \\
\hline 2030 & 7.35 & 46.50 & 10.76 & 8.50 & 50.33 & 12.14 \\
\hline 2031 & 7.75 & 48.00 & 11.32 & 9.06 & 52.13 & 12.88 \\
\hline 2032 & 8.18 & 49.53 & 11.92 & 9.65 & 53.97 & 13.67 \\
\hline 2033 & 4.16 & 7.20 & 4.44 & 5.59 & 9.69 & 5.97 \\
\hline 2034 & 4.38 & 7.42 & 4.67 & 6.02 & 10.19 & 6.41 \\
\hline 2035 & 4.62 & 7.65 & 4.92 & 6.48 & 10.71 & 6.88 \\
\hline 2036 & 4.88 & 7.88 & 5.17 & 6.97 & 11.25 & 7.39 \\
\hline 2037 & 5.15 & 8.11 & 5.45 & 7.50 & 11.82 & 7.94 \\
\hline 2038 & 5.43 & 8.35 & 5.73 & 8.07 & 12.40 & 8.52 \\
\hline 2039 & 5.73 & 8.67 & 6.04 & 8.68 & 13.14 & 9.15 \\
\hline 2040 & 6.04 & 9.04 & 6.35 & 9.33 & 13.97 & 9.82 \\
\hline 2041 & 6.36 & 9.42 & 6.69 & 10.03 & 14.86 & 10.55 \\
\hline 2042 & 6.71 & 9.82 & 7.04 & 10.78 & 15.79 & 11.32 \\
\hline \multicolumn{7}{|l|}{2043} \\
\hline Average & 6.18 & 24.02 & 8.12 & 7.71 & 27.46 & 9.86 \\
\hline
\end{tabular}


Table19 : The average constant and nominal costs per barrel equivalent for the project and each party

\begin{tabular}{|c|c|c|c|c|}
\hline Description & First Party & $\begin{array}{c}\text { Second } \\
\text { Party }\end{array}$ & Project & Units \\
\hline Cum. Production & 327 & 40 & 367 & MMBOE \\
\hline \multicolumn{5}{|c|}{ Real Costs (Constant 2018 Costs) } \\
\hline Capex & 731 & 731 & 1,462 & $\$ \mathrm{MM}$ \\
\hline Opex & 1,293 & 228 & 1,521 & $\$ M M$ \\
\hline Total Cost & 2,024 & 959 & 2,983 & $\$ M M$ \\
\hline Capital Cost/bbl. & 2.23 & 18.31 & 3.98 & $\$ / \mathrm{BOE}$ \\
\hline Operating Cost/bbl. & 3.95 & 5.71 & 4.14 & $\$ / \mathrm{BOE}$ \\
\hline Total Cost/bbl. & 6.18 & 24.02 & 8.12 & $\$ / \mathrm{BOE}$ \\
\hline \multicolumn{5}{|c|}{ Nominal Costs (Escalated) } \\
\hline Capex & 790 & 790 & 1,580 & $\$ M M$ \\
\hline Opex & 1,734 & 306 & 2,040 & $\$ M M$ \\
\hline Total Cost & 2,524 & 1,096 & 3,621 & $\$ \mathrm{MM}$ \\
\hline Capital Cost/bbl. & 2.41 & 19.79 & 4.30 & $\$ / \mathrm{BOE}$ \\
\hline Operating Cost/bbl. & 5.30 & 7.66 & 5.55 & $\$ / \mathrm{BOE}$ \\
\hline Total Cost/bbl. & 7.71 & 27.46 & 9.86 & $\$ / \mathrm{BOE}$ \\
\hline
\end{tabular}

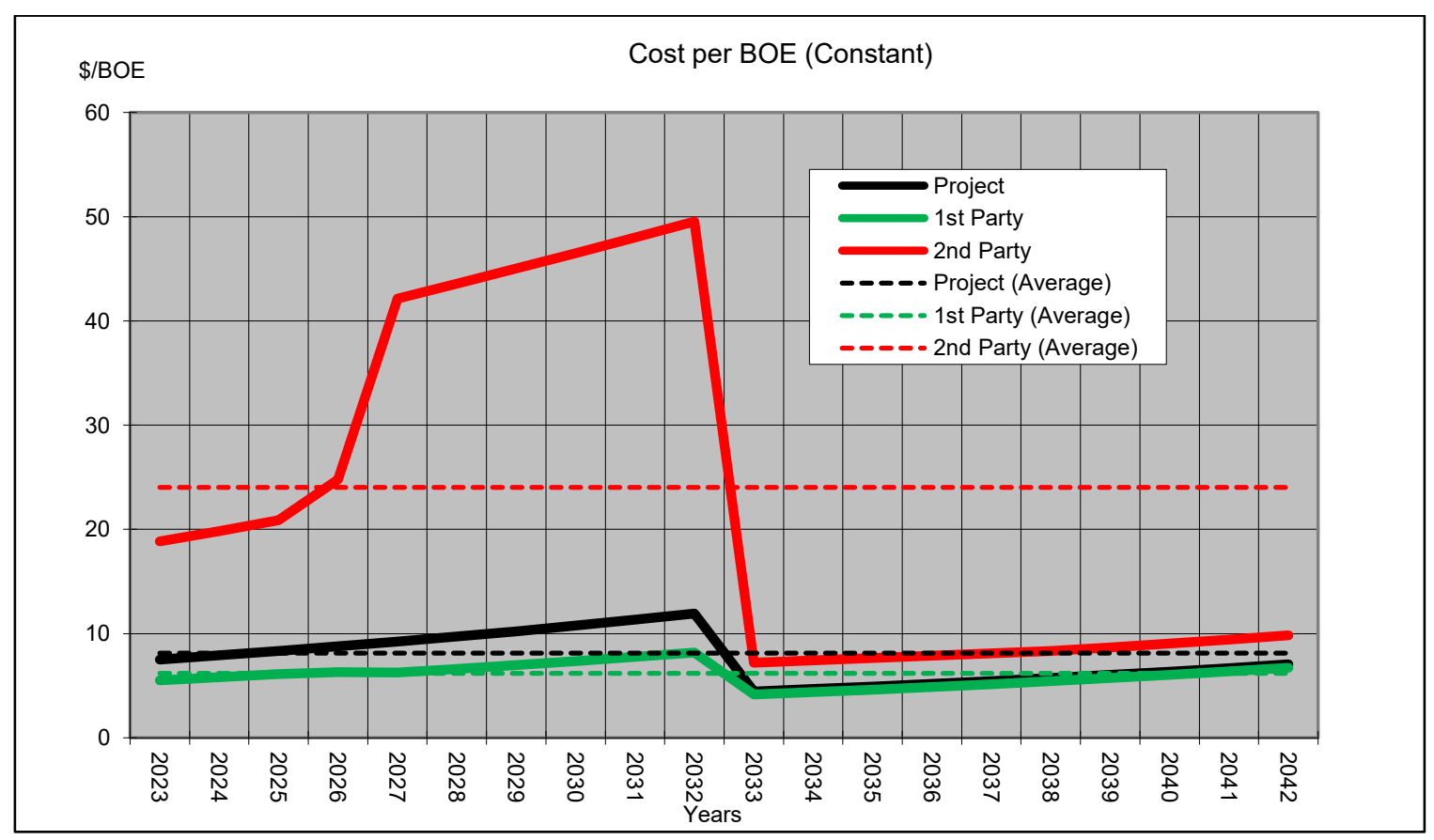

Figure 11: Production cost per barrel equivalent profile for the project and for each party based on constant costs 


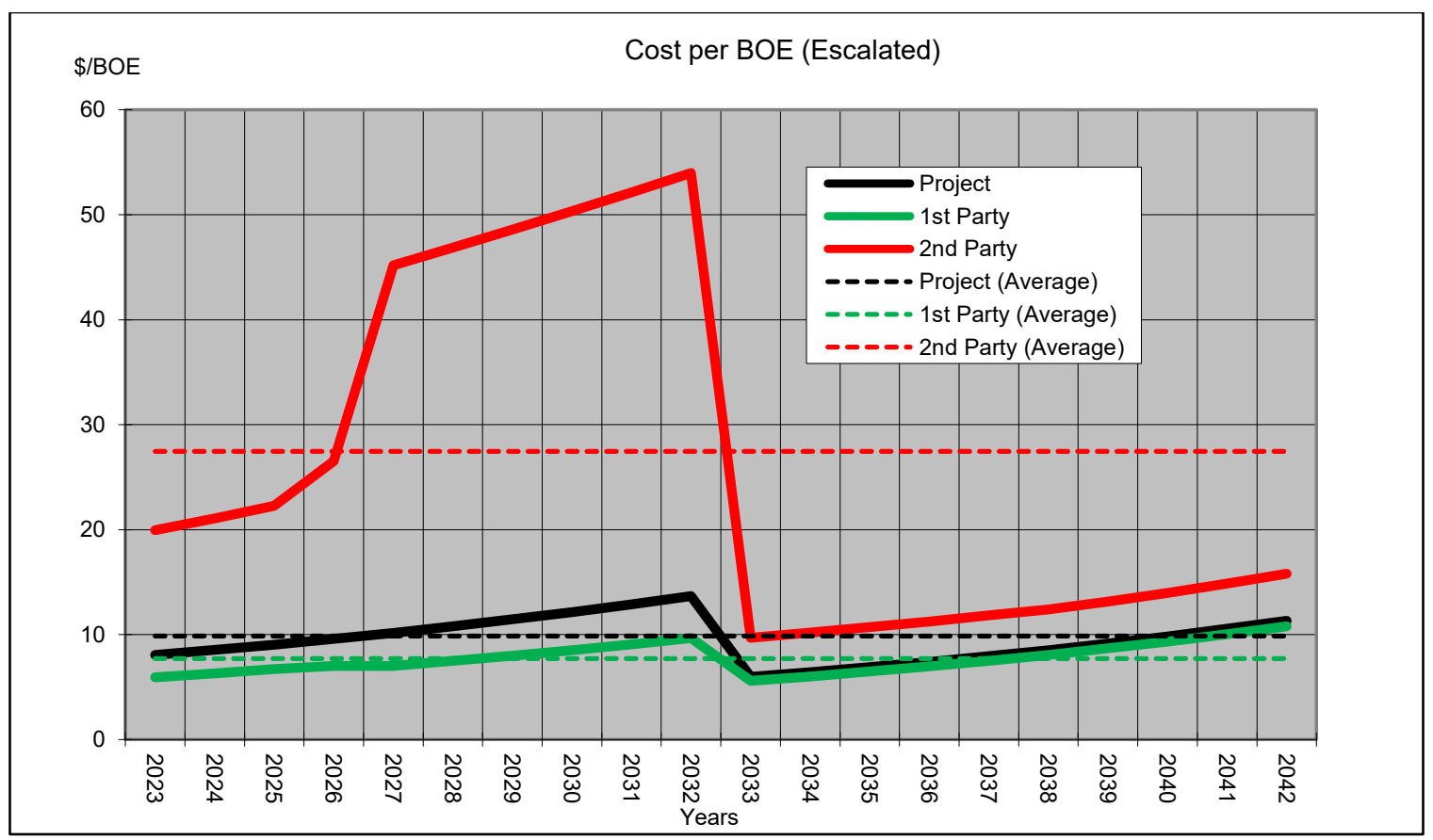

Figure 12: Production cost per barrel equivalent profile for the project and for each party based on Escalated costs

In general the upward trend of the cost per barrel profiles results from the gradual production decline. The odd shape of the second party cost per barrel profile can be explained as follows:

- During the first 4 years of production: Cost per barrel starts lower than its average rate at about $\$ 20 / \mathrm{BOE}$ due to receiving all its entitled revenue for cost recovery, and increases gradually as field production declines.

- During the following 6 years: Cost per barrel jumps to around \$45/BOE resulting from allocating a portion of its entitled revenue to NOC as its share of profit oil.

- During the remaining 10 years: Cost per barrel drops to around \$10/BOE after all Capex is depreciated. 


\section{Sensitivity Analysis}

Since the calculated economic indicators are based on future predictions then there is always a high degree of data uncertainty. To answer "What If" questions a sensitivity analysis was performed for the project as well as for each party. These analyses determine what would happen to project profitability in case a number of key parameters vary from their base case assumptions. The economic sensitivity is demonstrated by constructing spider and tornado diagrams.

For example, to determine how the NPV will change when varying the operating cost (such as by $\pm 50 \%$ ) from its base case assumption, two spreadsheets are dublicated from the base case "Cash Flow" sheet. On the first copy the operating cost is increased by $50 \%$ and on the other sheet it is decreased by $50 \%$. The resulting NPV's are then plotted versus the percentage variation of OPEX. The same calculation is repeated for each additional key parameter such as the production rate, selling prices, Capex and the assumed discount rate. The advantage of this method is that the spider diagram will be automatically updated whenever an input data is changed from its base case assumption.

The degree of the sensitivity of the NPV will depend on the slope of each line. The larger the slope the more sensitive the NPV to variation of this parameter. This sensitivity analysis investigated the effect of varying each of the mentioned parameter on the NPV's and IRR's separately.

The following Table-20 summarizes the calculated NPV's and IRR's for the project and for each party for each parameter variation. 
Table20 : The calculated NPV's and IRR's for the project and for each party for each parameter variation

\begin{tabular}{|c|c|c|c|c|c|c|c|c|c|}
\hline \multirow[t]{2}{*}{ NPV Sensitivity (\$MM) } & \multicolumn{3}{|c|}{ 1st Party } & \multicolumn{3}{|c|}{ 2nd Party } & \multicolumn{3}{|c|}{ Project } \\
\hline & $-50 \%$ & $0 \%$ & $50 \%$ & $-50 \%$ & $0 \%$ & $50 \%$ & $-50 \%$ & $0 \%$ & $50 \%$ \\
\hline \multirow{5}{*}{$\begin{array}{l}\text { Prod. Rate } \\
\text { Selling Price } \\
\text { Capex } \\
\text { Opex } \\
\text { Discount Rate }\end{array}$} & 2,754 & 6,787 & 10,953 & -43 & 354 & 618 & 2,711 & 7,141 & 11,571 \\
\hline & 2,768 & 6,787 & 10,848 & -57 & 354 & 723 & 2,711 & 7,141 & 11,571 \\
\hline & 7,166 & 6,787 & 6,416 & 555 & 354 & 145 & 7,721 & 7,141 & 6,561 \\
\hline & 7,040 & 6,787 & 6,533 & 380 & 354 & 328 & 7,420 & 7,141 & 6,862 \\
\hline & 11,791 & 6,787 & 4,167 & 849 & 354 & 103 & 12,641 & 7,141 & 4,270 \\
\hline \multirow{2}{*}{ IRR Sensitivity } & \multicolumn{3}{|c|}{ 1st Party } & \multicolumn{3}{|c|}{ 2nd Party } & \multicolumn{3}{|c|}{ Project } \\
\hline & $-50 \%$ & $0 \%$ & $50 \%$ & $-50 \%$ & $0 \%$ & $50 \%$ & $-50 \%$ & $0 \%$ & $50 \%$ \\
\hline \multirow{4}{*}{$\begin{array}{l}\text { Prod. Rate } \\
\text { Selling Price } \\
\text { Capex } \\
\text { Opex }\end{array}$} & $48.3 \%$ & $76.4 \%$ & $96.4 \%$ & $8.9 \%$ & $18.5 \%$ & $24.3 \%$ & $33.0 \%$ & $55.5 \%$ & $71.5 \%$ \\
\hline & $48.3 \%$ & $76.4 \%$ & $96.2 \%$ & $8.4 \%$ & $18.5 \%$ & $25.9 \%$ & $33.0 \%$ & $55.5 \%$ & $71.5 \%$ \\
\hline & $110.1 \%$ & $76.4 \%$ & $60.2 \%$ & $32.7 \%$ & $18.5 \%$ & $12.5 \%$ & $83.2 \%$ & $55.5 \%$ & $42.4 \%$ \\
\hline & $77.5 \%$ & $76.4 \%$ & $75.3 \%$ & $19.0 \%$ & $18.5 \%$ & $18.0 \%$ & $56.4 \%$ & $55.5 \%$ & $54.6 \%$ \\
\hline
\end{tabular}

The resulting spider diagrams for the sensitivity of the NPV's are given in Figure-13 thru Figure-15.

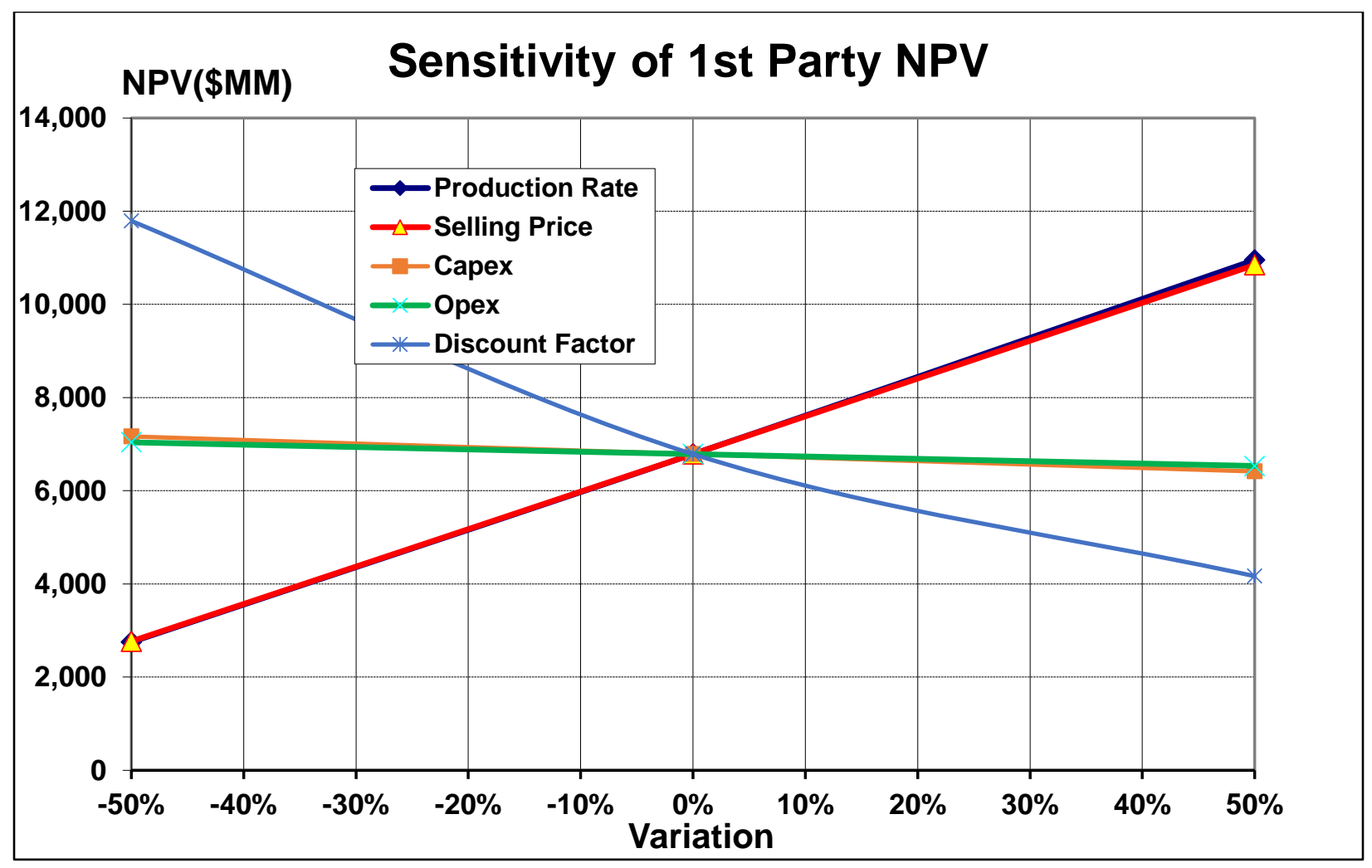

Figure 13: First party NPV Spider diagram 


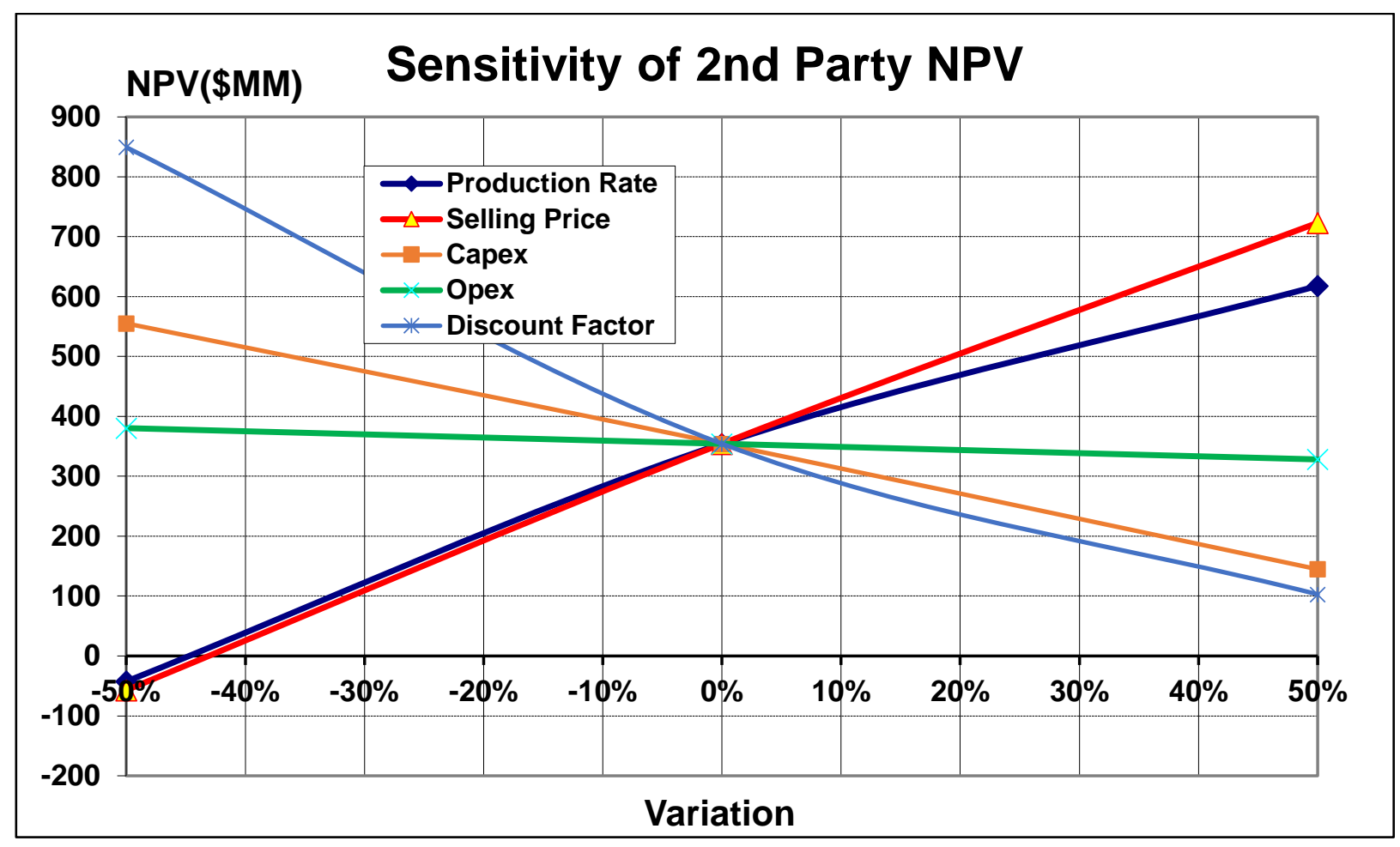

Figure 14: Second party NPV Spider diagram

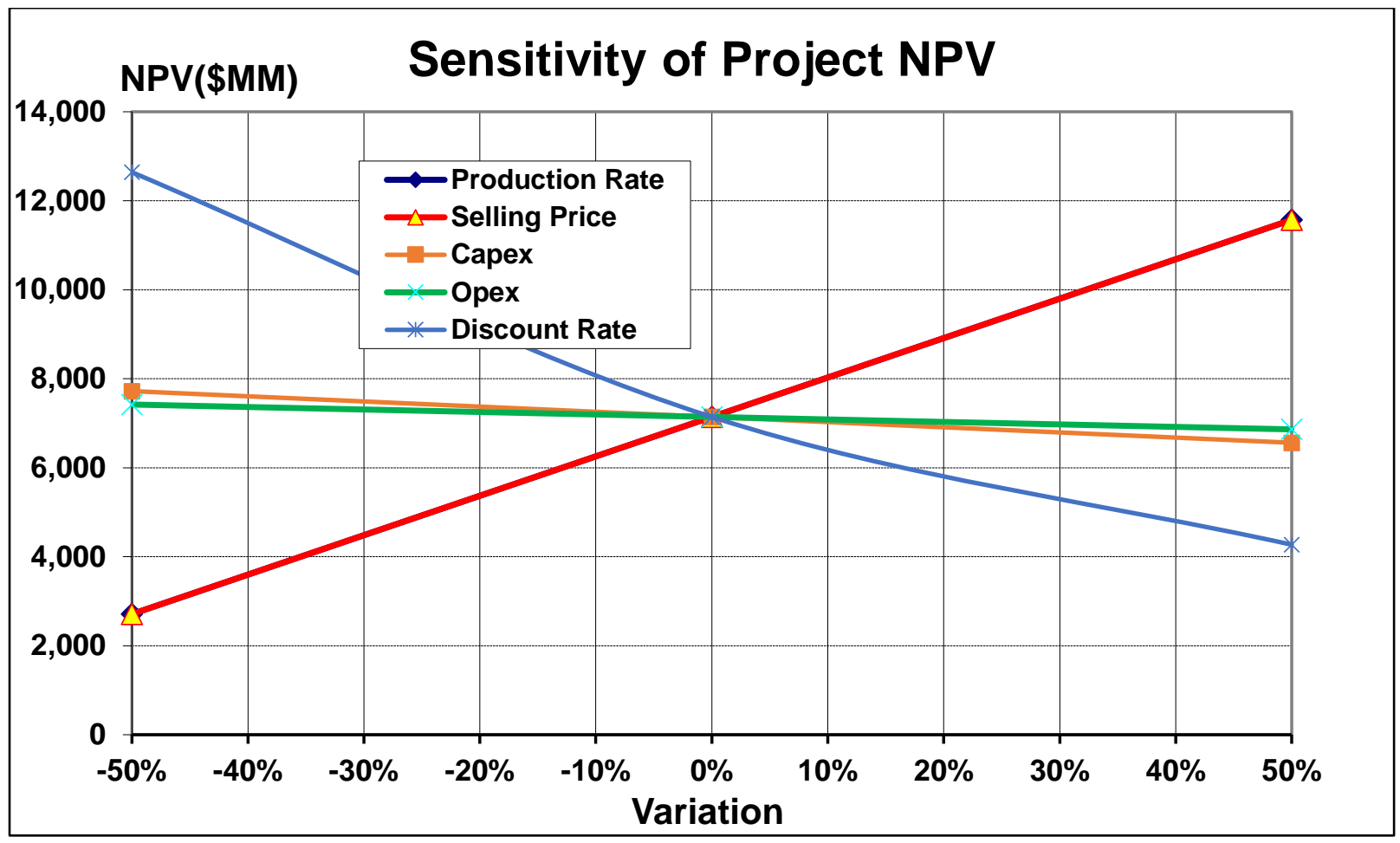

Figure 15: Project NPV Spider diagram 
The following tornado diagram (Figure-16) demonstrates the range of the project NPV's resulting from varying some parameters in a descending order.

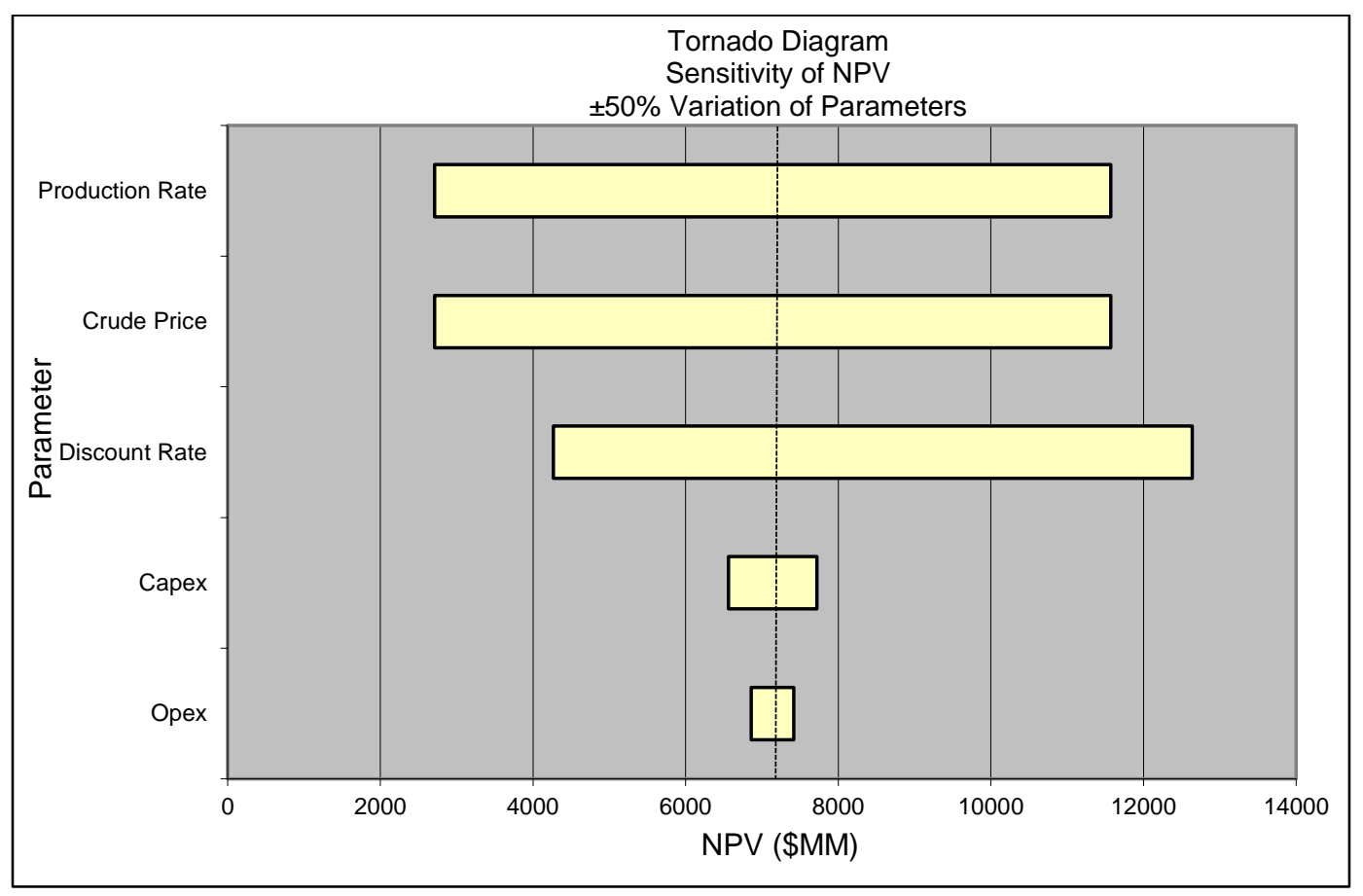

Figure 16: Project NPV Tornado Diagram

The resulting spider diagrams to investigate the sensitivity of the IRR are given in Figure-17 thru Figure-19. 


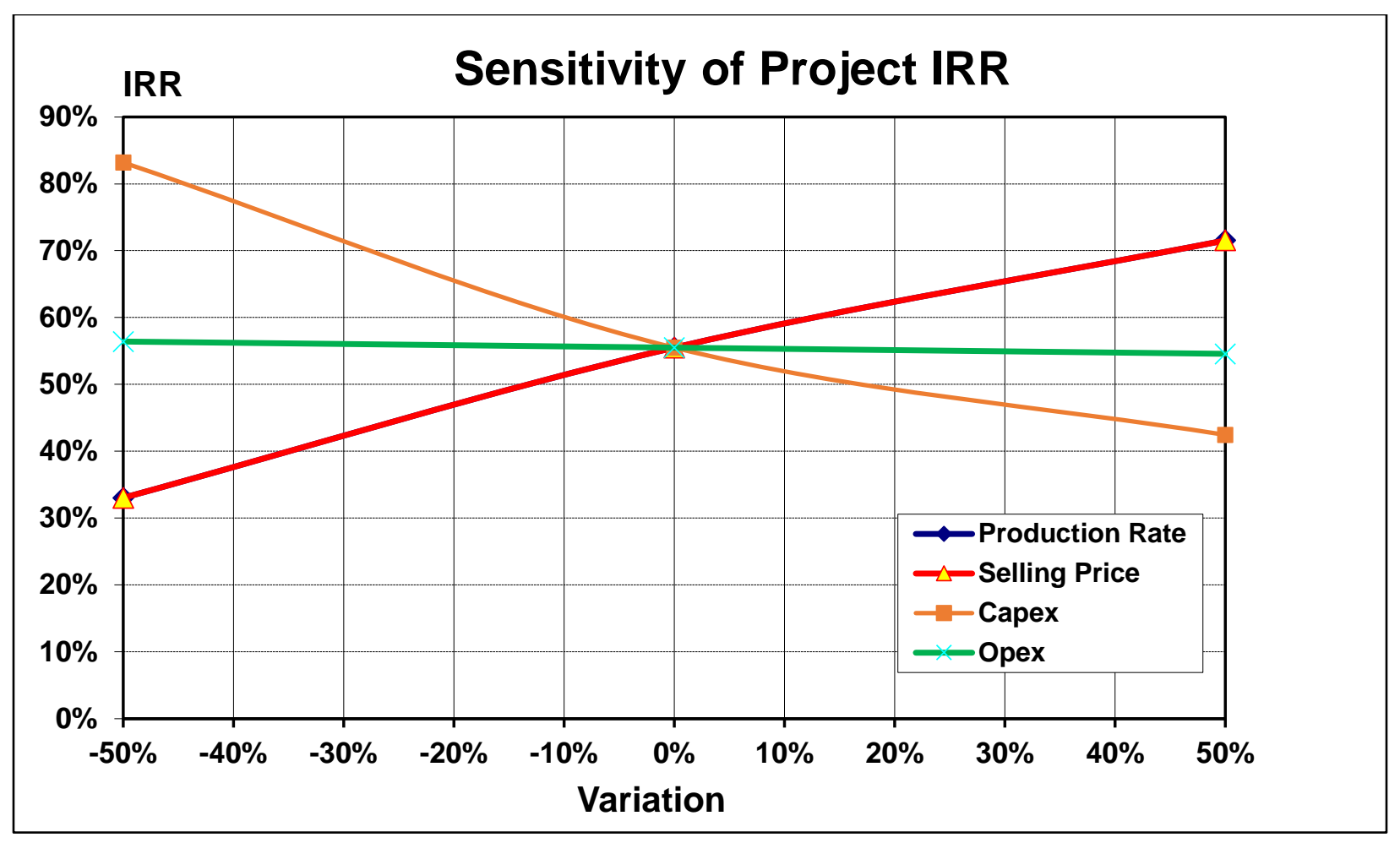

Figure 17: Project IRR Spider diagram

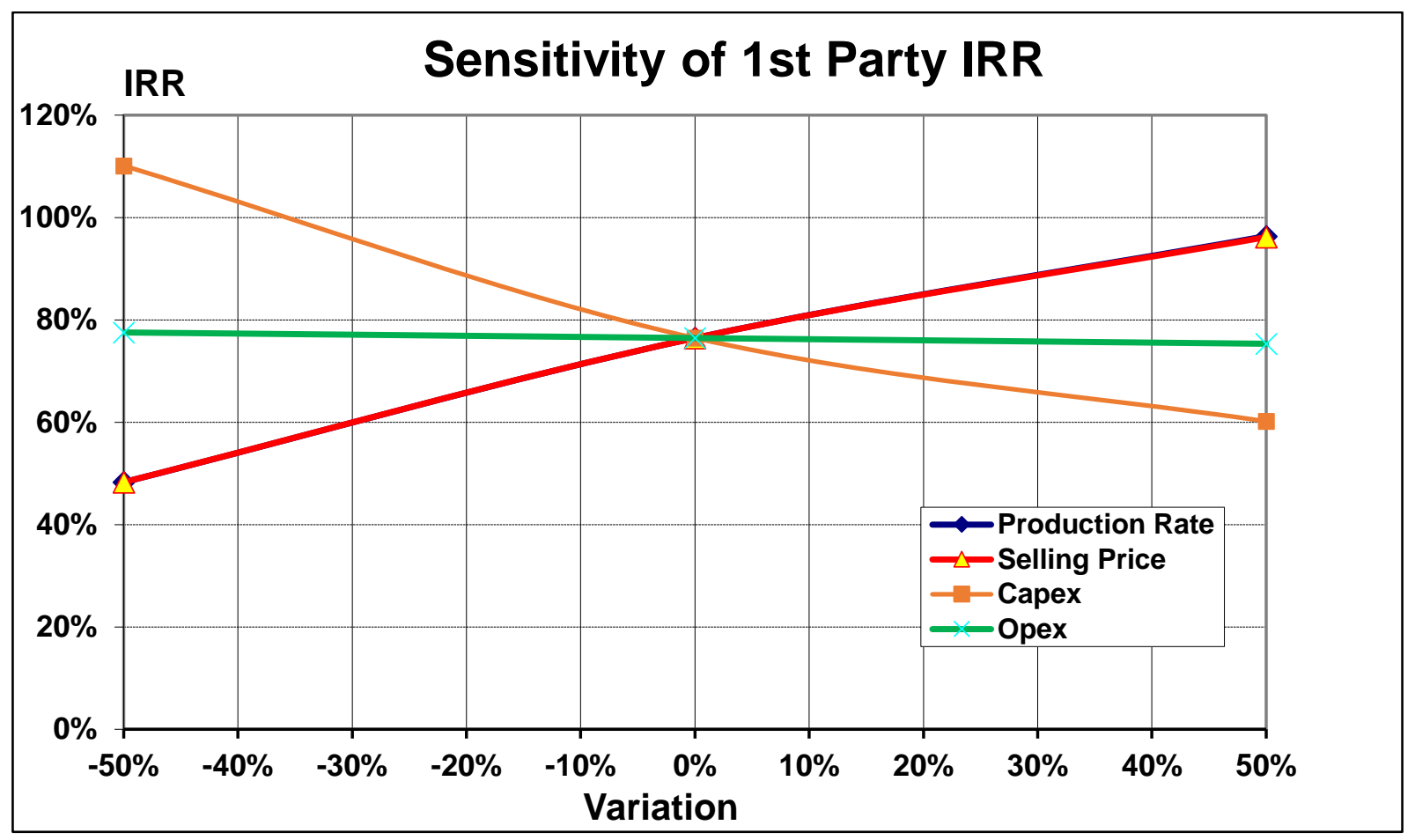

Figure 18: First Party IRR Spider diagram 


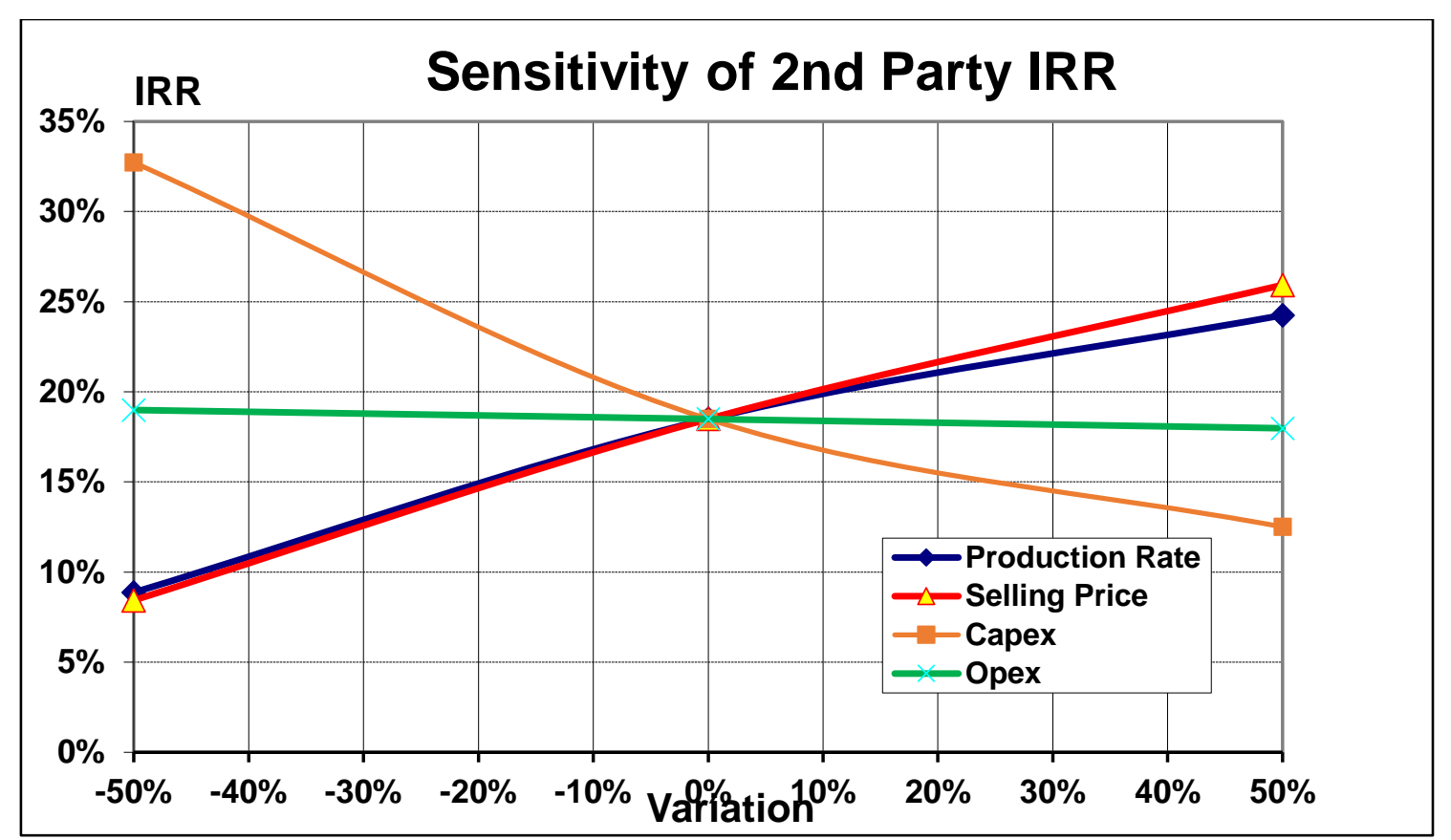

Figure 19: Second party IRR Spider diagram

The following tornado diagram (Figure-20) demonstrates the range of the second party IRR's resulting from varying some parameters in a descending order.

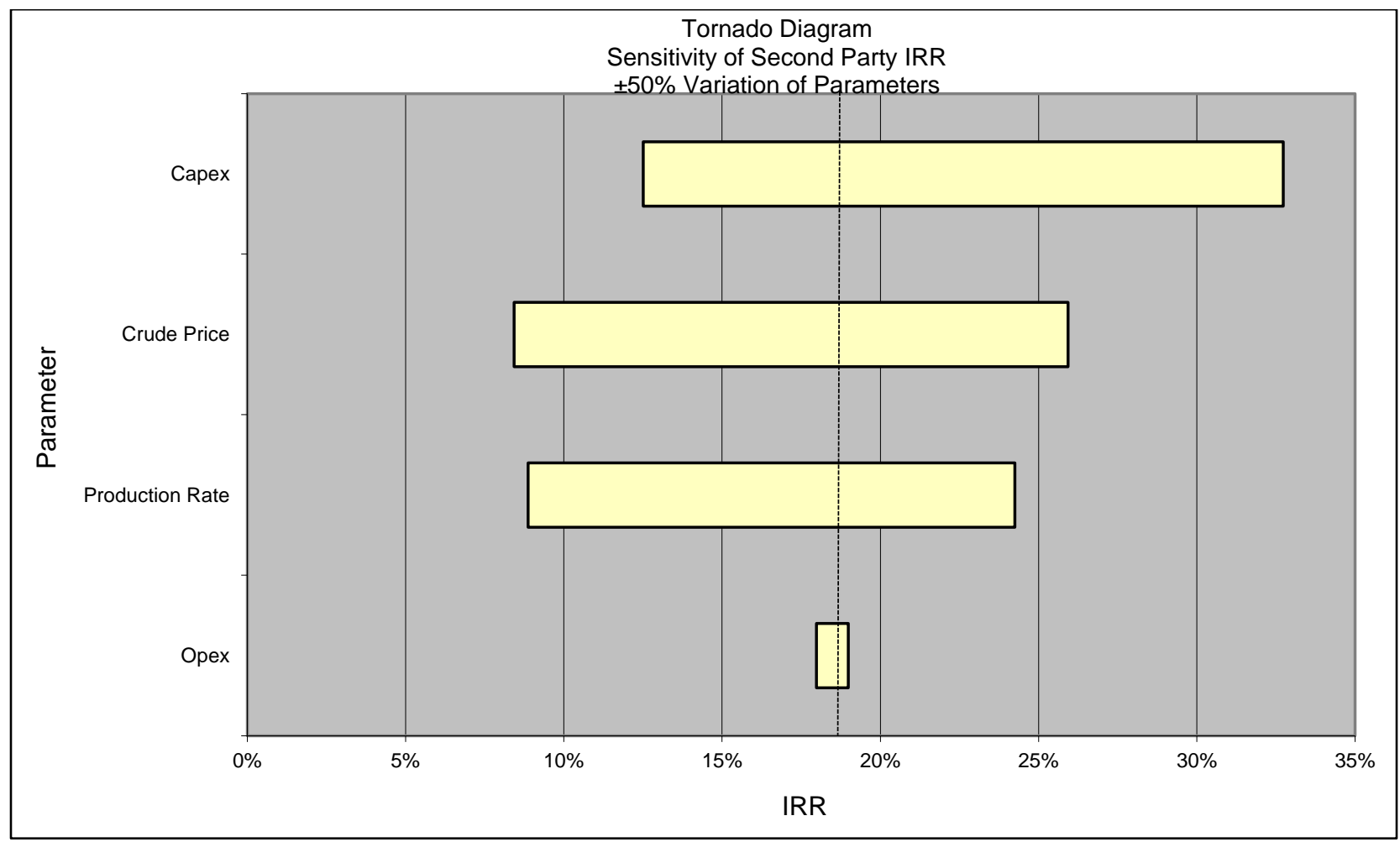

Figure 20: Second Party IRR Tornado Diagram 


\section{Monte Carlo Simulation}

Monte Carlo simulations are applied to simulate the probability of different outcomes when several variables are taking place. Using Monte Carlo simulations makes it viable to comprehend the effect of risk and uncertainty in forecasting models.

The constructed sensitivity analysis is used to study the project profitably when varying key parameters individually. The advantage of using Monte Carlo is to observe the project profitability when varying several parameters at the same time. Additionally, this approach provides the probability distribution function of several key parameters and their effect on the resulted Net Present Value.

Since it is challenging to perform Monte Carlo simulation of the economic model using spreadsheet, it is decided to perform Monte Carlo simulation using MATLAB software. To insure the accuracy of the simulation, the base case model is build using MATLAB. The economic indicators of the MATLAB model and the spreadsheet model are compared and their results are found identical (Table-21).

Table21 : Economic Indicator for the Project (MATLAB vs Spreadsheet)

\begin{tabular}{|l|c|c|l|c|c|}
\hline \multicolumn{4}{|c|}{ Economic Indicators for the Project } \\
\hline \multicolumn{3}{|c|}{ Using Matlab } & \multicolumn{3}{c|}{ Using Spreadsheet } \\
\hline NCF & 24,197 & $\$ \mathrm{MM}$ & NCF & 24,197 & $\$ \mathrm{MM}$ \\
NPV & 7,141 & \$MM & NPV & 7,141 & \$MM \\
IRR & 55.5 & $\%$ & IRR & 55.5 & $\%$ \\
Payout & 4.83 & Years & Payout & 4.83 & Years \\
CPI & 5.84 & \$ \$ & CPI & 5.84 & \$ \$ \\
ME Value & $-1,462$ & \$MM & ME Value & $-1,462$ & \$MM \\
Year of ME & 2022 & & Year of ME & 2022 & \\
\hline
\end{tabular}

After it was determined that the MATLAB model is valid, several key parameters were chosen to perform Monte Carlo simulation by changing them. The selected key parameters are: Production rate, oil price, gas price, condensate price, number of wells, cost contingency, gas oil ratio, discount rate, and inflation rate. 
In order confirm the accuracy of the forecasted production rate. It is determined to try several decline curve analyses and carry on the study with the worst possible decline case scenario. The investigated decline curve analyses are:

1. Model decline (Constant $5 \%$ decline).

2. Exponential decline (similar to the model decline).

3. Linear decline.

4. Harmonic decline.

5. Hyperbolic decline.

The following Figure-21 and Figure-22 illustrate the production forecast using each decline curve method.

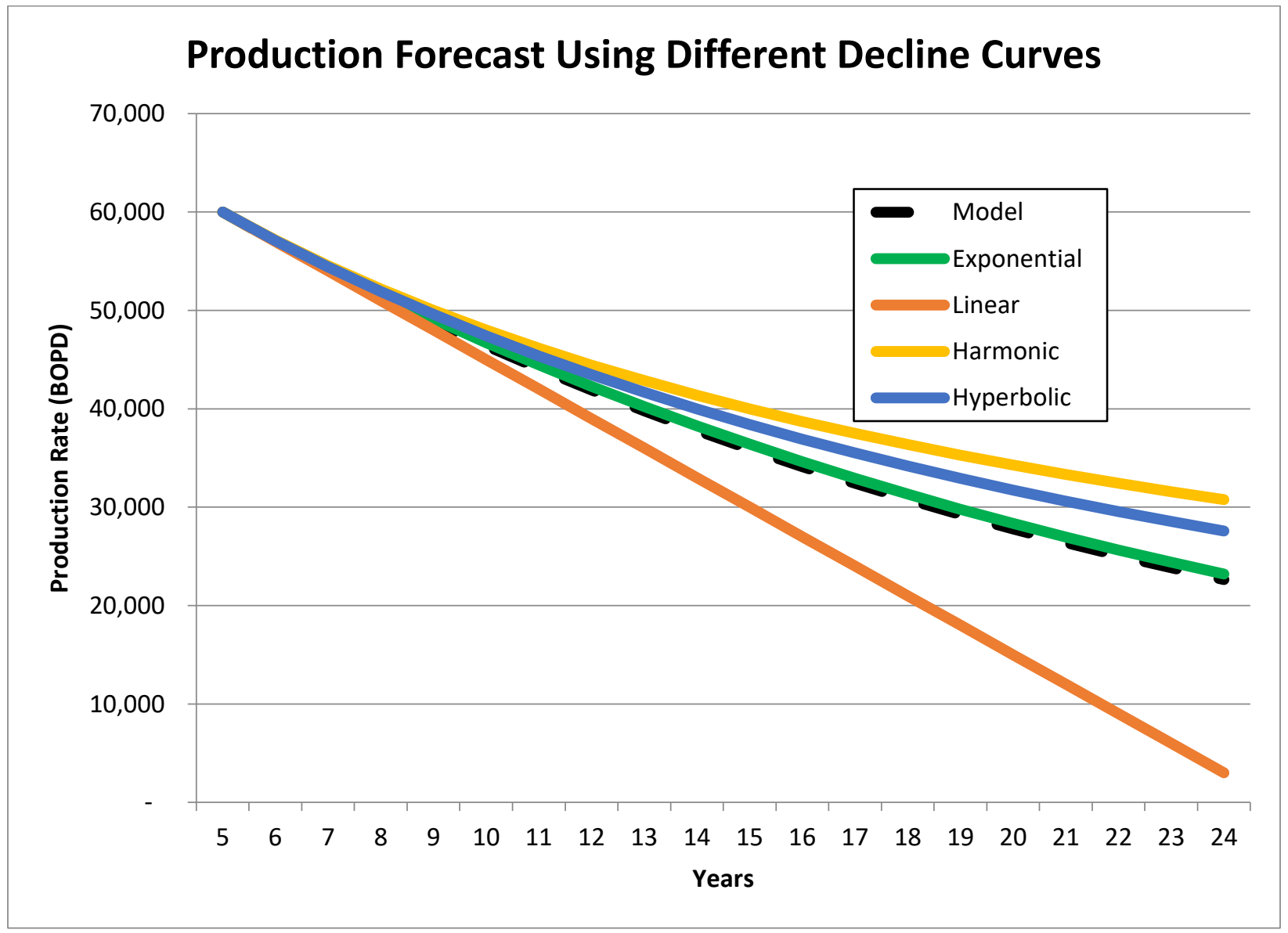

Figure 21: Production Forecast using Different Decline Curve 


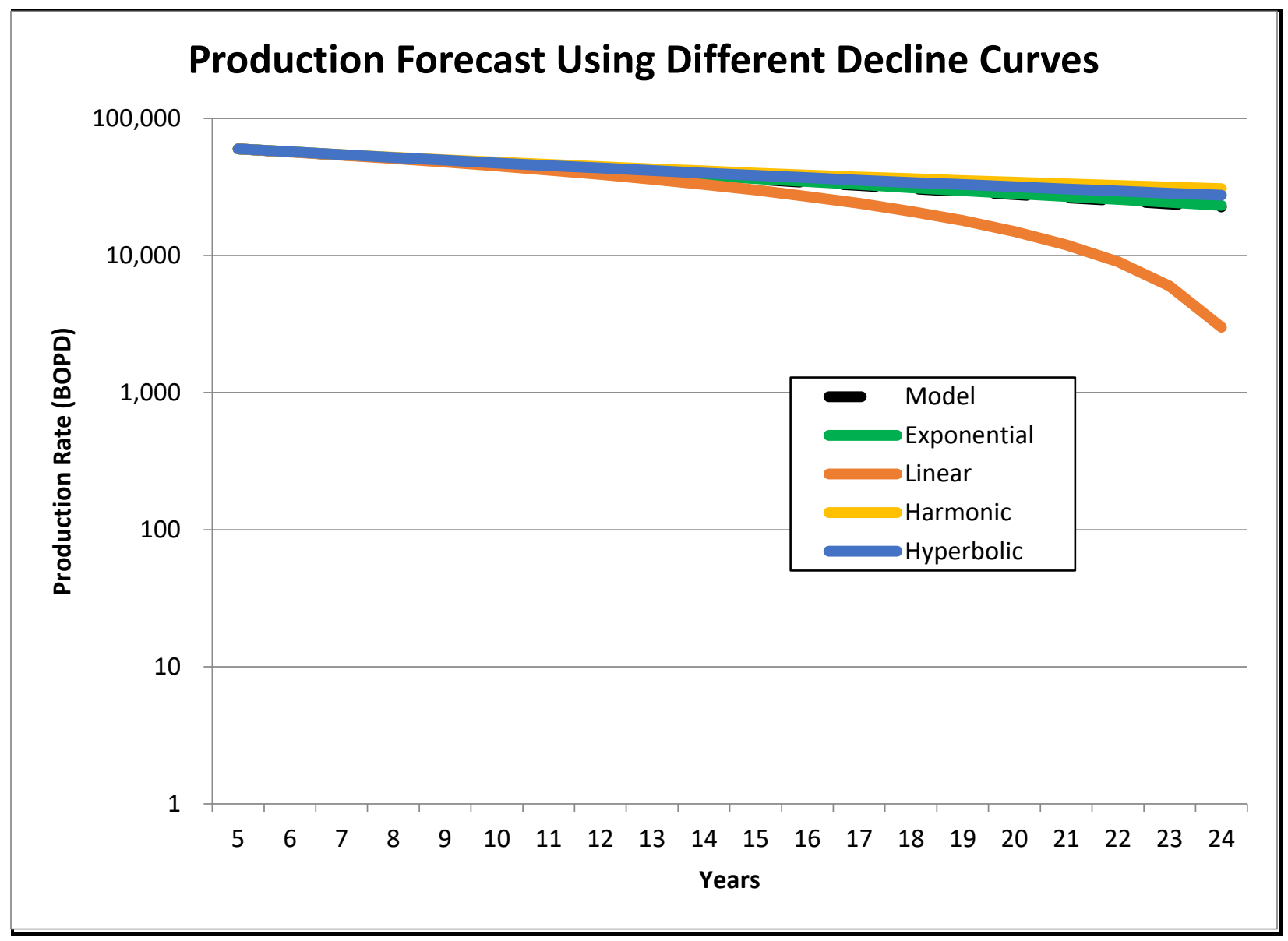

Figure 22: Production Forecast using Different Decline Curve (Semi-Log)

From the observed decline curves, it is seen that the worst-case scenario is the model decline ( $5 \%$ constant decline) when compared to the other decline curves. The linear decline is eliminated from the comparison since it does not represent a realistic decline curve. Therefore, the model decline curve is being used in the following Monte Carlo simulation study as the worst case.

Before performing Monte Carlo simulation, it is important to understand the effect of each key parameter on the resulting net present value in addition to understanding the probability distribution of the parameter itself. Both normal and uniform distributions are used by defining the mean, standard deviation, and limits for each parameter. Most of the selected key parameters follows a normal probability distribution, such as inflation 
rate and selling price, while other parameters use uniform distribution, such as manufacturing costs (Monte Carlo Simulation, n.d.).

The following plots describes the results of changing each of the key parameters on the net present value.

\section{Production rate}

Production rate is following a normal probability distribution with a mean of $60 \mathrm{MBD}$ (Figure-23). The resulted net present value remains positive with a minimum value of 4000 \$MM and maximum value of 11,000 \$MM. The relationship shown in Figure-24 between production rate and net present value is directly proportional. Moreover, net present value is highly sensitive to production rate.

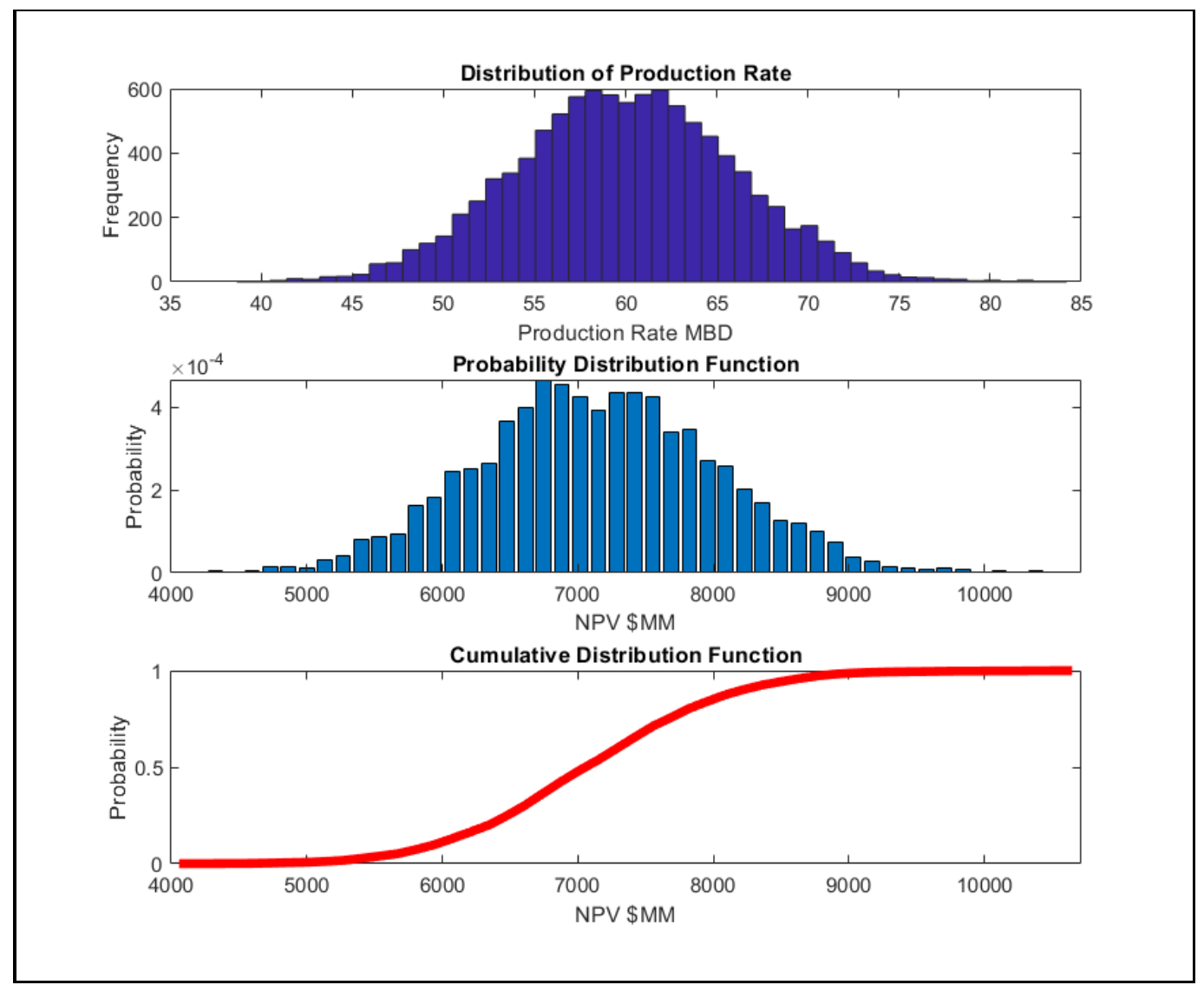

Figure23 : Distribution of Production Rate and NPV Distribution Functions 


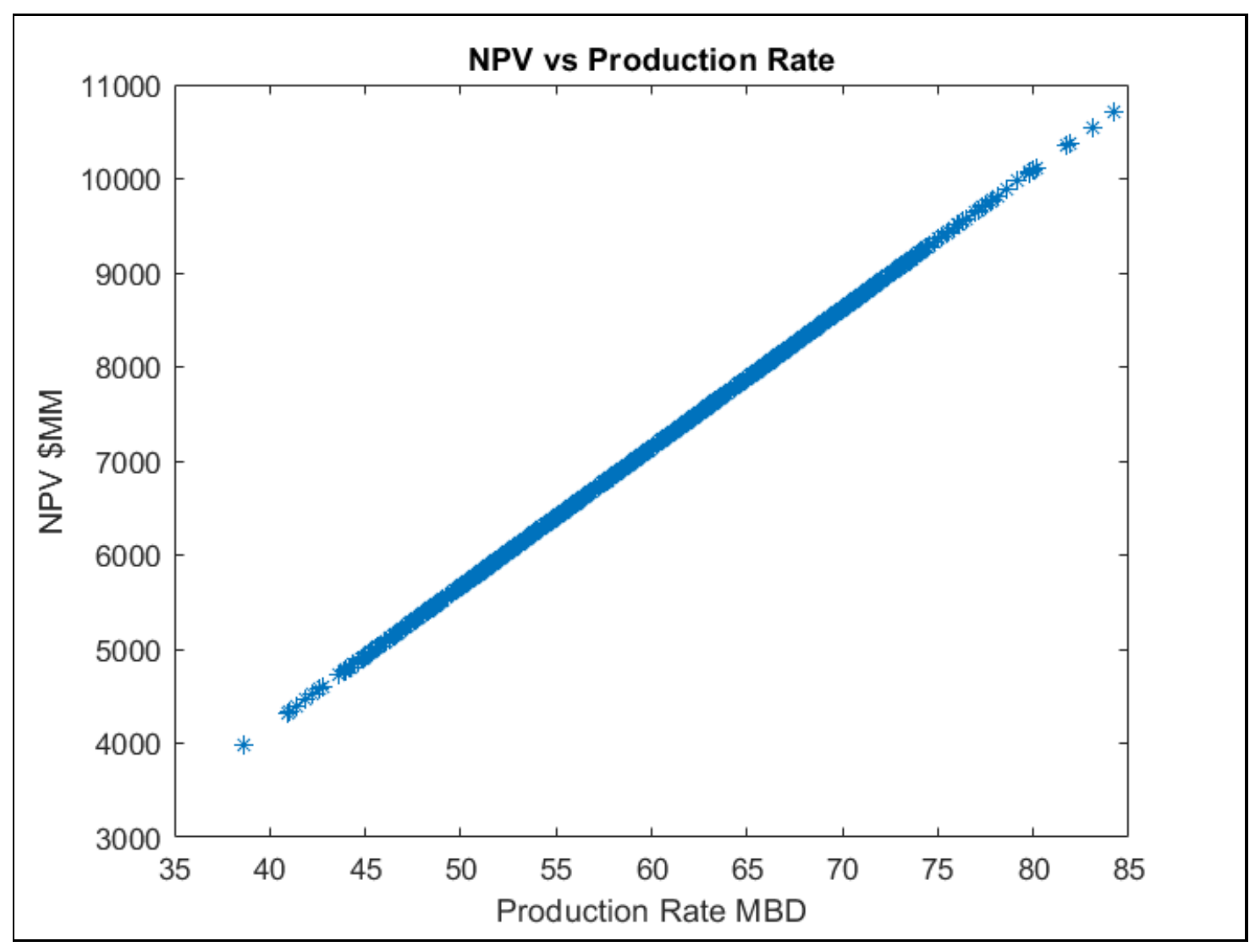

Figure24 : Net Present Value vs Production Rate

\section{Oil Price}

Oil Price is following a normal probability distribution with a mean of $60 \$ / \mathrm{bbl}$ (Figure25). The resulted net present value remains positive with a minimum value of 4500 $\$ M M$ and maximum value of 9,800 \$MM. Figure-26 shows that the relationship between oil price and net present value is directly proportional. Moreover, net present value is highly sensitive to oil price. 

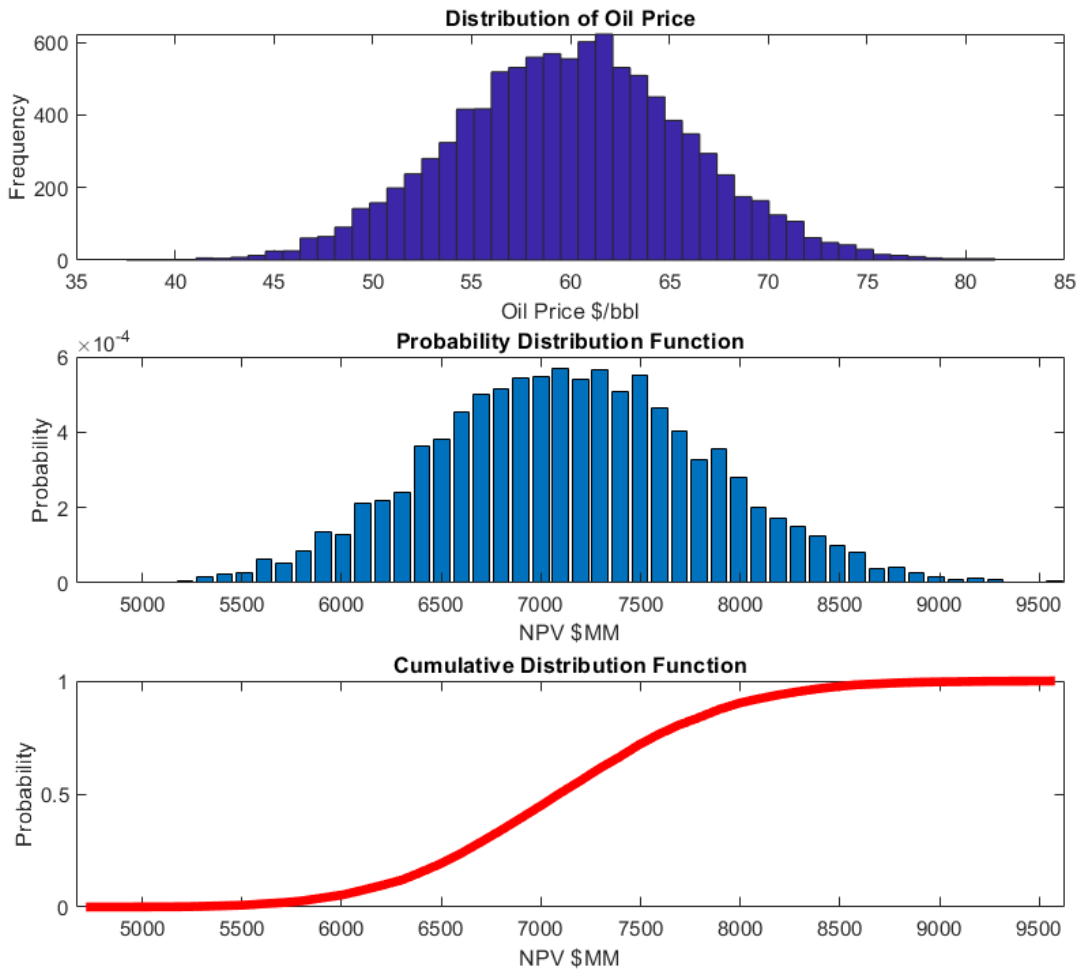

Figure 25: Distribution of Oil Price and NPV Distribution Functions

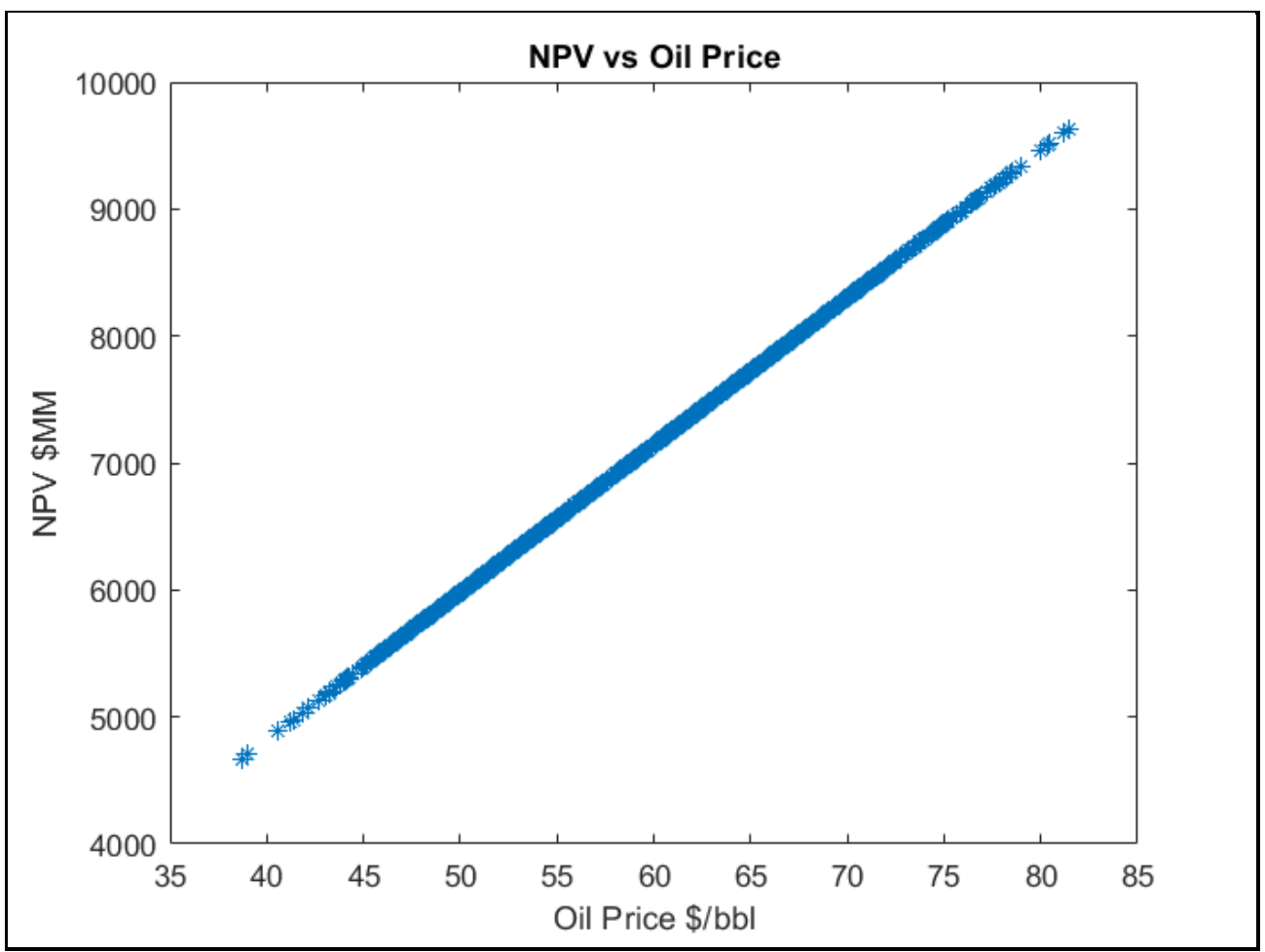

Figure 26: Net Present Value vs Oil Price 


\section{Gas Price}

Gas Price is following a normal probability distribution with a mean of 8 \$MCF (Figure27). The resulted net present value remains positive with a minimum value of 6,800 $\$ M M$ and maximum value of 7,500 \$MM. Figure-28 shows that the relationship between gas price and net present value is directly proportional. Moreover, net present value is not very sensitive to gas price.

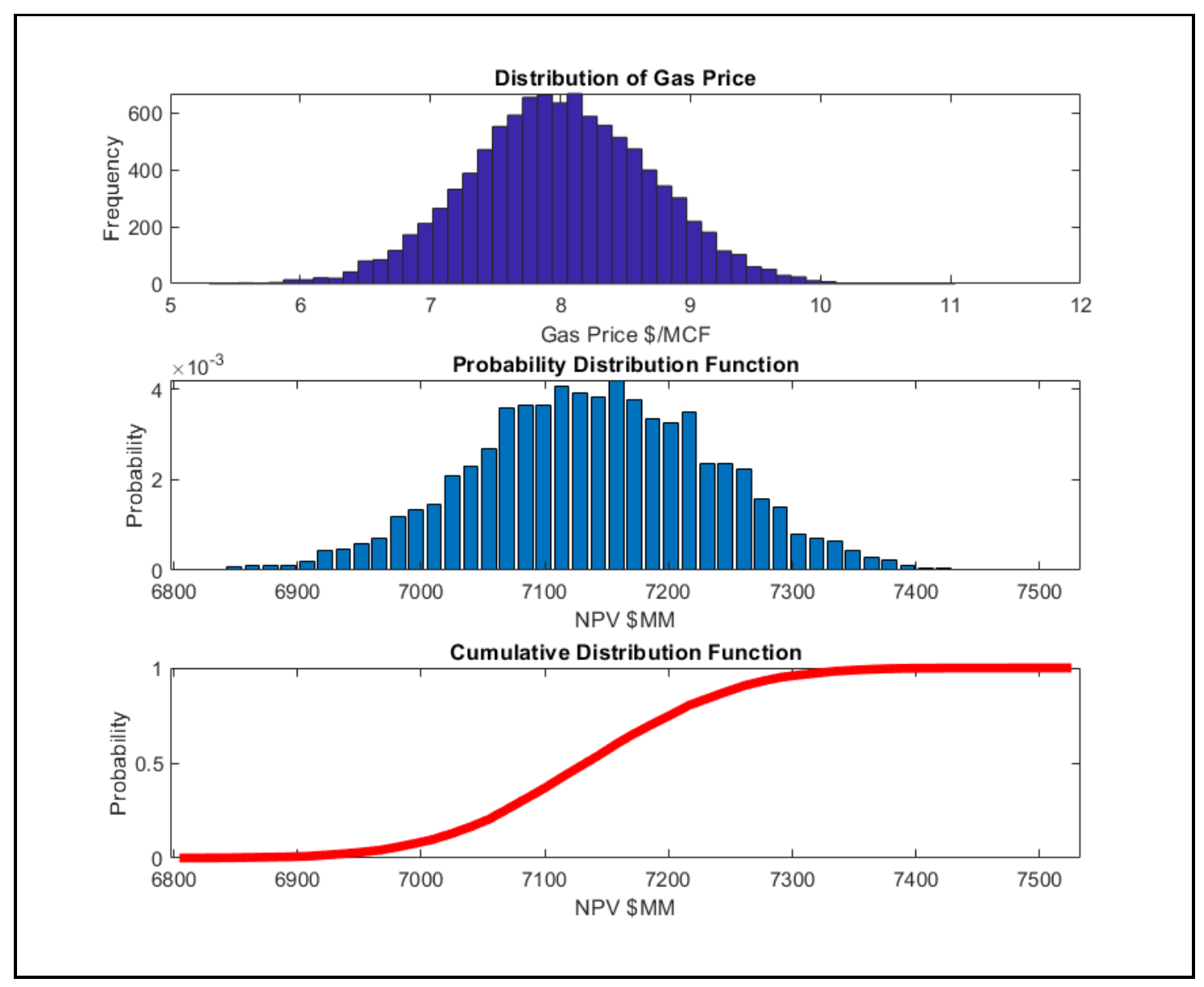

Figure 27: Distribution of Gas Price and NPV Distribution Functions 


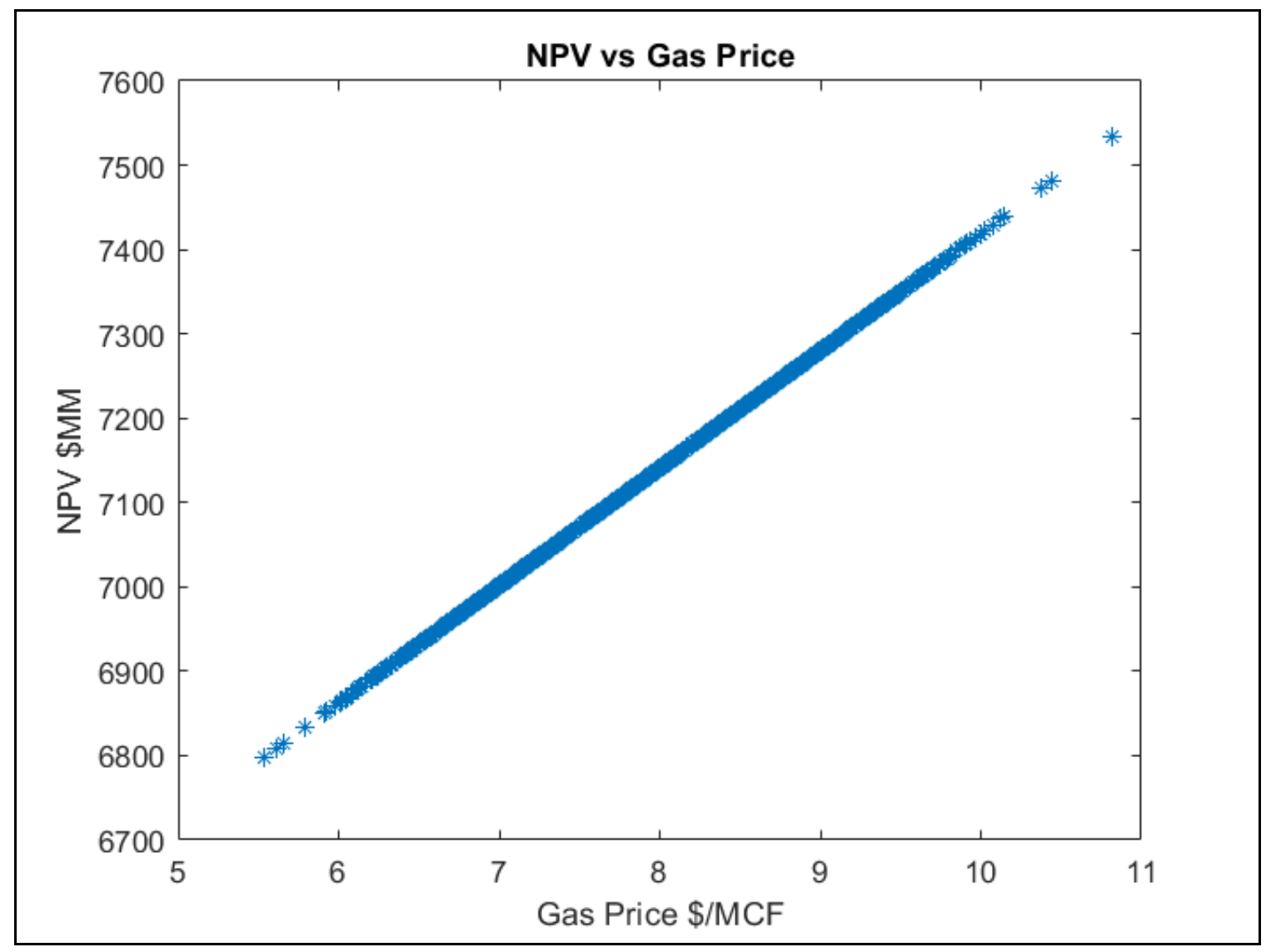

Figure 28: Net Present Value vs Gas Price

\section{Condensate Price}

Condensate Price is following a normal probability distribution with a mean of $70 \$ / \mathrm{bbl}$ (Figure-29). The resulted net present value remains positive with a minimum value of $6,800 \$ M M$ and maximum value of 7,500 \$MM. Figure-30 shows that the relationship between condensate price and net present value is directly proportional. Moreover, net present value is not very sensitive to condensate price. 


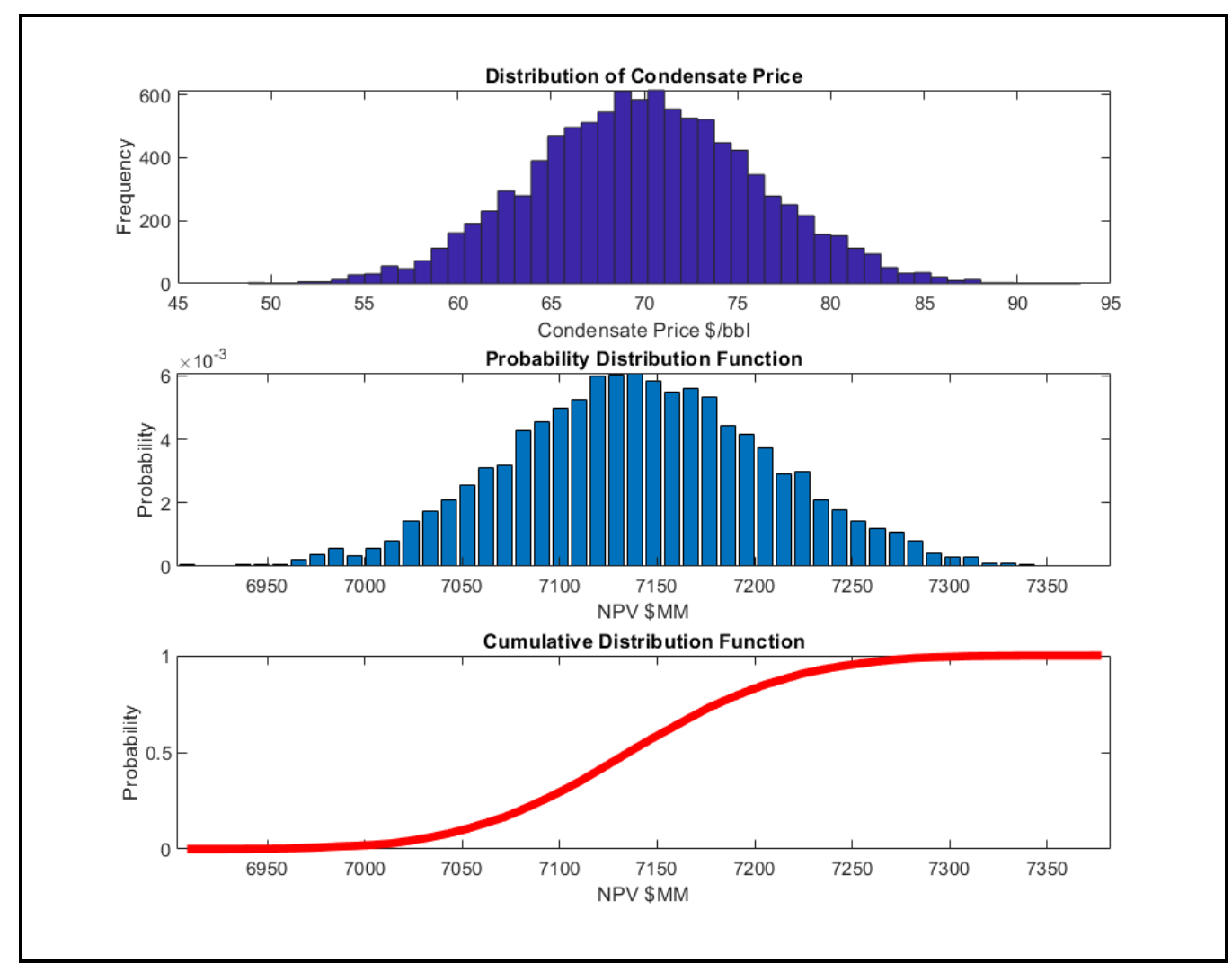

Figure 29: Distribution of Condensate Price and NPV Distribution Functions

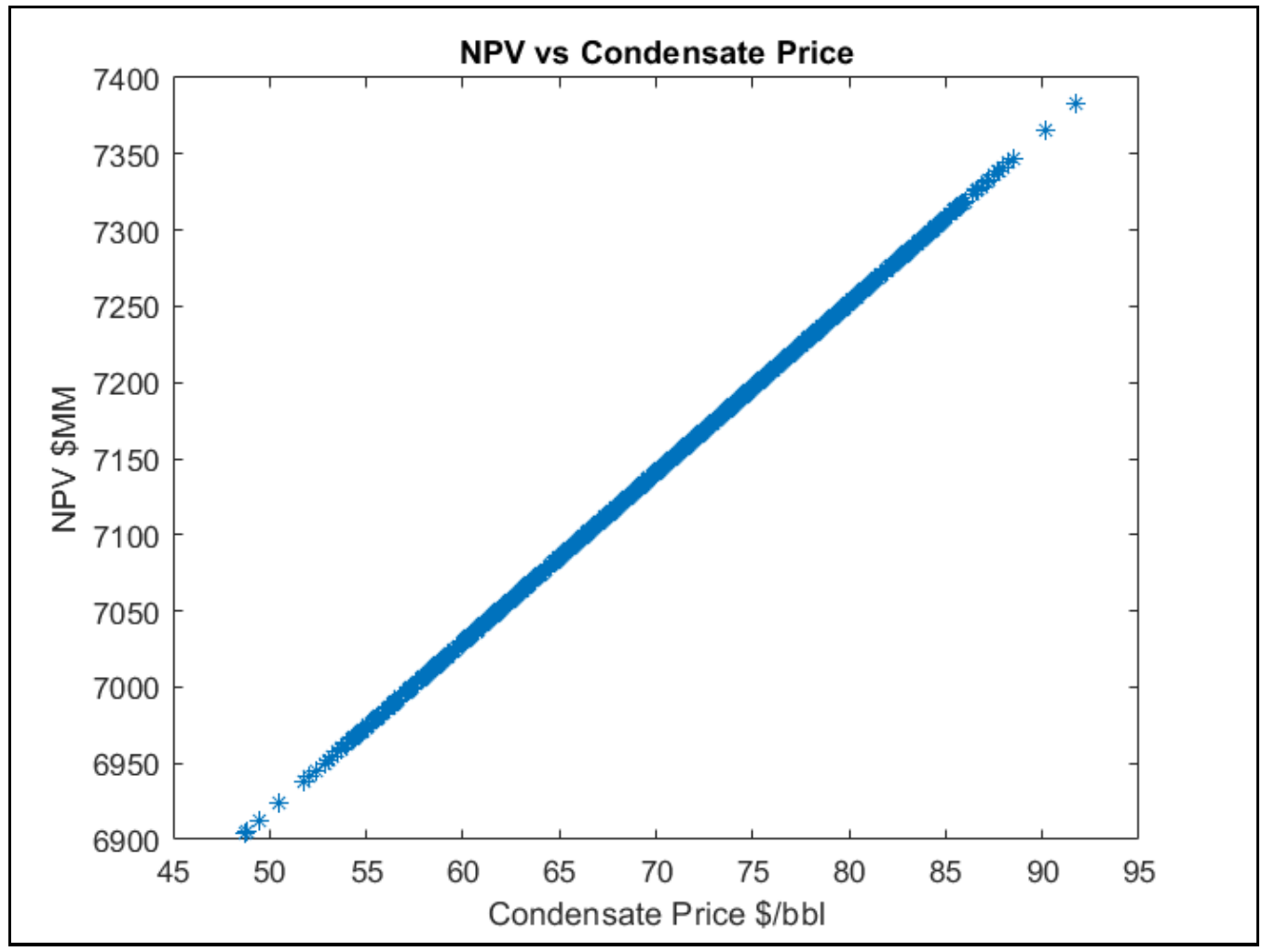

Figure 30: Net Present Value vs Condensate Price 


\section{Number of Wells}

Number of wells is following a uniform probability distribution with upper and lower limits of 50 and 90 wells (Figure-31). The resulted net present value remains positive with a minimum value of 6,900 \$MM and maximum value of 7,380 \$MM. Figure-32 shows that the relationship between number of wells and net present value is inversely proportional. Moreover, net present value is not very sensitive to number of wells.

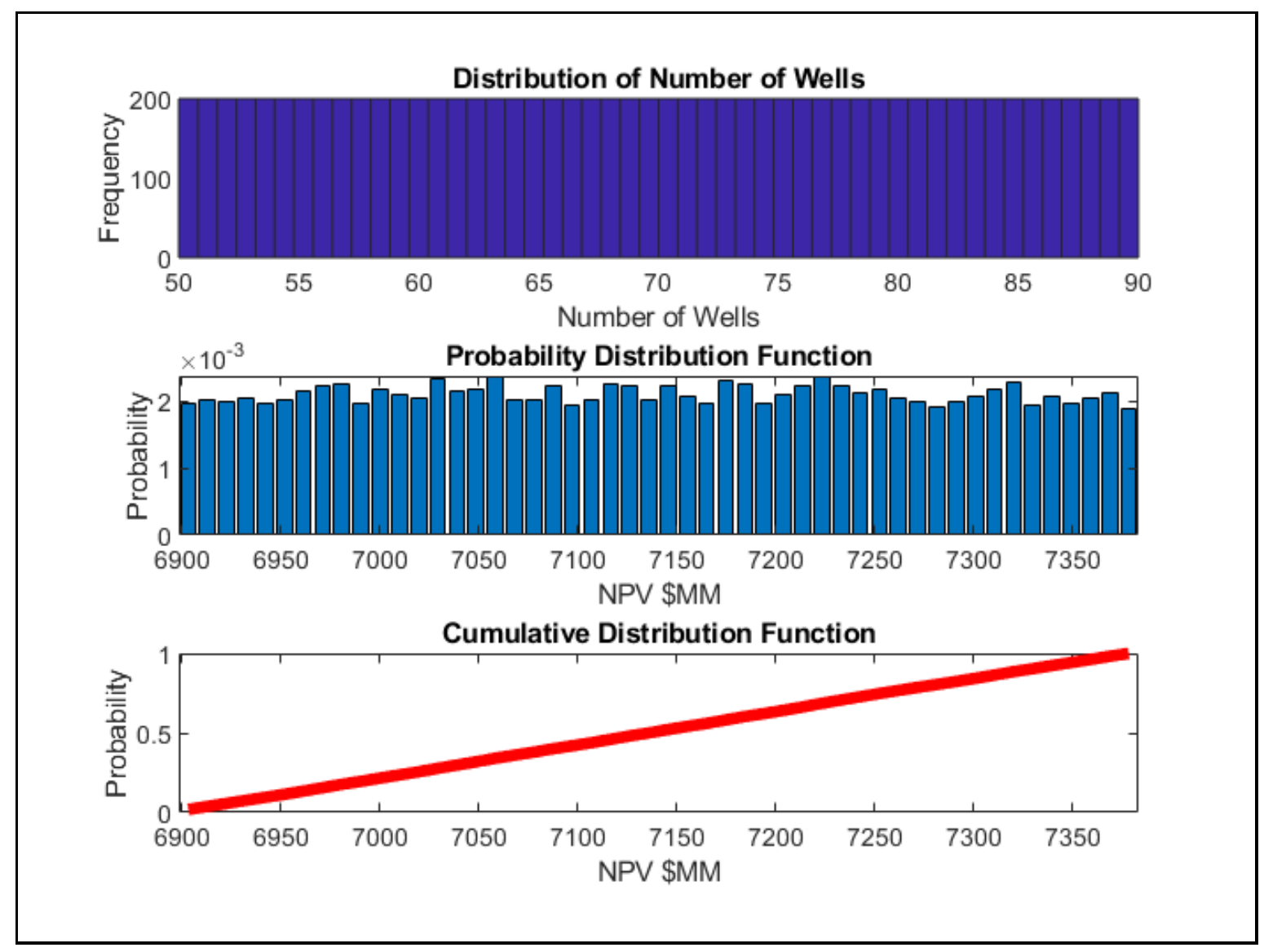

Figure 31: Distribution of Number of Wells and NPV Distribution Functions 


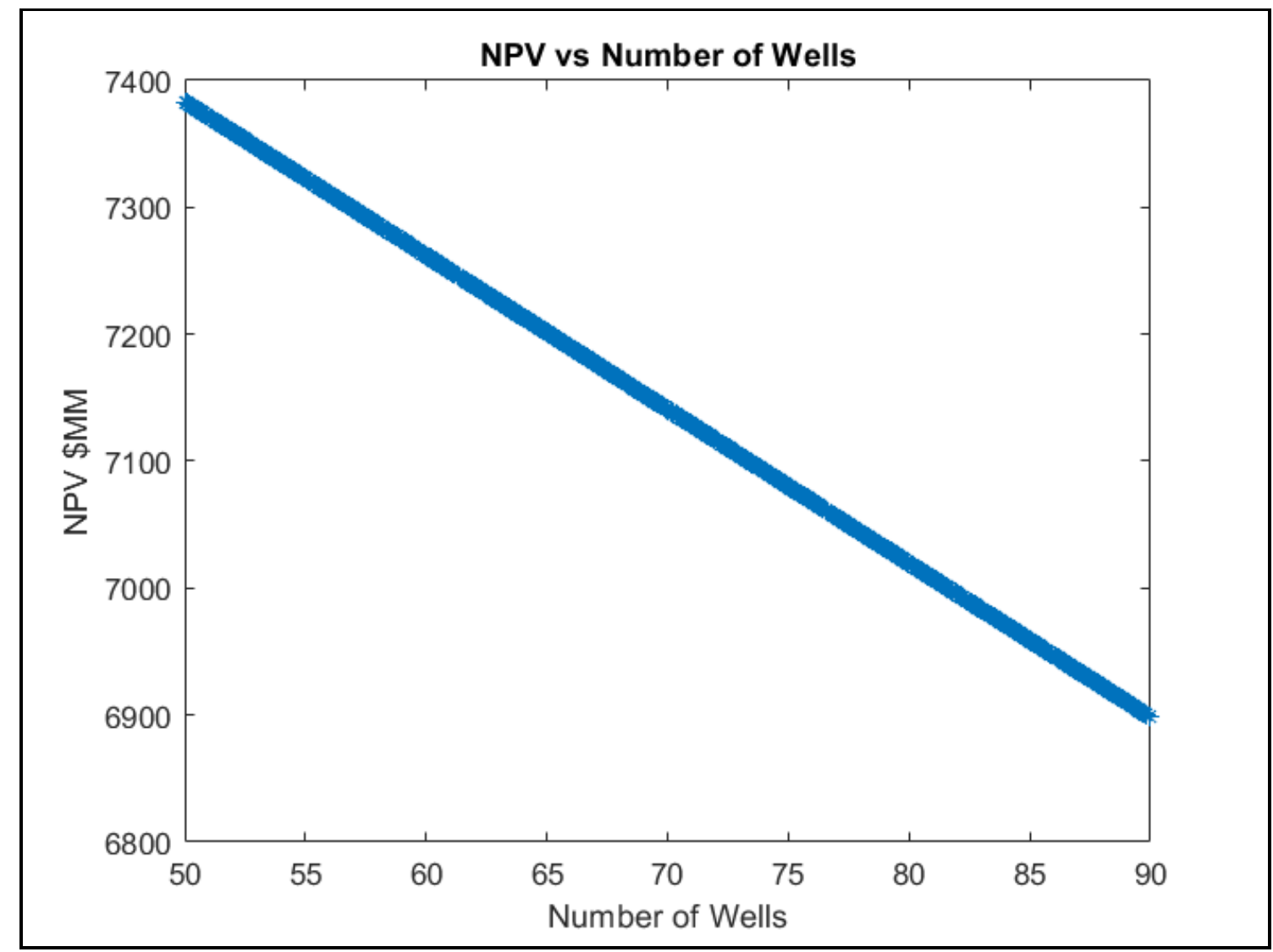

Figure 32: Net Present Value vs Number of Wells

\section{Cost Contingency}

Cost contingency is following a uniform probability distribution with upper and lower limits 10 and 30 percent (Figure-33). The resulted net present value remains positive with a minimum value of 7,000 \$MM and maximum value of 7,290\$MM. Figure-34 shows that the relationship between cost contingency and net present value is inversely proportional. Moreover, net present value is not very sensitive to cost contingency. 


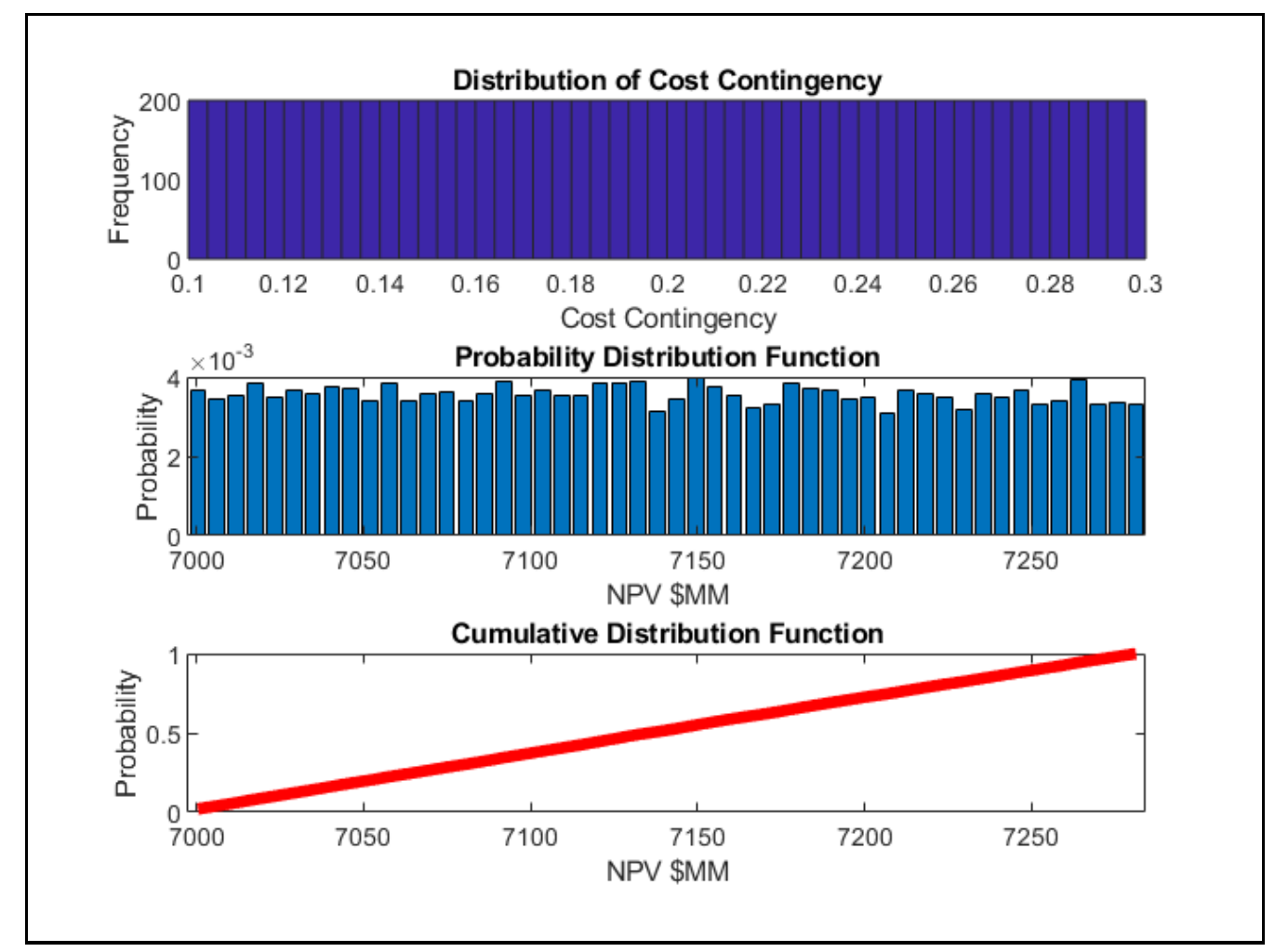

Figure 33: Distribution of Cost Contingency and NPV Distribution Functions

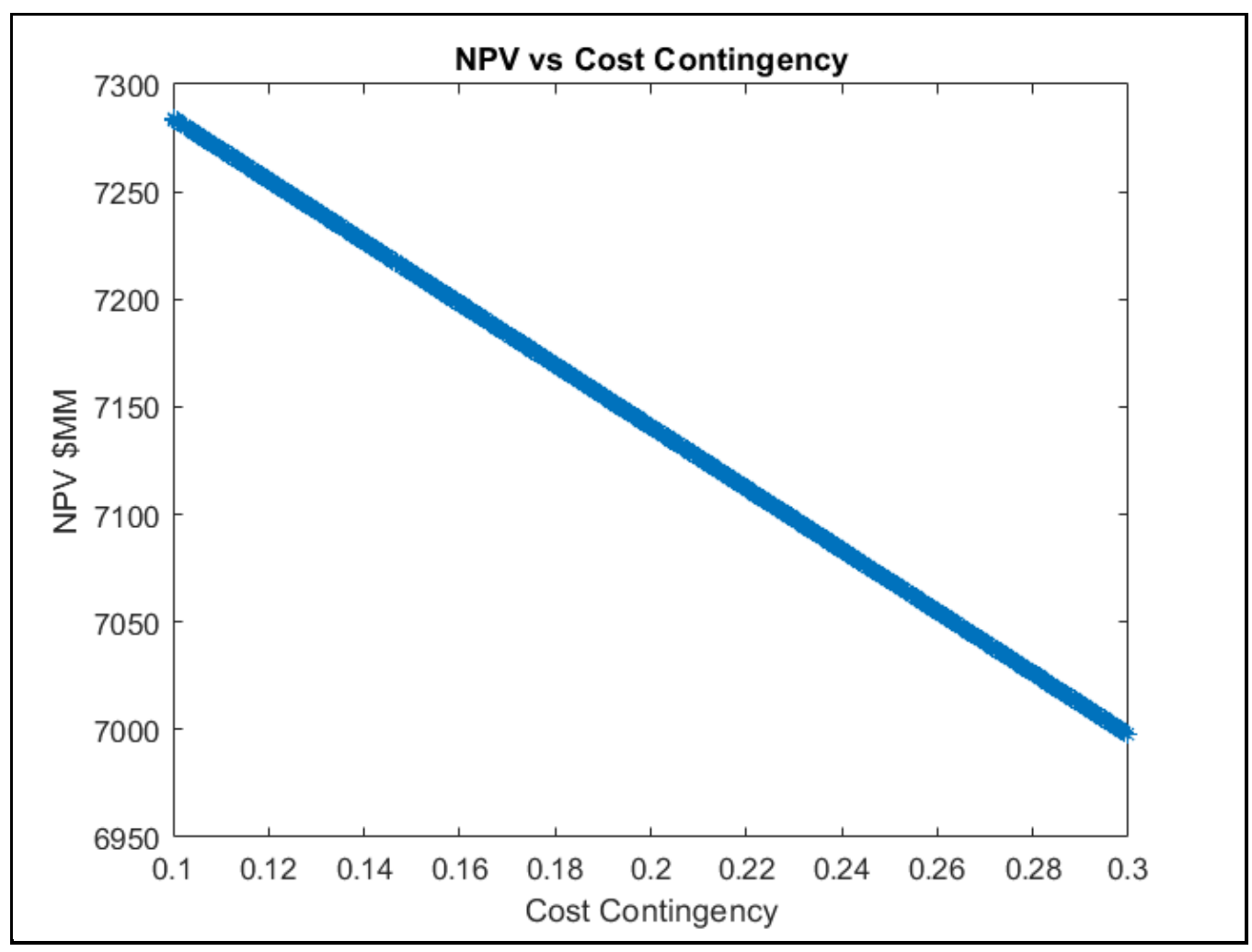

Figure 34: Net Present Value vs Cost Contingency 


\section{Gas Oil Ratio}

Gas oil ratio is following a normal probability distribution with a mean of 1.2 SCF/STB (Figure-35). The resulted net present value remains positive with a minimum value of $6,850 \$ M M$ and maximum value of 7,400 \$MM. Figure-36 shows that the relationship between gas oil ratio and net present value is directly proportional. Moreover, net present value is not very sensitive to gas oil ratio.

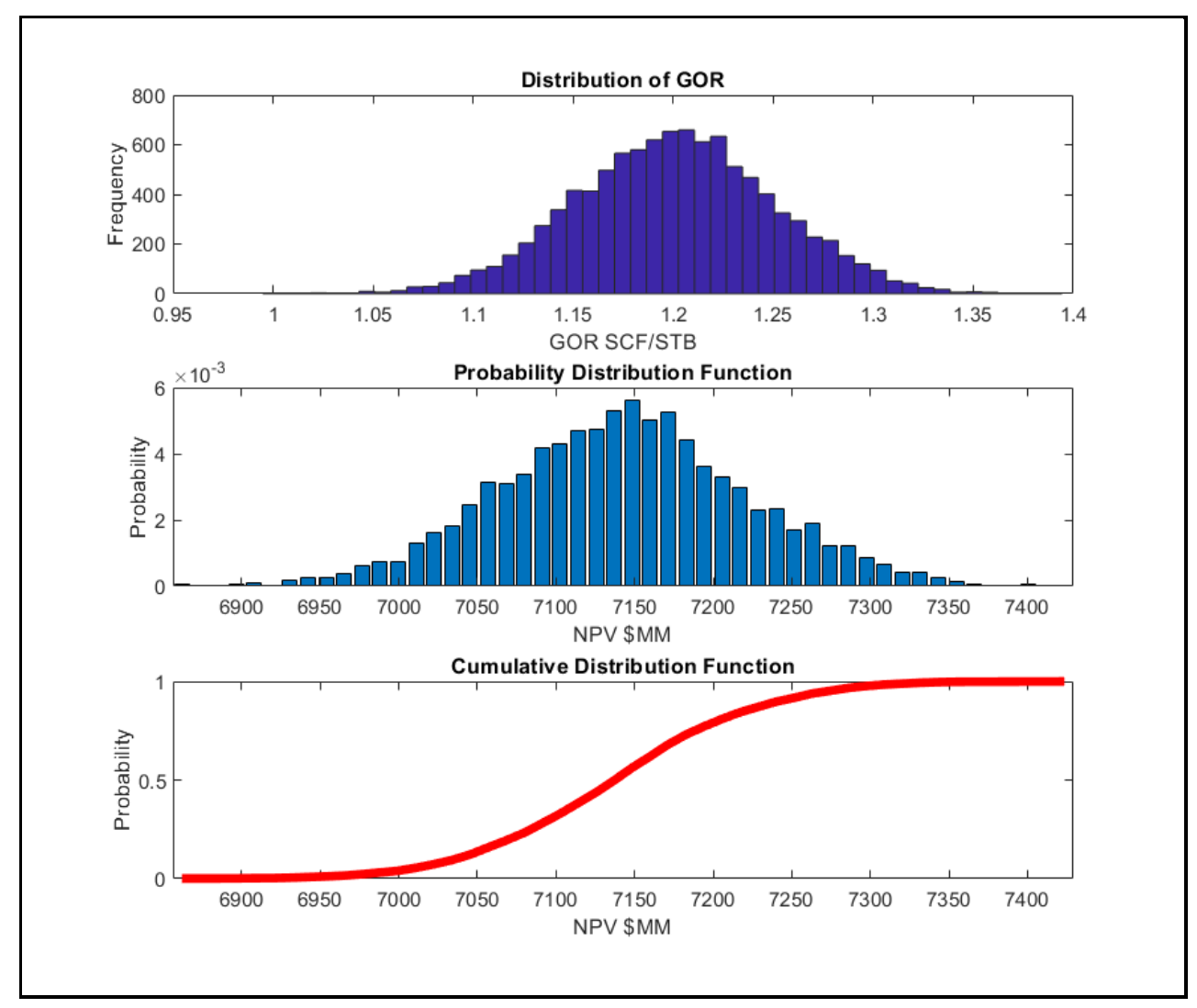

Figure 35: Distribution of Gas Oil Ratio and NPV Distribution Functions 


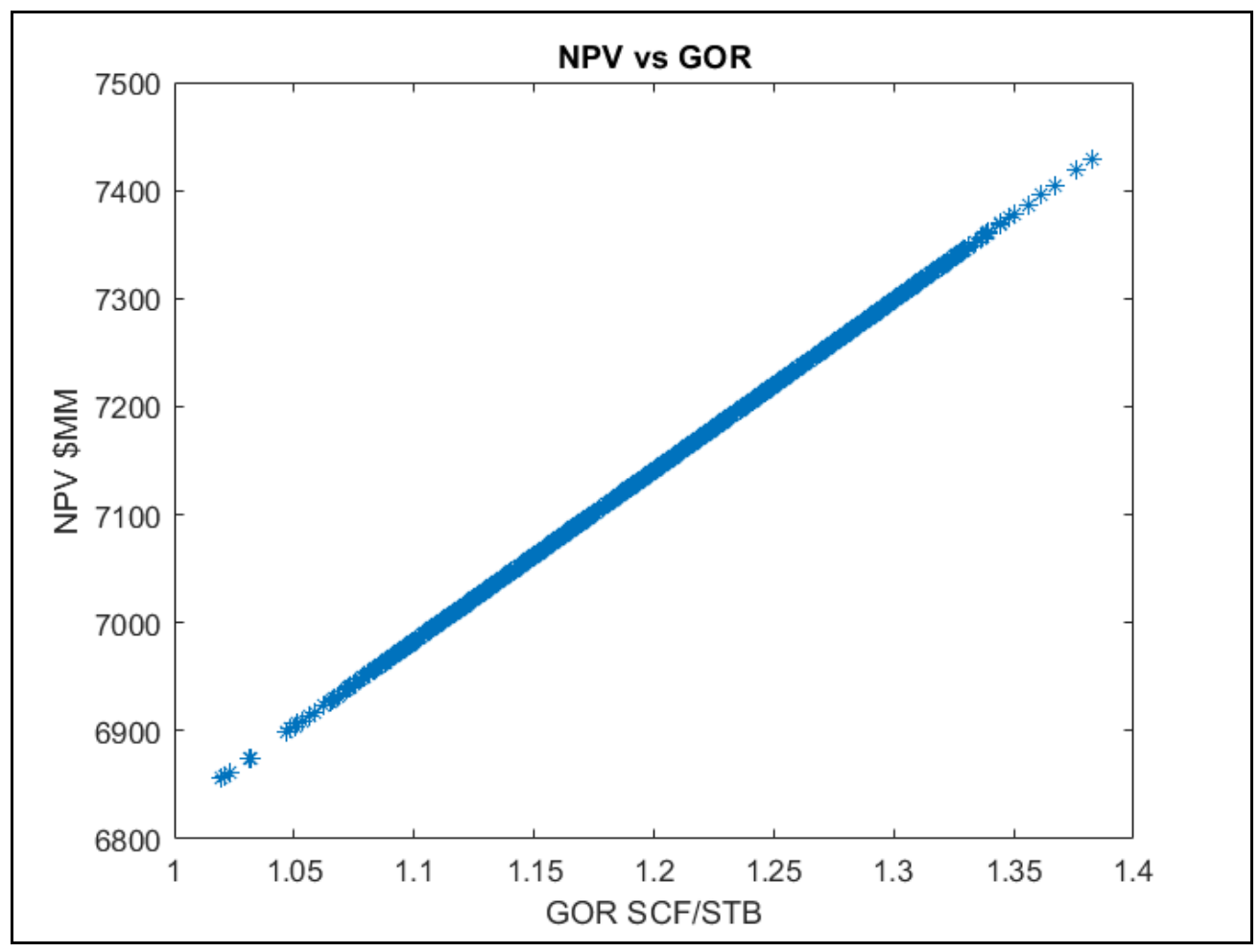

Figure 36: Net Present Value vs Gas Oil Ratio

\section{Discount Rate}

Discount rate is following a normal probability distribution with a mean of $10 \%$ (Figure37). The resulted net present value remains positive with a minimum value of 6,000 $\$ M M$ and maximum value of 8,500 \$MM. Figure-38 shows that the relationship between discount rate and net present value is inversely proportional. Moreover, net present value is moderately sensitive to discount rate. 

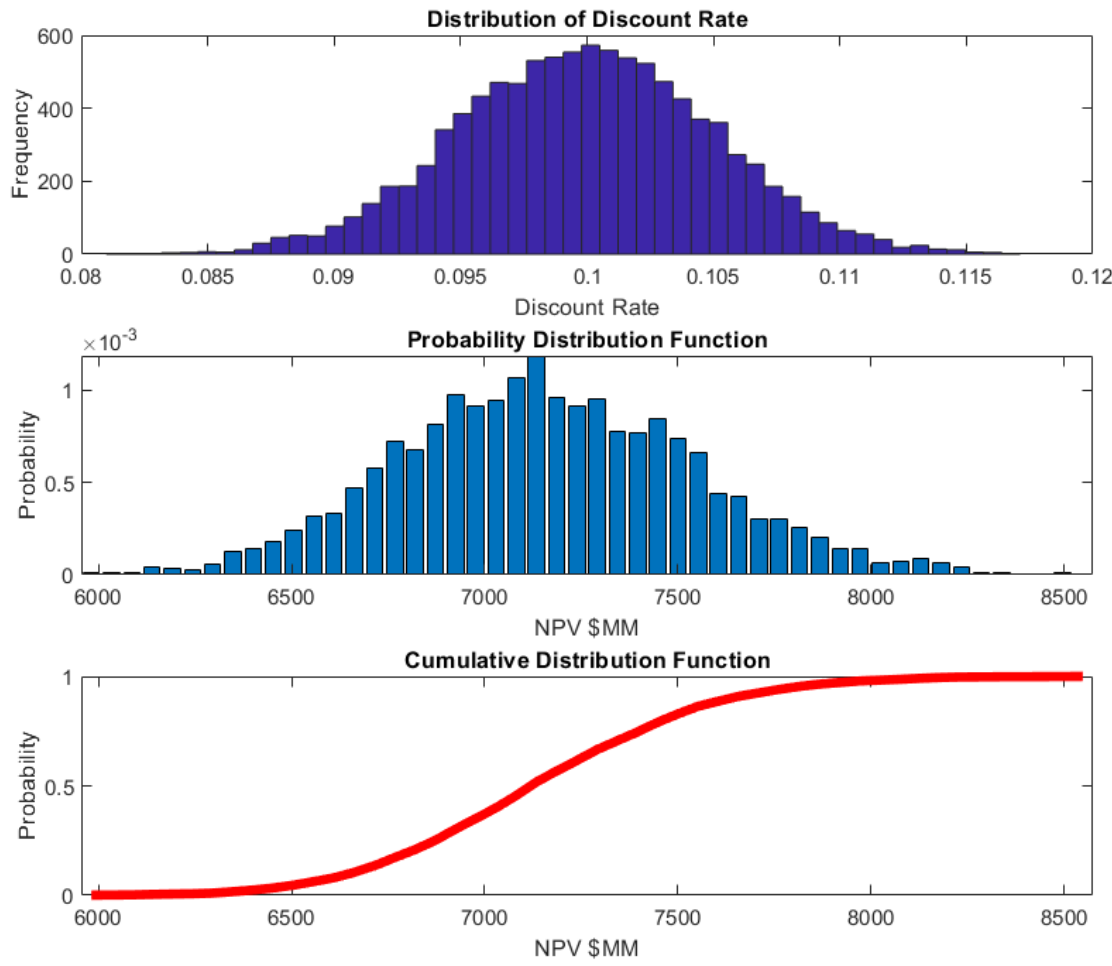

Figure 37: Discount Rate and NPV Distribution Functions

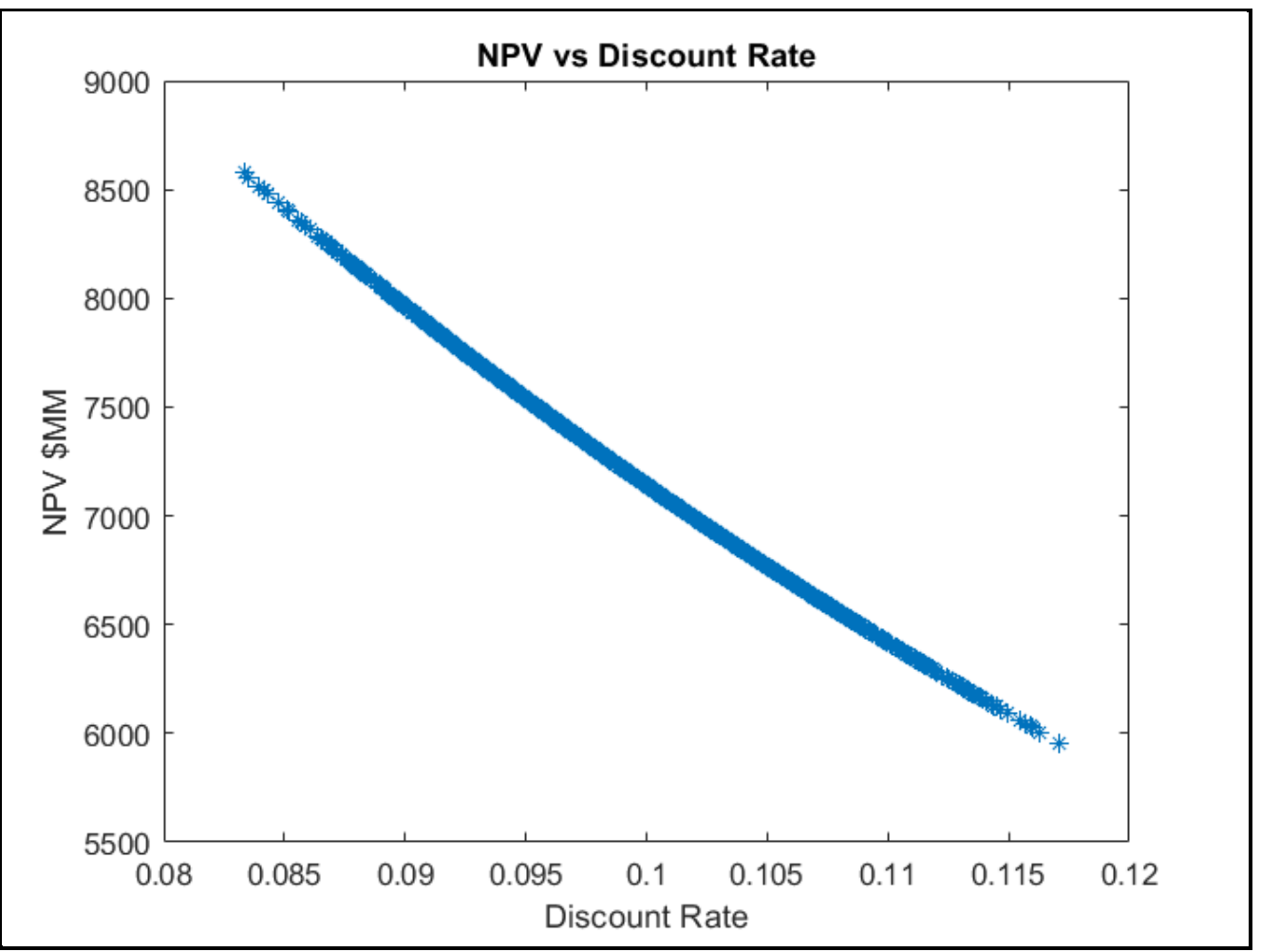

Figure 38: Net Present Value vs Discount Rate 


\section{Inflation Rate}

Inflation rate is following a normal probability distribution with a mean of $2 \%$ (Figure-39). The resulted net present value remains positive with a minimum value of 5,800 \$MM and maximum value of $8,600 \$ \mathrm{MM}$. Figure-40 shows that the relationship between inflation rate and net present value is directly proportional. Moreover, net present value is moderately sensitive to inflation rate.

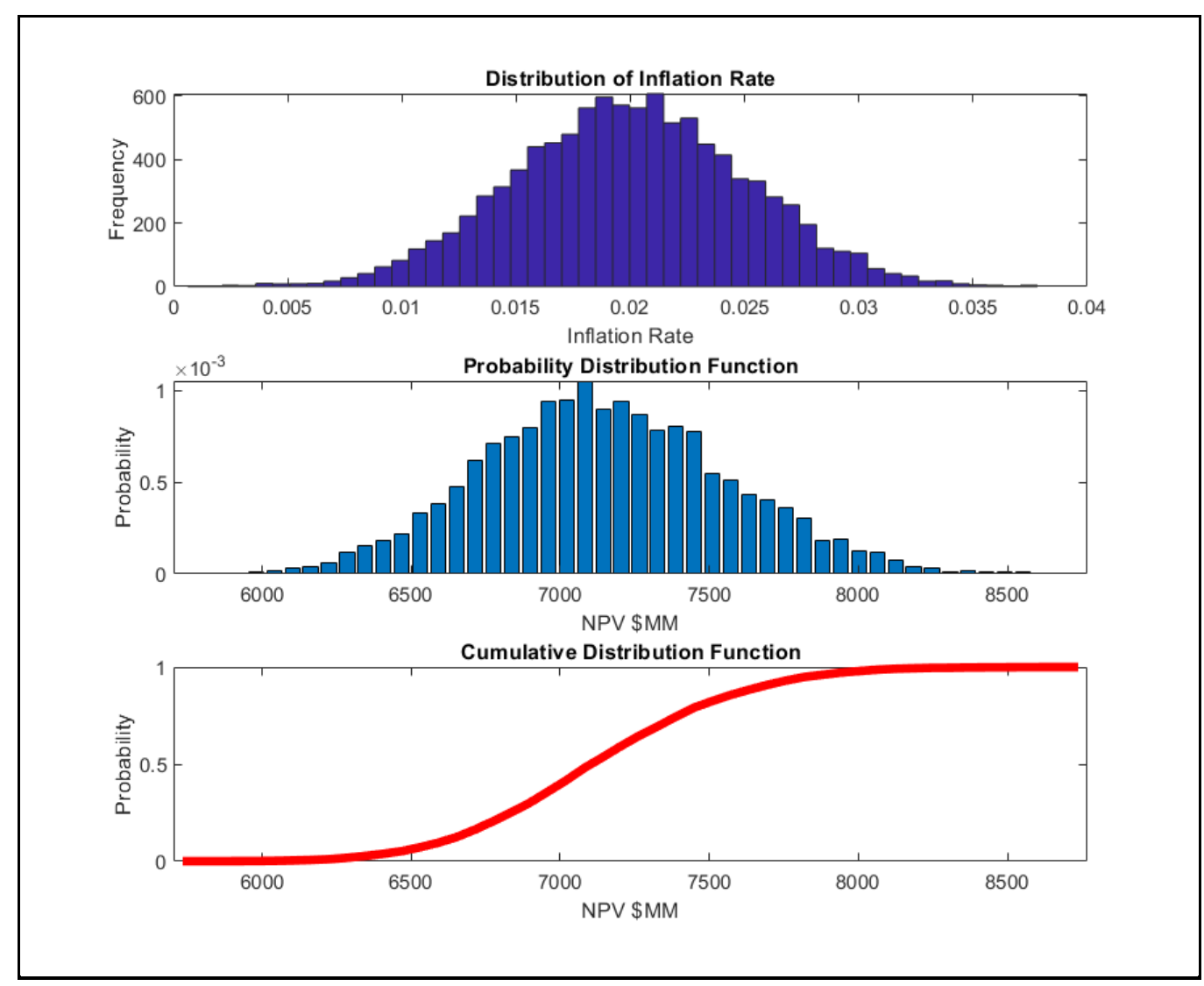

Figure 39: Inflation Rate and NPV Distribution Functions 


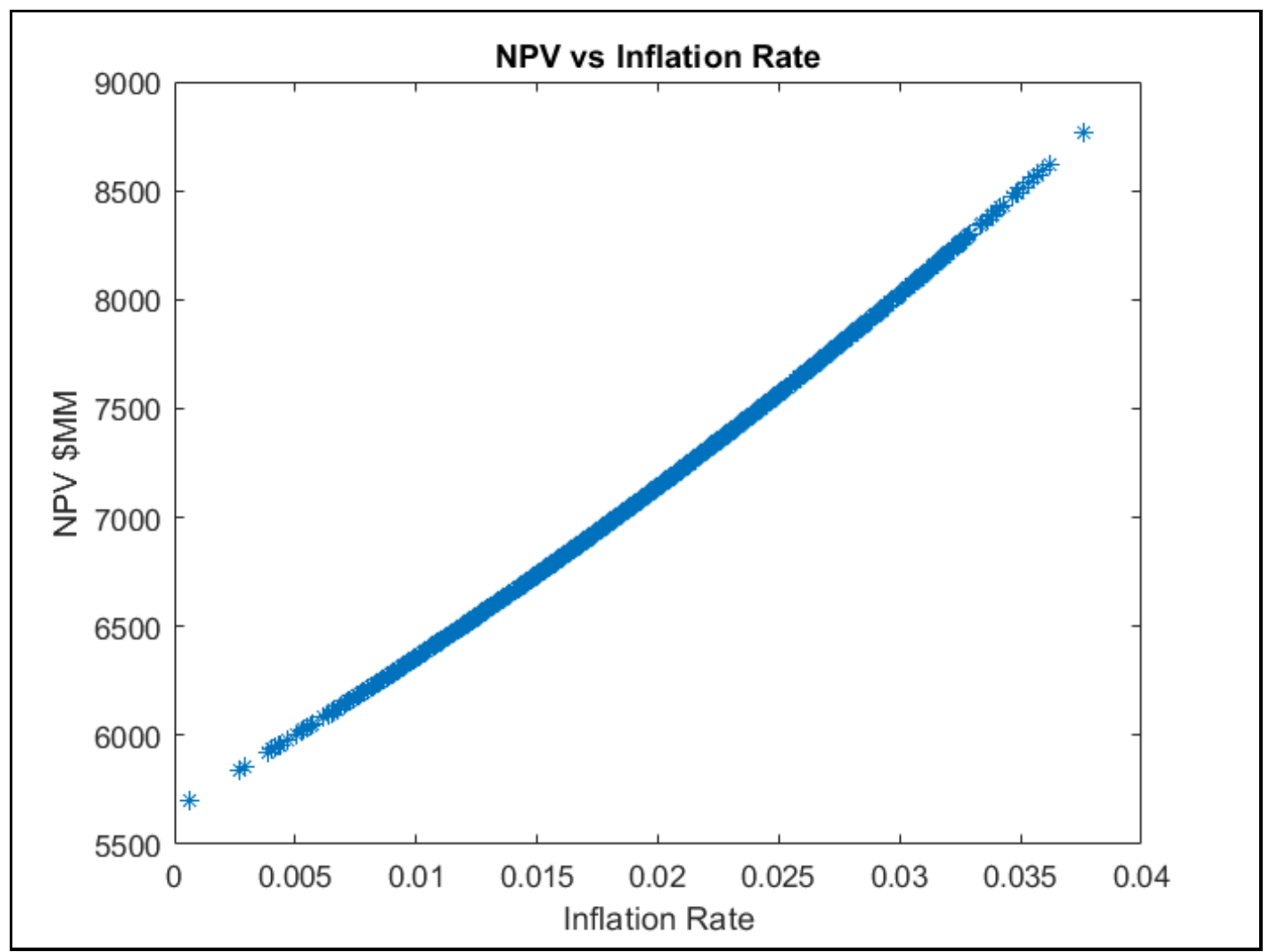

Figure 40: Net Present Value vs Inflation Rate

The results show that the project would remain profitable when any of the key parameters changes. However, these analyses do not show the project profitability when these parameters changes simultaneously. This is when Monte Carlo simulation takes place and becomes an effective method of project profitability investigation.

The results of Monte Carlo study of all the economic indicators are given in Figure-41 thru Figure-48 when the selected key parameters change concurrently following a normal distribution. 


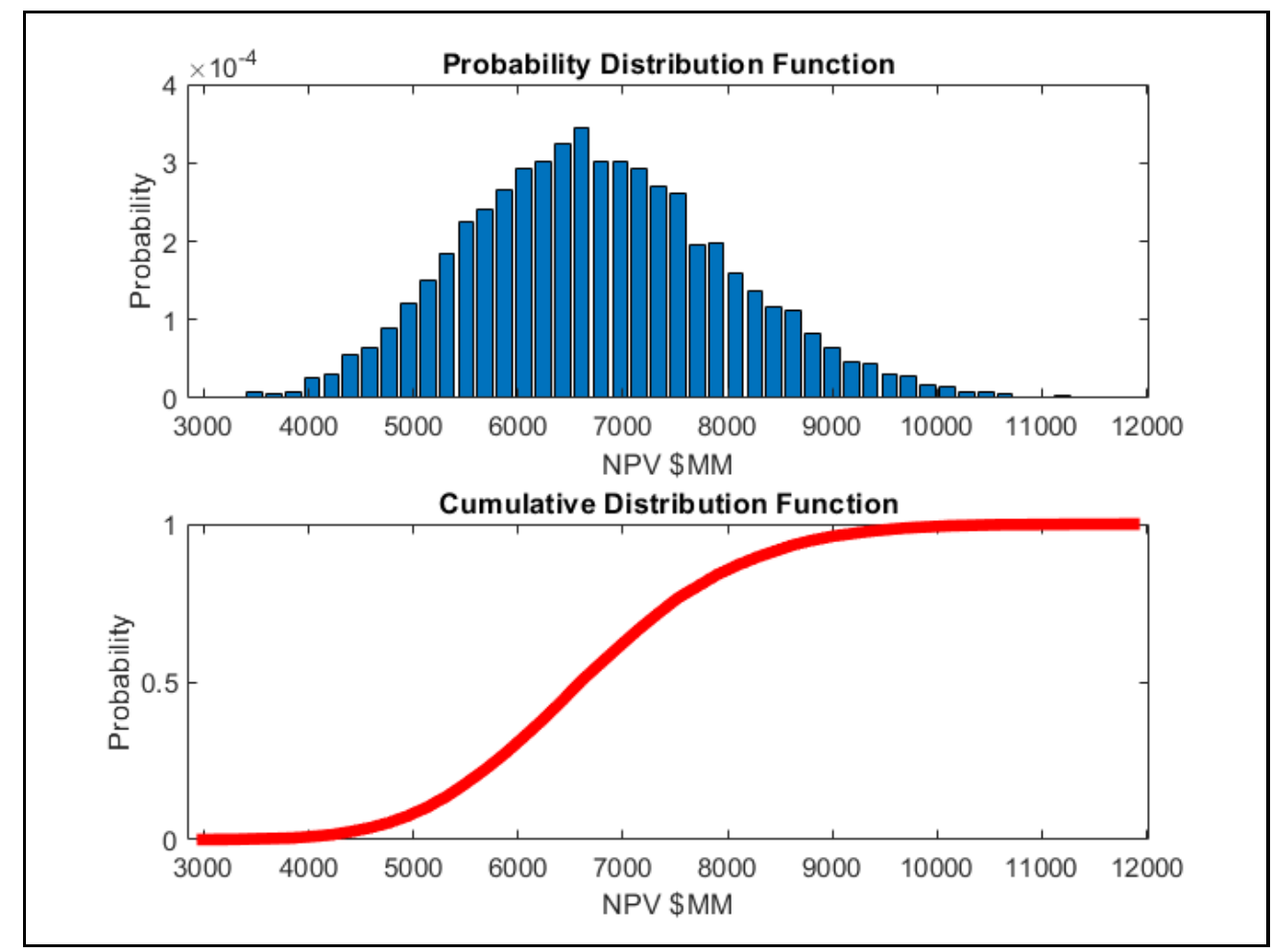

Figure 41: NPV Probability and Cumulative Distribution Functions (All Key Parameters Change)

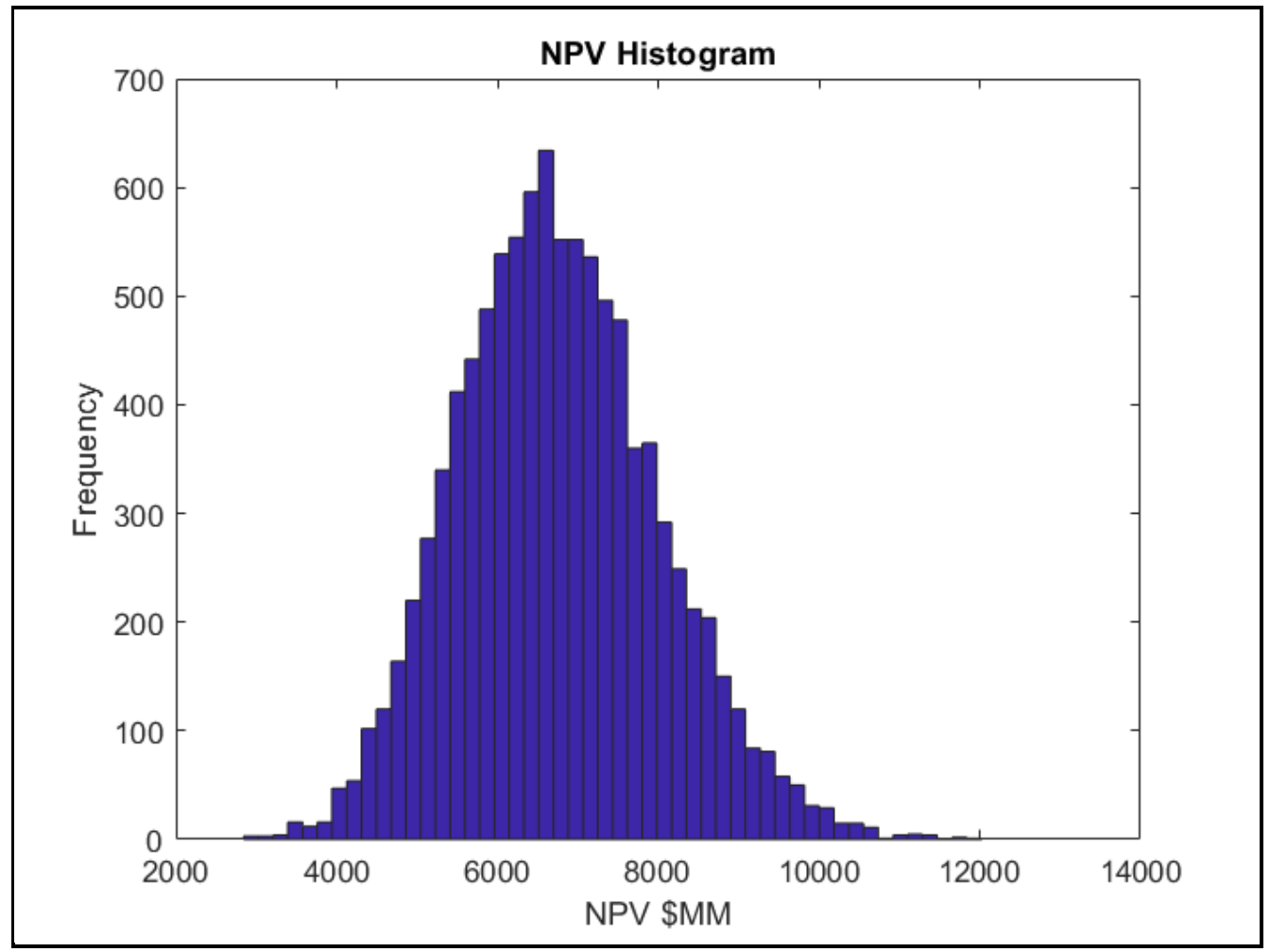

Figure 42: NPV Histogram (All key parameters change) 


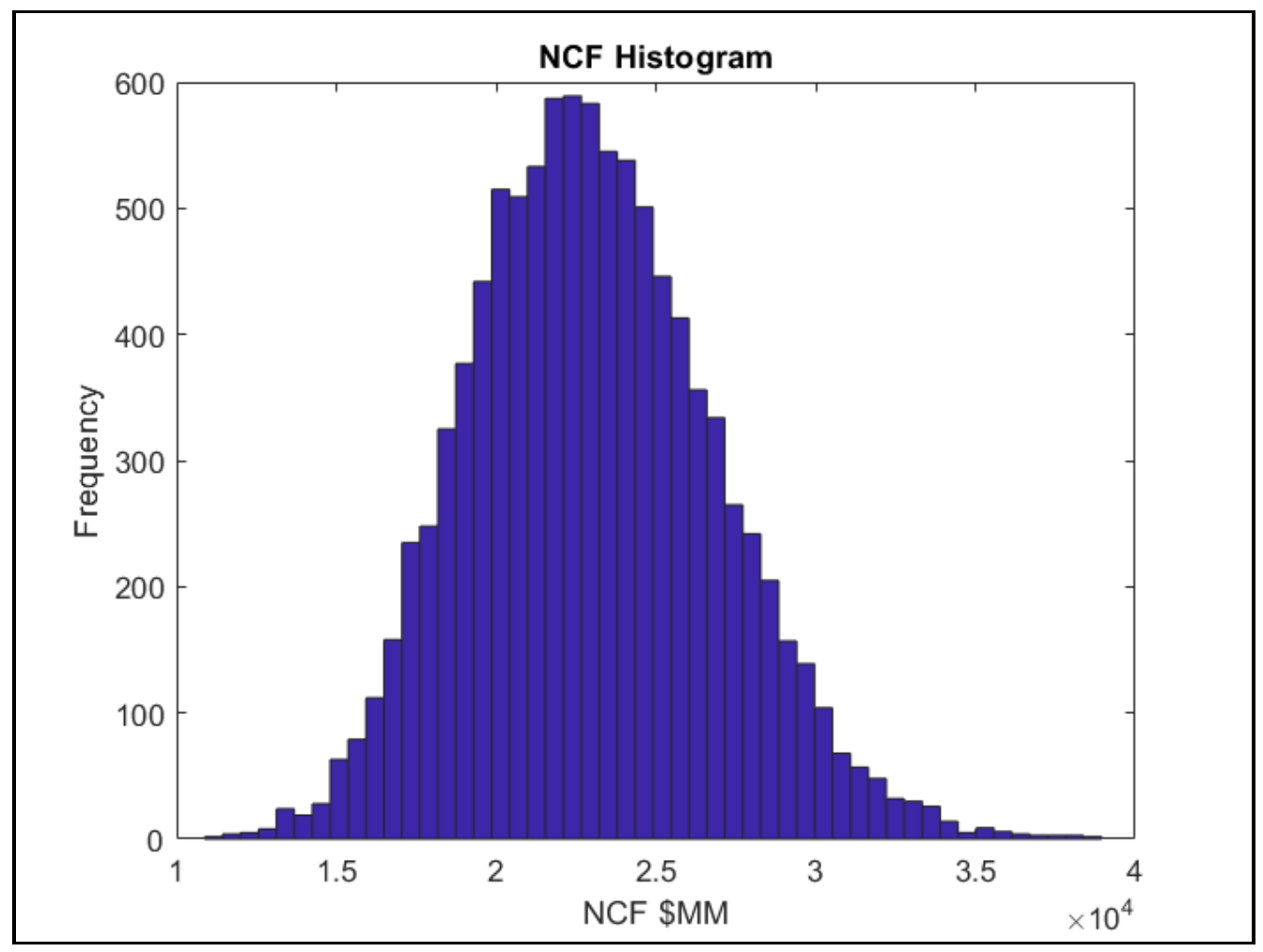

Figure 43: NCF Histogram (All key parameters change)

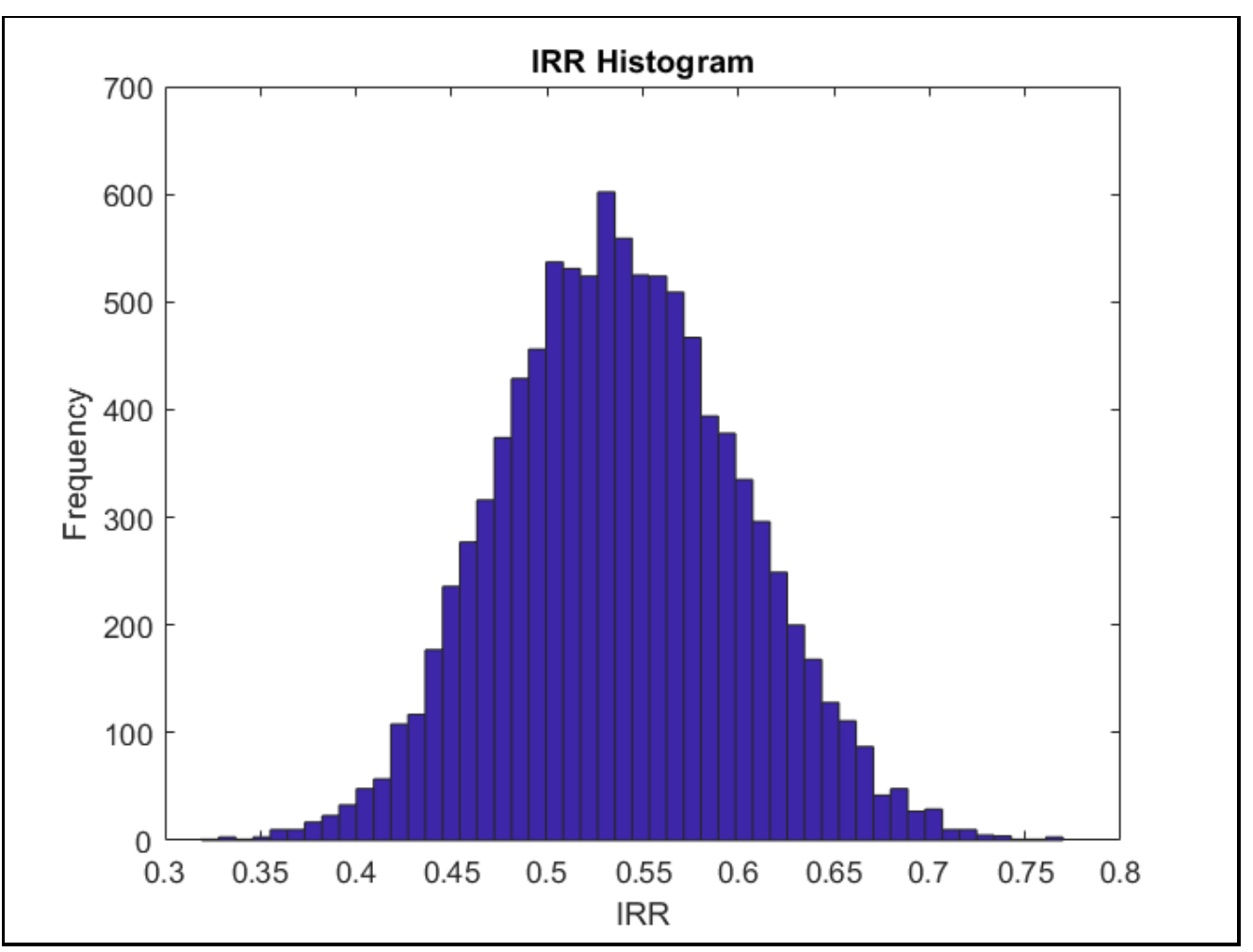

Figure 44: IRR Histogram (All key parameters change) 


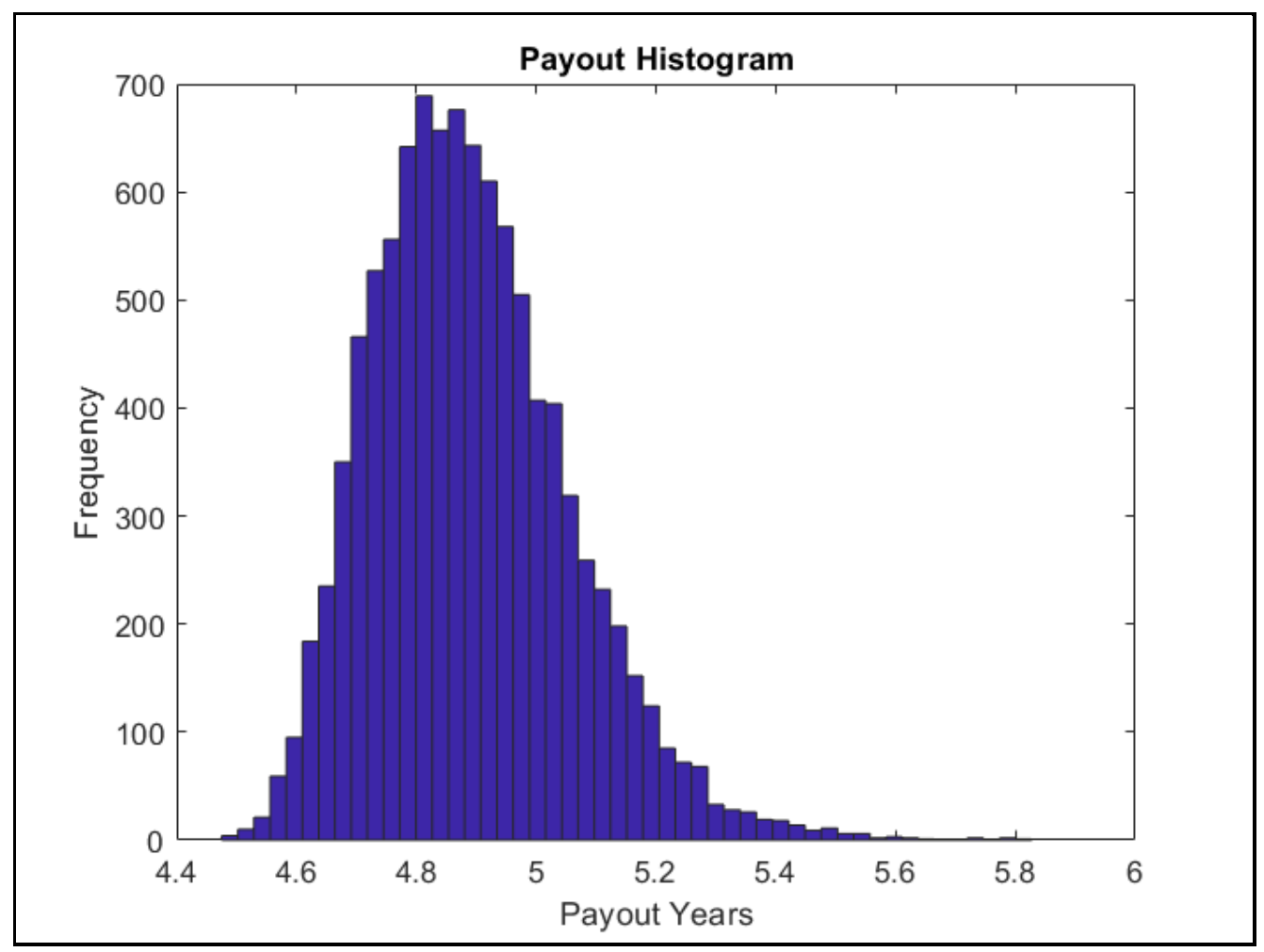

Figure 45: Payout Histogram (All key parameters change)

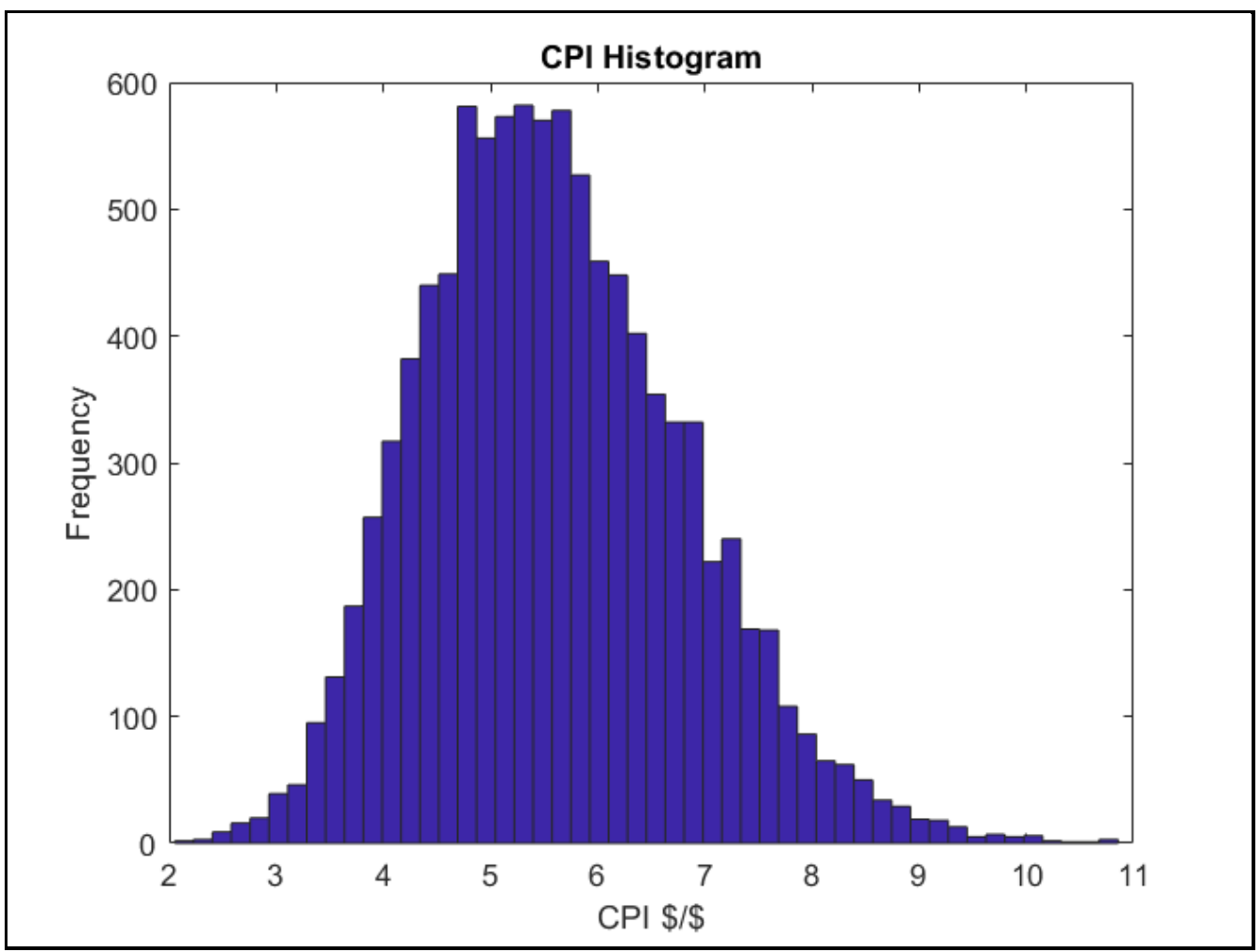

Figure 46: CPI Histogram (All key parameters change) 


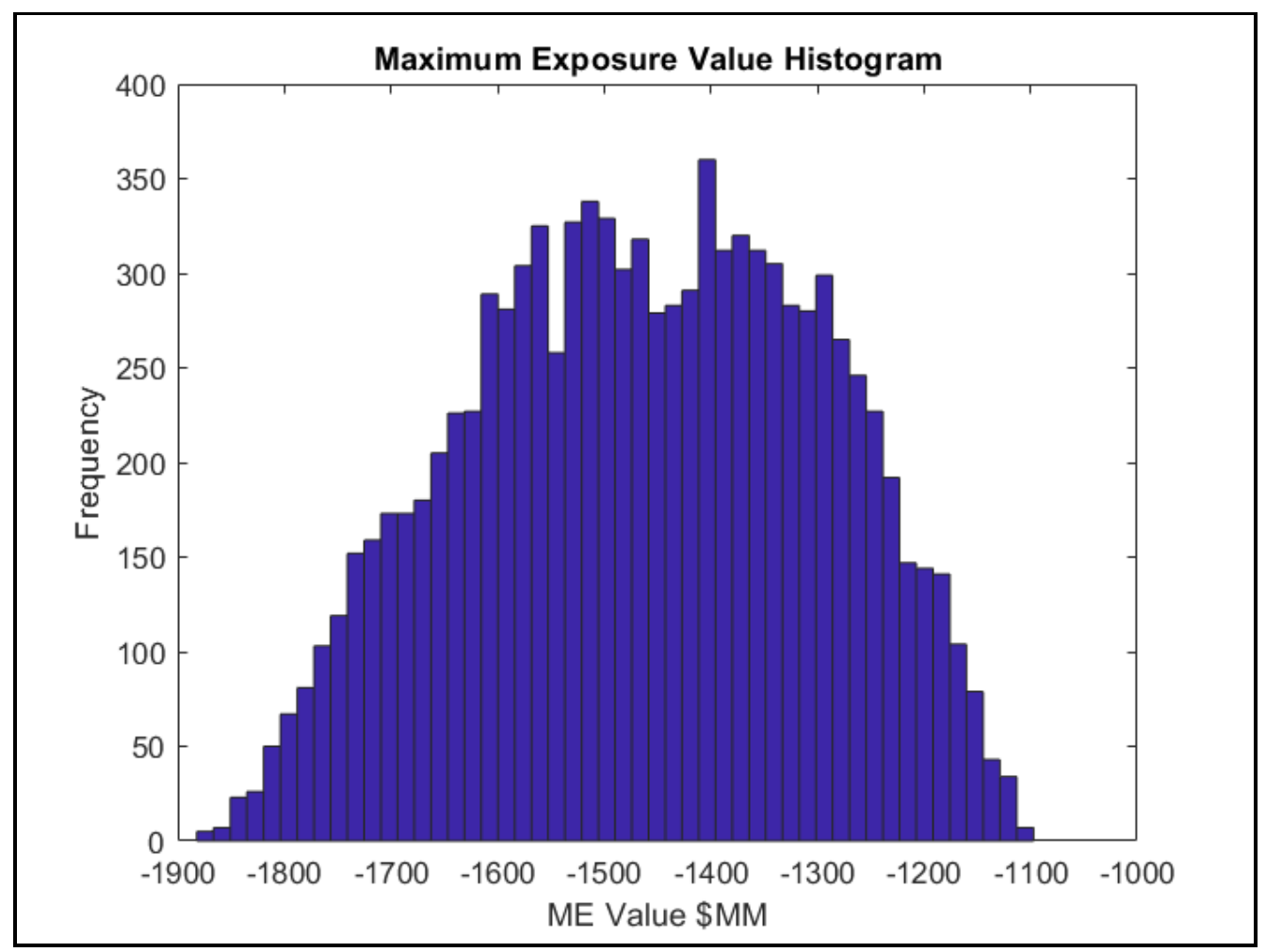

Figure 47: ME value Histogram (All key parameters change)

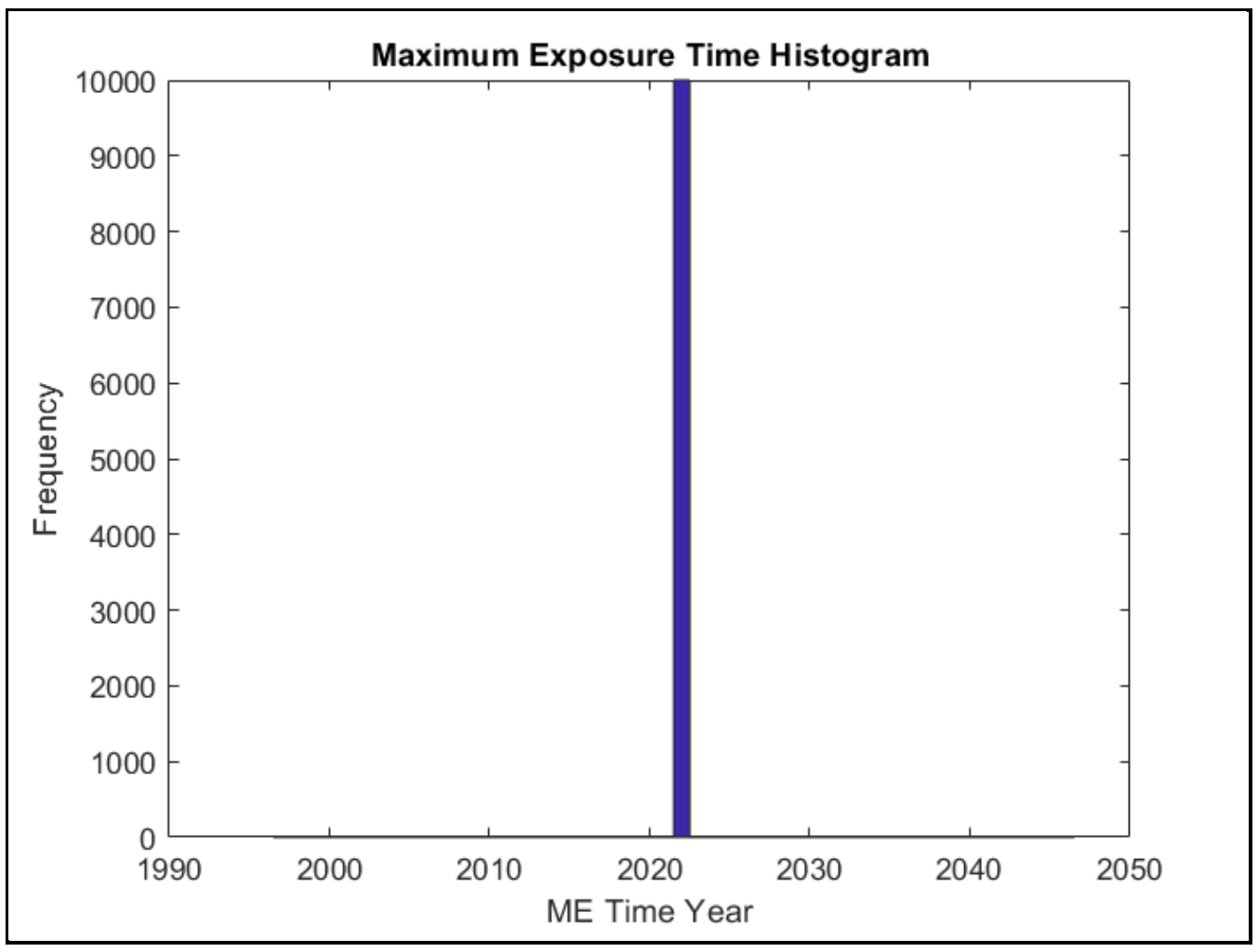

Figure 48: ME Time Histogram (All key parameters change) 
Monte Carlo simulation results indicate that the project net present value remains positive (profitable) with a worst-case scenario of 3,000 \$MM, and best scenario of $11,200 \$ M M$. Additionally, the rest of the economic indicators show the project remains feasible even with all the worst-case scenarios.

The following Table-22 summarizes the results obtained with the Monte Carlo simulation for the best and worst possible scenarios using the selected probability distributions for each key parameter.

Table22 : Monte Carlo Simulation Worst/Best-Case scenario

\begin{tabular}{|l|c|c|l|c|c|l|c|c|}
\hline \multicolumn{3}{|c|}{ Monte Carlo Simulation } \\
\hline Worst-Case & \multicolumn{3}{c|}{ Base-Case } & \multicolumn{3}{c|}{ Best-Case } \\
\hline NCF & 11,200 & \$MM & NCF & 24,197 & \$MM & NCF & 38,000 & \$MM \\
IRR & 3,000 & \$MM & NPV & 7,141 & \$MM & NPV & 12,000 & SMM \\
Payout & 33 & $\%$ & IRR & 55.5 & $\%$ & IRR & 77 & $\%$ \\
CPI & 5.8 & Years & Payout & 4.83 & Years & Payout & 4.5 & Years \\
ME Value & 2 & \$/\$ & CPI & 5.84 & \$ \$ & CPI & 10.9 & \$ \$ \\
Year of ME & 2022 & \$MM & ME Value & $-1,462$ & \$MM & ME Value & $-1,100$ & \$MM \\
\hline
\end{tabular}




\section{Summary of Results}

- The overall project economics indicate that:

- Its 20 years cumulative production is $367 \mathrm{MMBOE}$

- Its 20 years net profit is $\$ 24,197 \mathrm{MM}$.

- The net present value of its profit is $\$ 7,141 \mathrm{MM}$ assuming $10 \%$ annual discount rate.

- Its Internal Rate of Return is $55.5 \%$.

- Its Payback Period is 4.83 years from project start.

- Its Capital Productivity Index (or its Return on Investment) is $\$ 5.84$ for each dollar invested in term of its present value.

- Its Maximum Exposure is $\$ 1,462 \mathrm{MM}$ in year 2022

- Its average cost per barrel equivalent is $\$ 8.12 / \mathrm{BOE}$ (2018 costs) or \$9.86/BOE (escalated costs)

- The economics of the first party indicates that:

- Its 20 years cumulative production is $327 \mathrm{MMBOE}$

- Its 20 years net profit is $\$ 22,275 \mathrm{MM}$.

- The net present value of its profit is $\$ 6,787 \mathrm{MM}$ assuming $10 \%$ annual discount rate.

- Its Internal Rate of Return is $76.4 \%$.

- Its Payback Period is 4.49 years from project start.

- Its Capital Productivity Index (or its Return on Investment) is $\$ 10.47$ for each dollar invested in term of its present value.

- Its Maximum Exposure is $\$ 731 \mathrm{MM}$ in year 2022

- Its average cost per barrel equivalent is $\$ 6.18 / \mathrm{BOE}$ (2018 costs) or \$7.71/BOE (escalated costs)

- The economics of the second party indicates that:

- Its 20 years cumulative production is $40 \mathrm{MMBOE}$

- Its 20 years net profit is $\$ 1,923 \mathrm{MM}$.

- The net present value of its profit is $\$ 354 \mathrm{MM}$ assuming $10 \%$ annual discount rate. 
- Its Internal Rate of Return is $18.5 \%$.

- Its Payback Period is 6.86 years from project start.

- Its Capital Productivity Index (or its Return on Investment) is $\$ 0.61$ for each dollar invested in term of its present value.

- Its Maximum Exposure is $\$ 731 \mathrm{MM}$ in year 2022

- Its average cost per barrel equivalent is $\$ 24.02 / \mathrm{BOE}$ (2018 costs) or \$27.46/BOE (escalated costs)

- Conducting Monte Carlo simulation indicates that the project remains profitable even if worst case scenario accrued as displayed on the following table.

Table 23 : Monte Carlo results

\begin{tabular}{|l|c|c|l|c|l|l|c|c|}
\hline \multicolumn{9}{|c|}{ Monte Carlo Simulation } \\
\hline \multicolumn{3}{|c|}{ Worst-Case } & \multicolumn{3}{c|}{ Base-Case } & \multicolumn{3}{c|}{ Best-Case } \\
\hline NCF & 11,200 & \$MM & NCF & 24,197 & \$MM & NCF & 38,000 & \$MM \\
NPV & 3,000 & \$MM & NPV & 7,141 & \$MM & NPV & 12,000 & \$MM \\
IRR & 33 & $\%$ & IRR & 55.5 & $\%$ & IRR & 77 & $\%$ \\
Payout & 5.8 & Years & Payout & 4.83 & Years & Payout & 4.5 & Years \\
CPI & 2 & $\$ / \$$ & CPI & 5.84 & $\$ / \$$ & CPI & 10.9 & \$ \$ \\
ME Value & $-1,890$ & \$MM & ME Value & $-1,462$ & \$MM & ME Value & $-1,100$ & \$MM \\
Year of ME & 2022 & & Year of ME & 2022 & & Year of ME & 2022 & \\
\hline
\end{tabular}




\section{Conclusions}

Based on the results of this study, the followings are concluded:

- A new spreadsheet model is developed to study the economics of an Exploration and Production Sharing Agreement for an oil field in Libya. The results of the spreadsheet is verified with a Monte Carlo model.

- The sensitivity of NPV indicates that the project economics is highly sensitive to variations in the production rate, selling prices and the assumed discount rate, while less sensitive to variations in the capital and operating expenditures.

- The sensitivity of IRR indicates that the project economics is highly sensitive to variations in the capital cost, moderately sensitive to variations in the production rate and selling prices and less sensitive to variations in the operating cost.

- The second party considers IRR a critical indicator as it should not fall below its chosen limit rate which is normally higher than the assumed discount rate.

- The overall project is economically viable provided that:

- Its production rate does not fall below $20 \%$ of the assumed value (or a reduction of not more than $80 \%$ )

- The selling prices do not fall below $20 \%$ from the assumed values (or a reduction of not more than $80 \%$ ).

○ The discount rate does not exceed $55.5 \%$ (Its IRR\%)

- Its capital costs do not exceed $715 \%$ of the assumed values (or increase by more than $615 \%$ above the assumed values).

- Its operating costs do not exceed $1,378 \%$ of the assumed values (or increase by more than $1,278 \%$ above the assumed values).

- For the first party the project is economically viable provided that:

- Its production rate does not fall below $15 \%$ of the assumed value (or a reduction of not more than $85 \%$ ).

- The selling prices do not fall below $15 \%$ of the assumed values (or a reduction of not more than $85 \%$ ).

○ The discount rate does not exceed $76.4 \%$ (Its IRR\%) 
- Its capital costs do not exceed $1,205 \%$ of the assumed values (or increase by more than $1,105 \%$ above the assumed values).

- Its operating costs do not exceed $1,463 \%$ above the assumed values (or increase by more than $1,363 \%$ above the assumed values).

- For the second party the project is economically viable provided that:

- Its production rate does not fall below $55 \%$ of the assumed value (or a reduction of not more than $45 \%$ ).

- The selling prices do not fall below $57 \%$ of the assumed values (or a reduction of not more than $43 \%$ ).

- The discount rate does not exceed $18.5 \%$ (Its IRR\%)

○ its capital costs do not exceed $182 \%$ of the assumed values (or increase by more than $82 \%$ above the assumed values)

- Its operating costs do not exceed $805 \%$ of the assumed values (or increase by more than $705 \%$ above the assumed values).

- Based on the received data from NOC the proposed development project appears economically feasible for both parties.

- The results of Monte Carlo simulation show that the project remains positive (profitable) even with a worst-case scenario for all economic indicators. 


\section{Recommendations}

Based on the results of this study, the followings are recommended:

- Data received from NOC is to be verified before deciding to implement the project to guarantee the project viability.

- The project is to be implemented as planned as project delay normally has a negative impact on the project profitability.

- Since NPV is highly sensitive to production rate, IOC should carry out additional well testing to ensure the accuracy of the assumed well production rate.

- The economic model should be updated when any of the input data is changed.

- NOC should adopt the spreadsheet model to be able to evaluate the economics of other EPSA-IV projects. 


\section{References}

- Economics of Petroleum Exploration and Production" Course by Petroconsultants Australasia Pty Ltd, 1995

- EPSA-IV, http://wiki.openoil.net/EPSA IV

- Exploration and Production Sharing Agreement http://www.eisourcebook.org/cms/files/attachments/other/Libya\%20Model\%20E\& P\%20Agreement,\%200il\%20\&\%20Gas.pdf Articles 12-14, pages 21-29, and Article 26, page 38, and Exhibit "E" Example Calculation.

- Johnston, Daniel. (1994). International petroleum fiscal systems and production sharing contracts. PennWell Books.

- Karbal, Mohamed (2015). Libyan Oil Contracts: Negotiating the Future Generation of EPSA, Managing Partner at Karbal \& Co. http://www.karbal.net/publications-inner.php?page=epsa-contracts-in-libyanegotiating-the-future-generation-of-epsa-

- MonteCarlo http://www.palisade.com/risk/monte carlo simulation.asp

- Palmer, Bob., Partner, Energy, 2016, Conducting oil and gas activities in Libya cms.law

https://cms.law/en/content/download/279334/6964328/version/1/file/Conducting \%200il\%20\%26\%20Gas\%20Activities\%20-\%20Libya.PDF

- Shereih, Kenanah. (2015) Economics Modeling for Petroleum Exploration and Production Projects Considering Risk and imprecise Data. https://www.researchgate.net/publication/306354054 Economics modeling for petroleu $\underline{m}$ exploration and production projects considering risk and imprecise data 
- Yas, Hisham. (2010) Economic Evaluation of Petroleum Projects (Basic Aspects) https://www.iasj.net/iasj?func=fulltext\&ald=56734 


\section{- Appendix A-MATLAB Code}

This appendix displays the MATLAB codes that were used to build the economic model and perform the Monte Carlo simulation. The results for different decline curve values are displayed in Table-24 and Table-25.

\section{The MATLAB Code (Base Case Model-Project)}

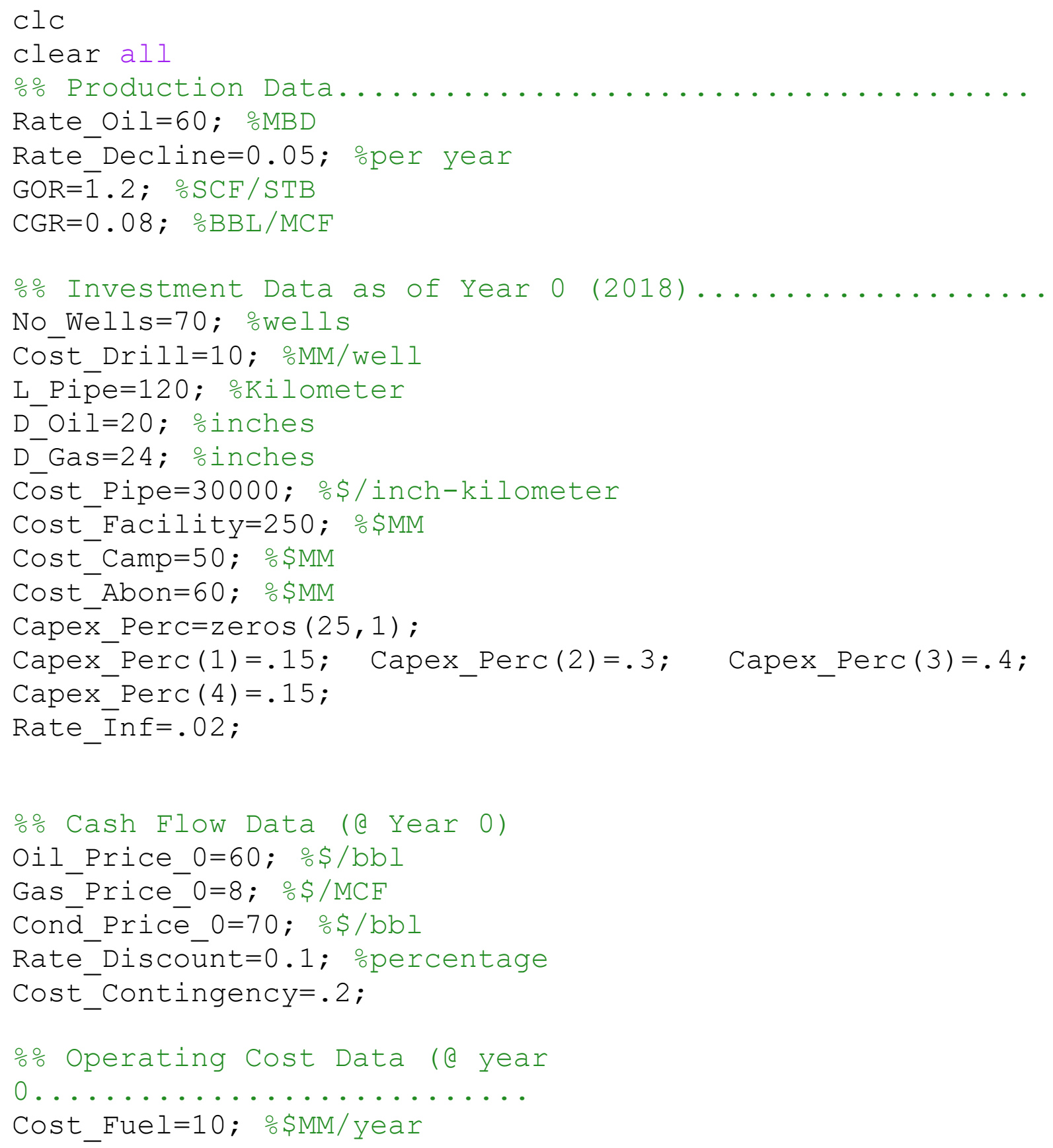


Cost_Spare=8; $\% \$ M M /$ year

Cost Maintenance $=15 ; \% \$ M M /$ year

Cost_Salary $=2000 ;$ o $\$ /$ person/month

Cost_Service $=150 ; \%$ person $/$ day

Cost_Overhead=5; $\% \$ M M /$ year

Cost Workover $=0.25$; $\frac{\circ}{0} \mathrm{MM} /$ year/well

No_Personnel=100; \%people

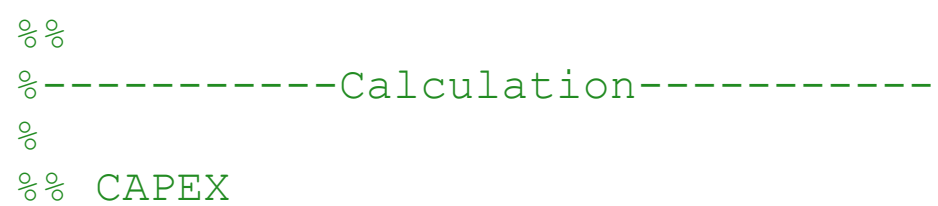

$\therefore$ CAPEX

delta_year $=[1: 25]$;

CAPEX Total=No Wells*Cost Drill+L Pipe*Cost Pipe*D Oil/1000 $000+L_{-}$Pipe ${ }^{*}$ Cost_tPipe*D_Gas $/ 100000 \overline{0}+$ Cost_Camp-Cost_Facility; CAPEX $=$ zeros $(25, \overline{1})$;

for $i=1: 25$

CAPEX (i) $=$ CAPEX Total $*(1+$ Cost Contingency $) *$ Capex Perc $(i) *(1+$ Rate_Inf)^i; if $i==25$

$\operatorname{CAPEX}(i)=$ Cost_Abon* $(1+$ Cost_Contingency $) *(1+$ Rate_Inf $) \wedge i$; end

end

$\therefore$ Production

Oil=zeros $(25,1)$;

Gas $=$ zeros $(25,1)$;

Cond $=$ zeros $(25,1)$;

for $i=5: 24$

Oil(i)=Rate Oil*.365*(1-Rate Decline)^(i-5);

Gas (i) $=\mathrm{Oil}(\bar{i}) * \mathrm{GOR}$;

Cond $(i)=\mathrm{Gas}(i){ }^{*} \mathrm{CGR}$;

end

$\therefore$ Price

Oil Price=zeros $(25,1)$;

Gas Price $=$ zeros $(25,1)$;

Cond Price=zeros $(25,1)$;

for $\bar{i}=5: 24$

Oil Price (i)=Oil Price 0*(1+Rate Inf)^(i);

Gas Price (i)=Gas Price $0 *(1+$ Rate Inf)^(i);

Cond̄_Price (i) $=$ Coñd_Pri $\bar{c} e \_0 *\left(1+R a \bar{t} e \_I n f\right) \wedge(i)$; 
end

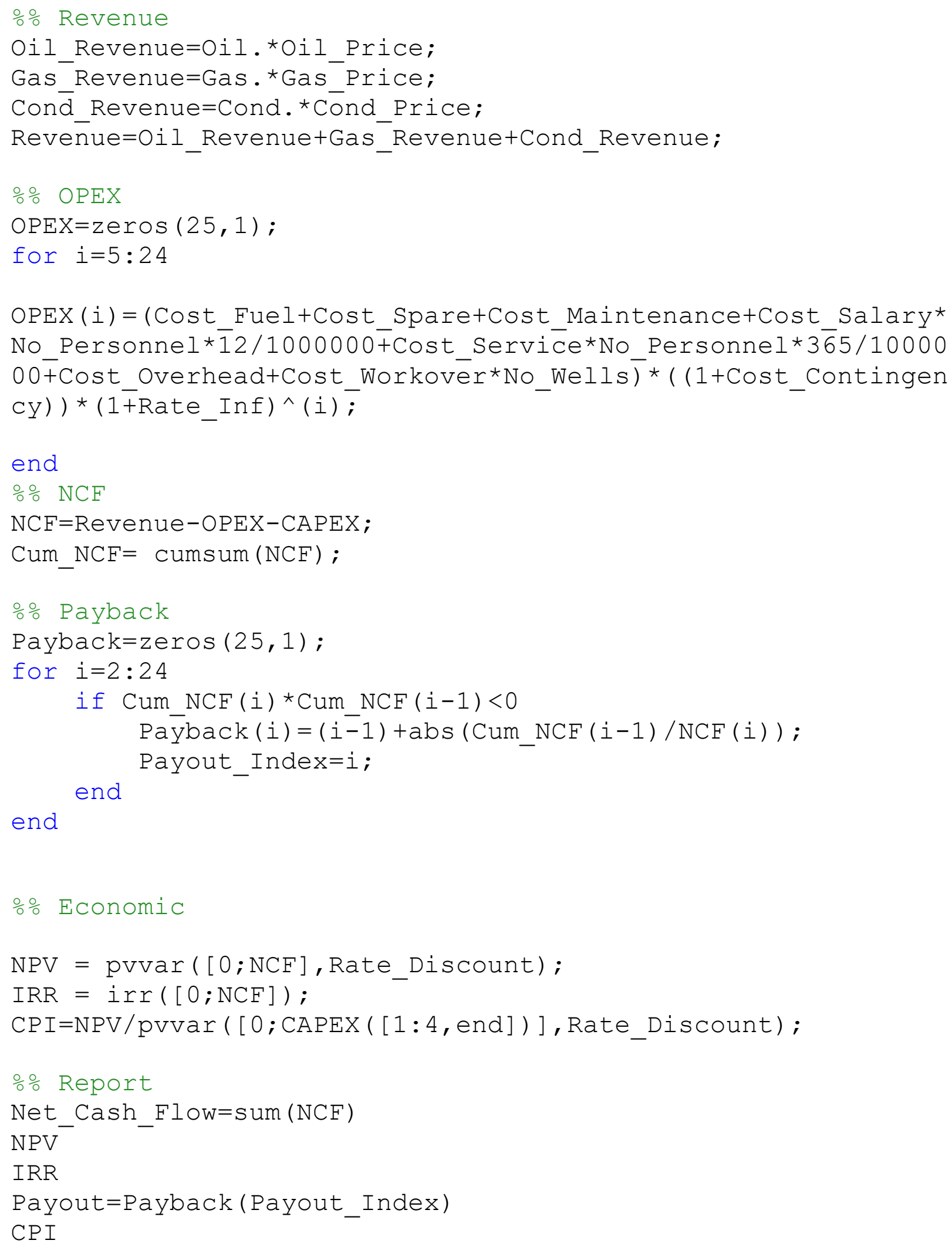


[Max_Exposure, Index_Exposure] = min (Cum_NCF) ; Max_Exposure

Year_ME=Index_Exposure+2018

\section{The MATLAB Results (Base Case Model-Project)}

$$
\begin{aligned}
& \text { Net_Cash_Flow = } \\
& 2.4197 e+04 \\
& \mathrm{NPV}= \\
& 7.1408 e+03 \\
& \mathrm{IRR}= \\
& 0.5550 \\
& \text { Payout }= \\
& 4.8302 \\
& \mathrm{CPI}= \\
& 5.8400 \\
& \text { Max_Exposure = } \\
& -1.4623 e+03 \\
& \text { Year_ME = } \\
& 2022
\end{aligned}
$$




\section{The MATLAB Code to perform Monte Carlo including all the key parameters}

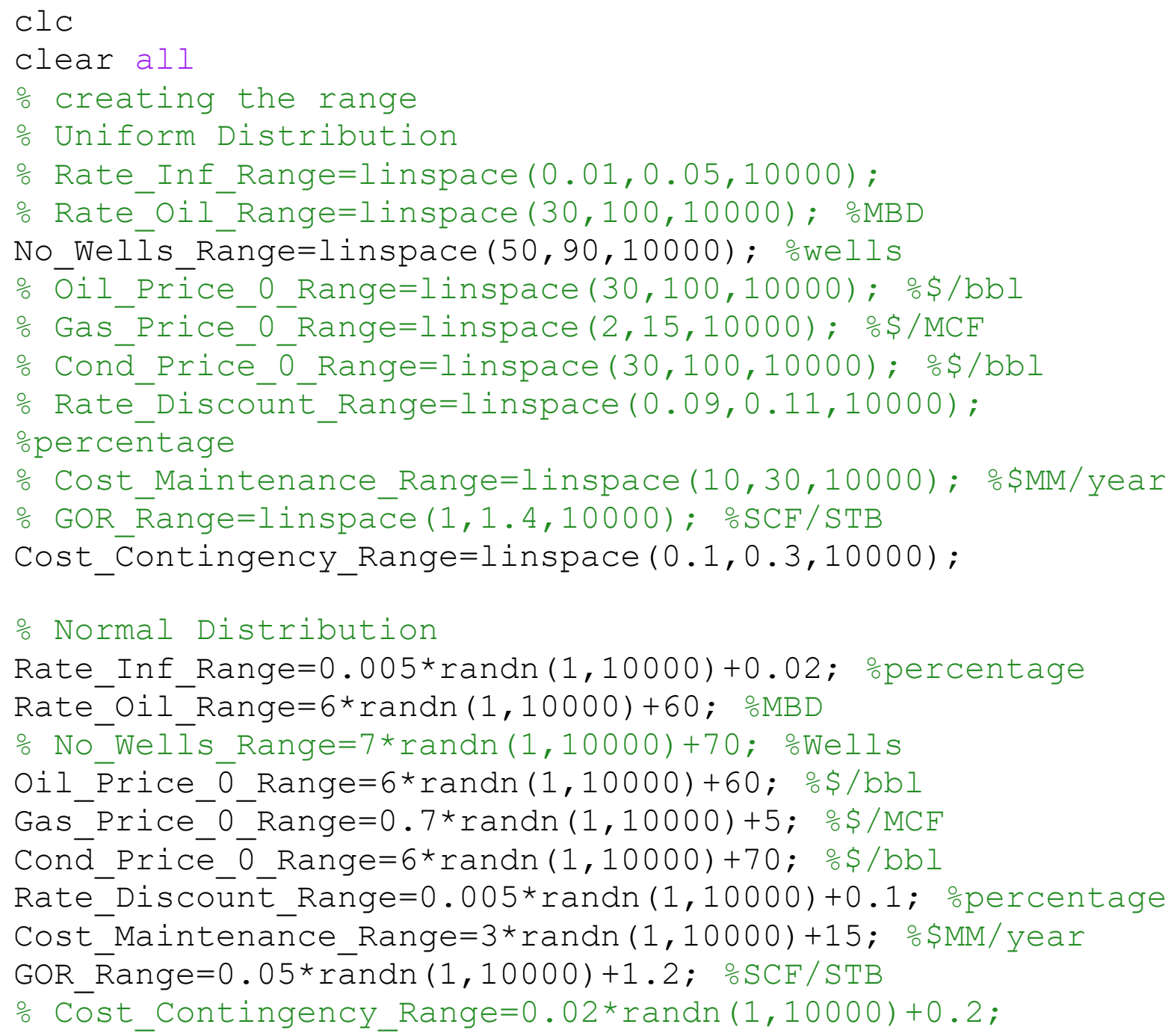


Gas Price 0=datasample (Gas Price 0 Range, 1 ); $\%$ / MCF Gas_Price_0_values $(j)=$ Gas_Price_ 0 ;

Cond_Price_0=datasample (Cond_Price_0 Range, 1 ); $\frac{0}{0} / \mathrm{bbl}$ Cond_Price_0_values $(j)=$ Cond_Price_o;

Rate Discount=datasample (Rate Discount_Range, 1$) ; \% \$ / b b l$ Rate_Discount_values $(j)=$ Rate_Discount; $\circ \$ / \mathrm{bbl}$

Cost_Maintenance=datasample (Cost_Maintenance_Range, 1);

Cost_Maintenance_values $(j)=$ Cost_Maintenance;

GOR=data sample (GOR_Range, 1$) ; \% \$ / M C F$

GOR_values $(j)=G O R$;

Cost_Contingency=datasample (Cost_Contingency_Range, 1$)$; Cost_Contingency_values $(j)=G O R$;

응 Production

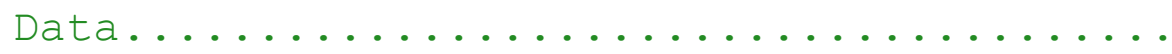

Rate Decline=0.05; oper year

$\mathrm{CGR}=\overline{0} .08 ; \therefore \mathrm{BBL} / \mathrm{MCF}$

음 Investment Data as of Year 0

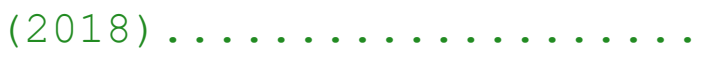

Cost_Drill=10; $\frac{\mathrm{MM} / \text { well }}{}$

L_Pipe=120; \%Kilometer

D Oil=20; \%inches

D_Gas=24; \%inches

Cost_Pipe $=30000 ;$ \% $/$ inch-kilometer

Cost_Facility $=250 ; \% \$ M M$

Cost_Camp $=50 ; \% \$ M M$

Cost_Abon $=60 ; \% \$ M M$

Capex_Perc=zeros $(25,1)$;

Capex_Perc $(1)=.15 ; \quad$ Capex_Perc $(2)=.3$;

Capex_PerC $(3)=.4 ; \quad$ Capex_PerC $(4)=.15$;

응 Operating Cost Data ( @ year

$0 \ldots \ldots \ldots \ldots \ldots \ldots$

Cost_Fuel=10; $\%$ MM/year

Cost_Spare $=8 ; \circ \$ \mathrm{MM} /$ year 
Cost_Salary $=2000 ; \%$ \$person/month

Cost_Service=150; $\% /$ person/day

Cost_Overhead=5; $\%$ MM/year

Cost_Workover $=0.25$; $\frac{0}{\mathrm{MM}} /$ year/well

No_Personnel=100; \%people

$\frac{\circ}{0} \frac{\circ}{\circ}$

음---------Calculation----------

$\frac{0}{\circ}$

응 CAPEX

delta_year $=[1: 25]$;

CAPEX_Total=No_Wells*Cost_Drill+L_Pipe*Cost_Pipe*D_Oil/1000 $000+L_{-}$Pipe ${ }^{*}$ Cost__Pipe*D_Gas $/ 100000 \overline{0}+$ Cost_Camp + Cost_Facility; CAPEX $=$ zeros $(25,1)$;

for $i=1: 25$

CAPEX $(i)=$ CAPEX_Total $*(1+$ Cost_Contingency $){ }^{*}$ Capex_Perc $(i) *(1+$ Rate_Inf)^i;

if $i==25$

$\operatorname{CAPEX}(i)=$ Cost_Abon* $(1+$ Cost_Contingency $) *(1+$ Rate_Inf $) \wedge i$; end

end

$\div$ Production

Oil=zeros $(25,1)$;

Gas=zeros $(25,1)$;

Cond=zeros $(25,1)$;

for $i=5: 24$

Oil (i)=Rate_Oil*.365*(1-Rate_Decline)^(i-5);

$\operatorname{Gas}(i)=\mathrm{Oil}(\bar{i}){ }^{*} \mathrm{GOR}$;

Cond $(i)=\mathrm{Gas}(i){ }^{*} \mathrm{CGR}$;

end

응 Price

Oil_Price=zeros $(25,1)$;

Gas_Price=zeros $(25,1)$;

Cond_Price=zeros $(25,1)$;

for $\bar{i}=5: 24$

Oil_Price (i)=Oil_Price_0*(1+Rate_Inf)^(i);

Gas Price (i)=Gas Price $0 *(1+$ Rate Inf)^(i);

Cond̄_Price $(i)=$ Coñd_Price_o* $(1+\text { Rate_e_Inf })^{\wedge}(i)$;

end 


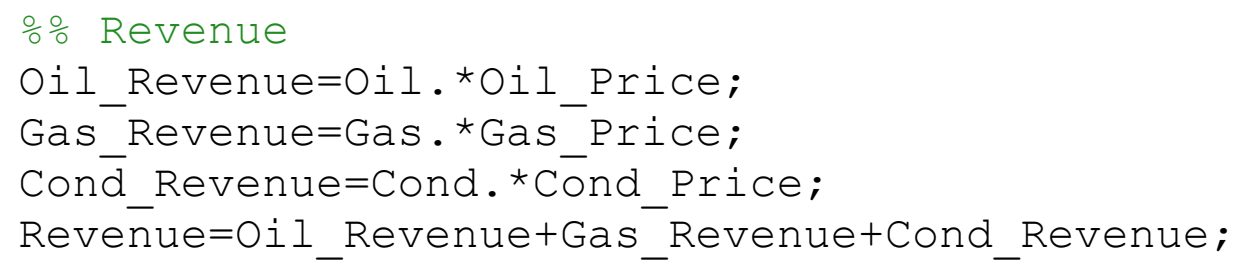

OPEX $(i)=$ Cost_Fuel+Cost_Spare+Cost_Maintenance+Cost_Salary* No Personnel* $\overline{1} 2 / 1000000+$ Cost_Service*No Personnel*365/10000 $00 \overline{+}$ Cost Overhead+Cost Workover ${ }^{*}$ No Wells $) *((1+$ Cost_Contingen cy) $) *(1+\text { Rate_Inf })^{\wedge}(i)$;

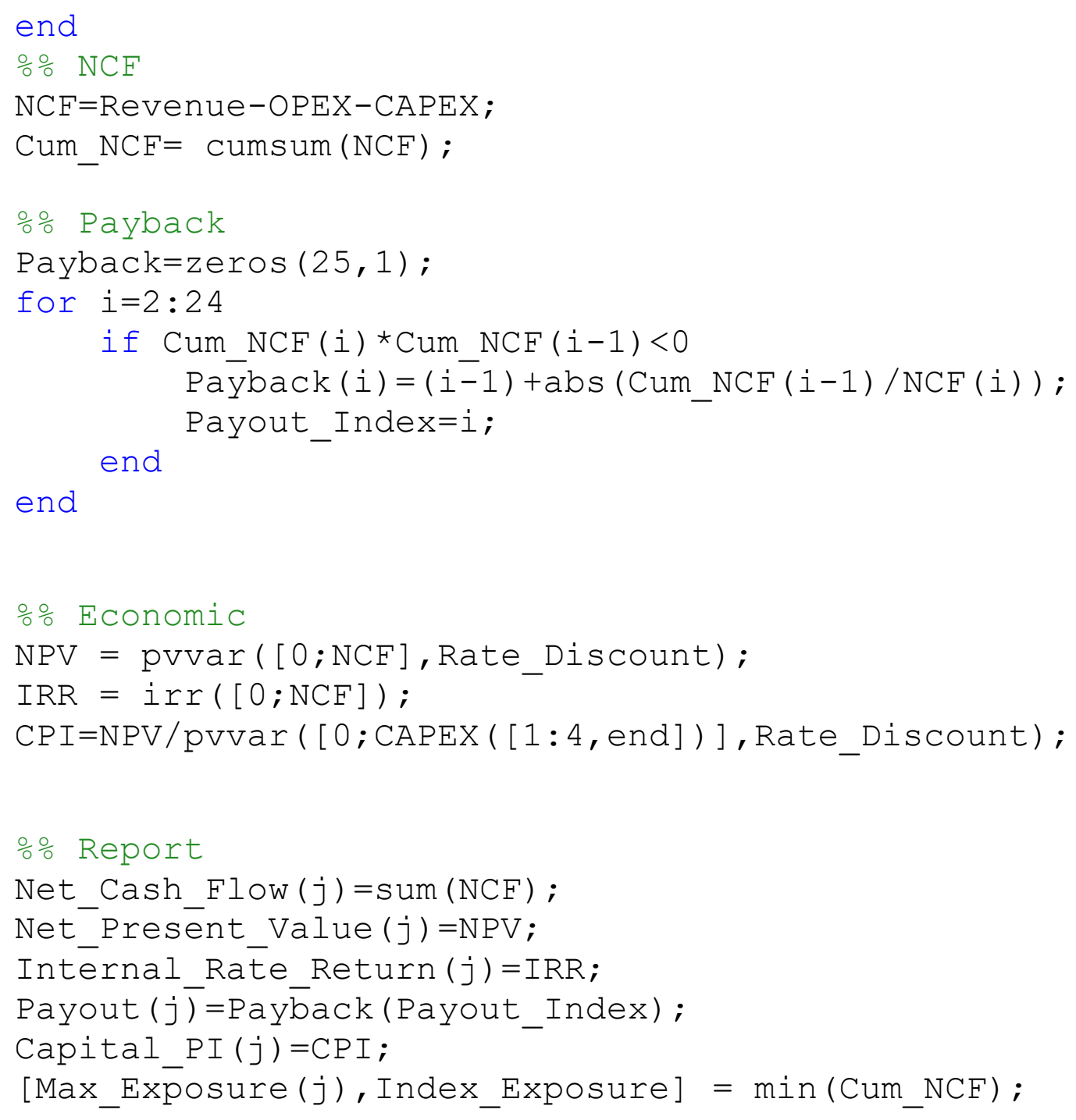




\section{Max_Exposure; \\ Year_ME $(j)=$ Index_Exposure+2018;}

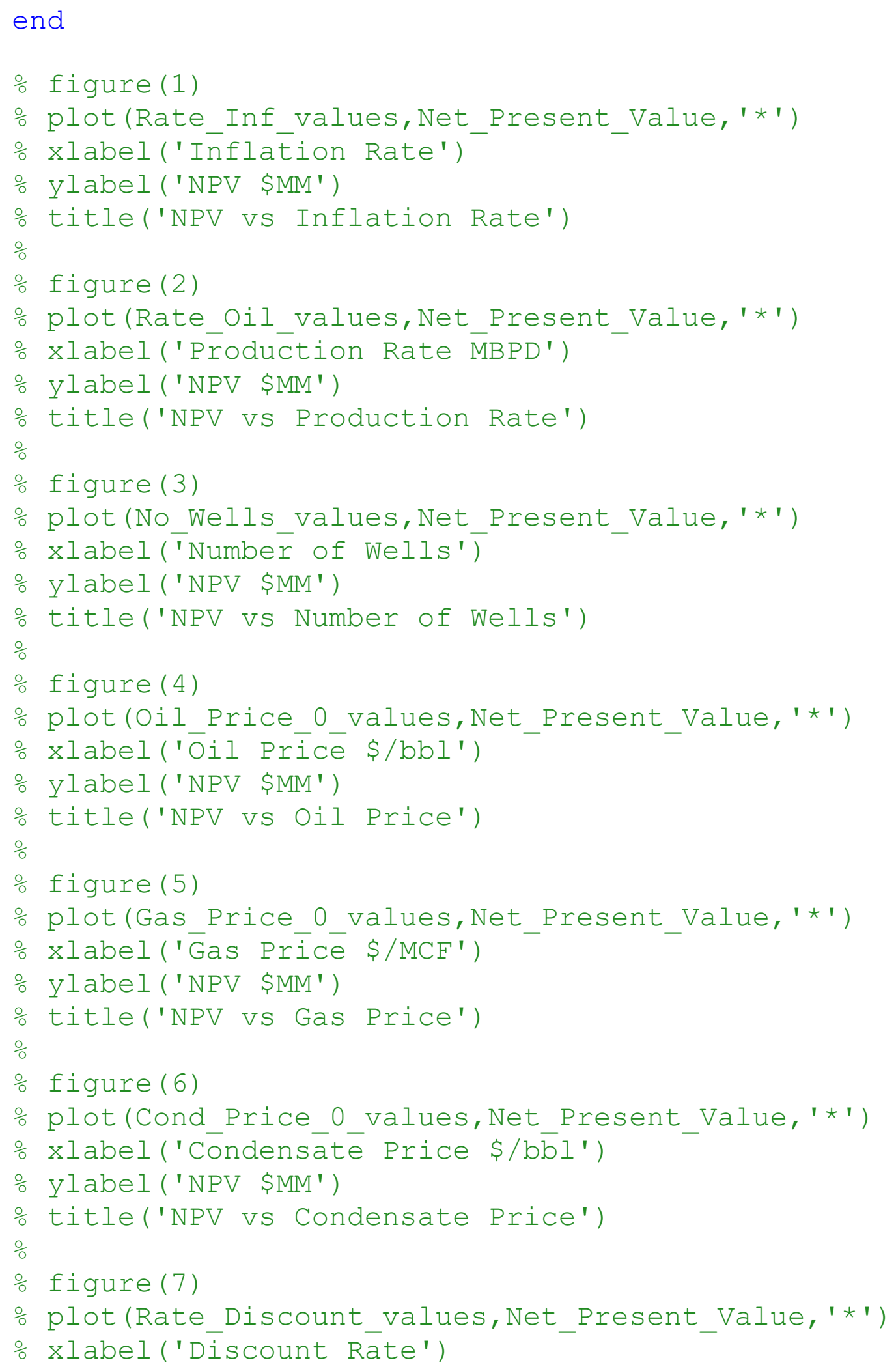




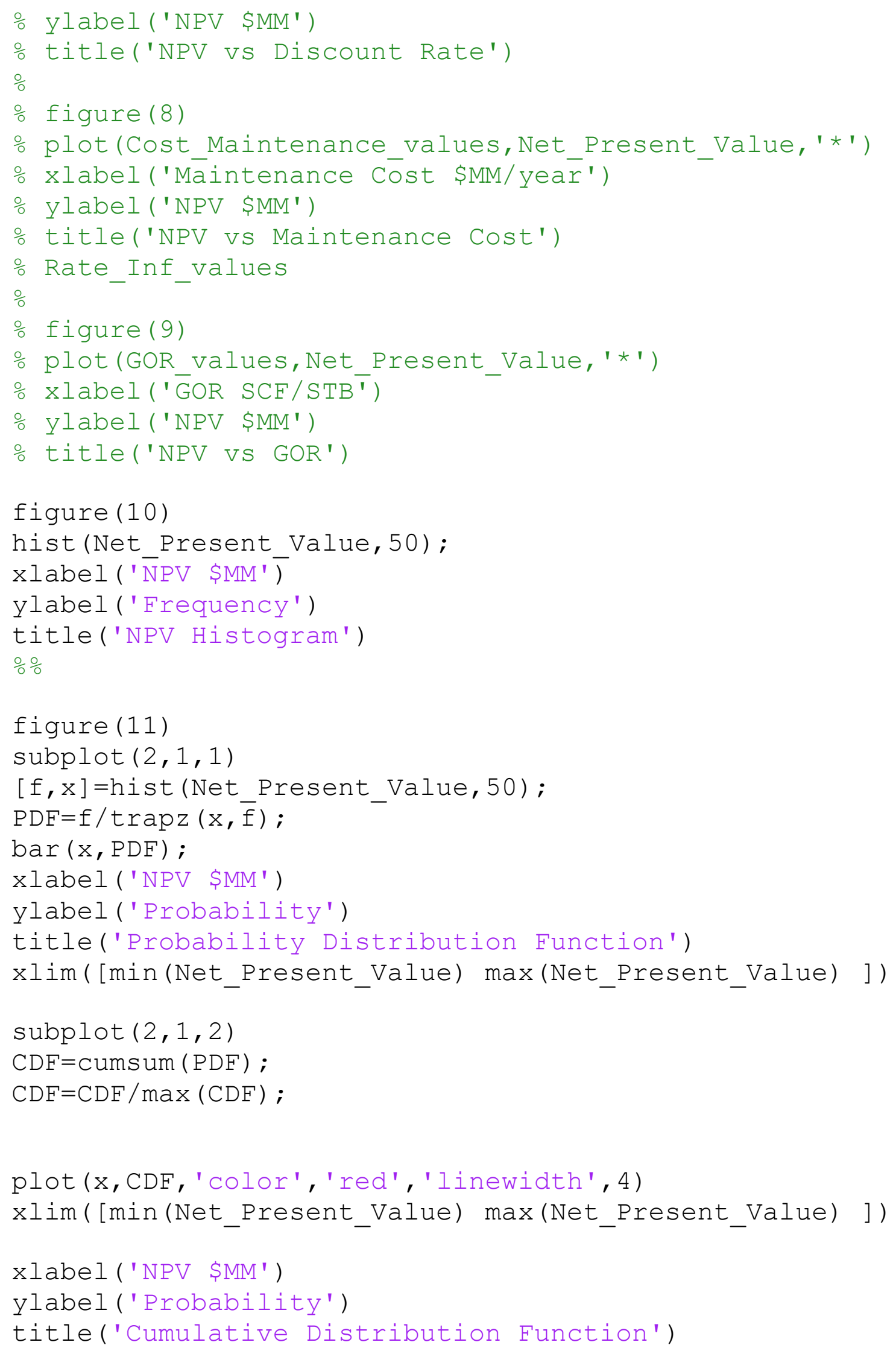




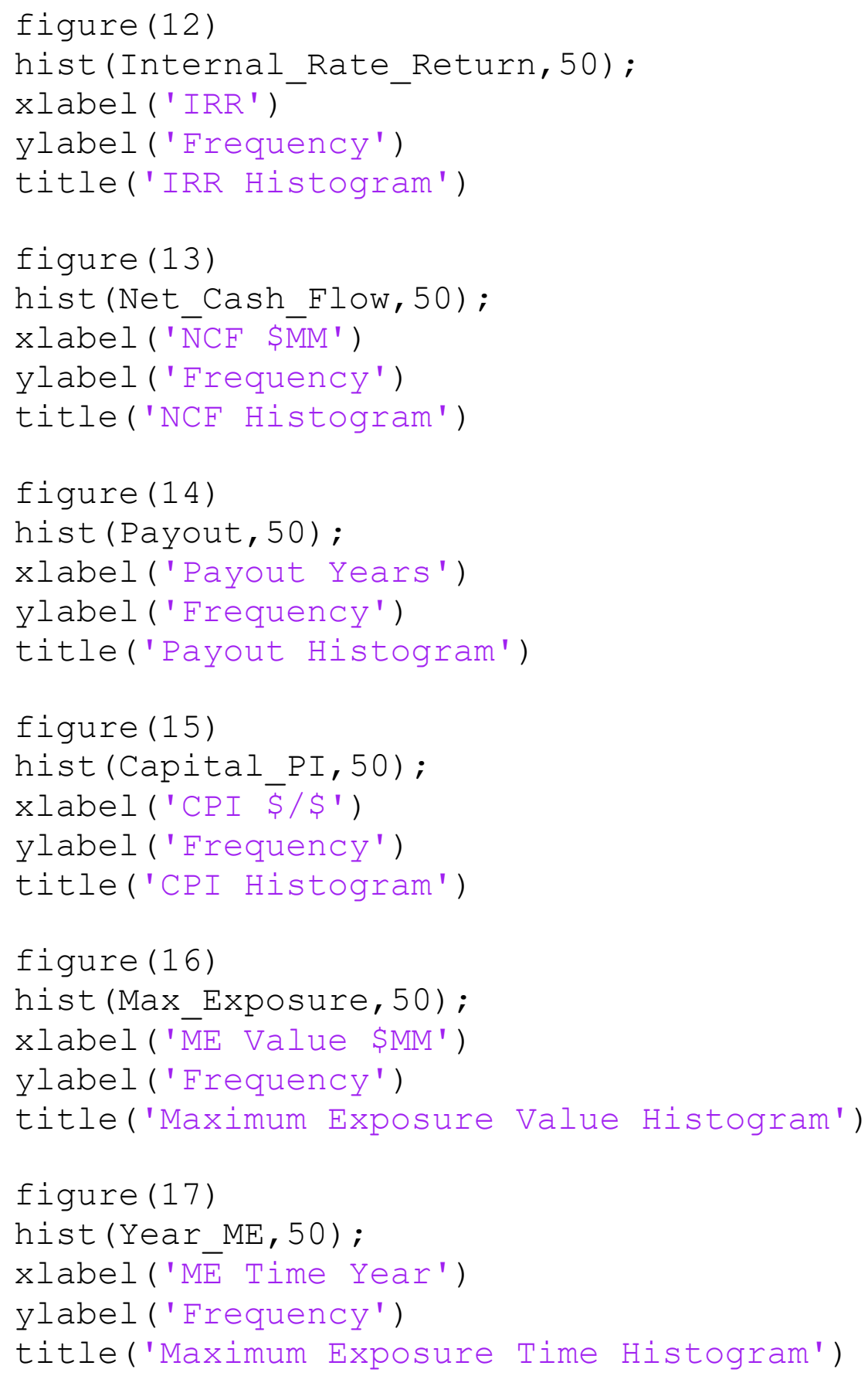


Table 24: Decline curves (Model, Exponential and Linear Decline)

\begin{tabular}{|c|c|c|c|c|c|c|c|c|c|c|}
\hline \multicolumn{2}{|c|}{ Time (years) } & \multicolumn{3}{|c|}{ Model Decline } & \multicolumn{3}{|c|}{ Exponential Decline } & \multicolumn{3}{|c|}{ Linear Decline } \\
\hline Cash Flow & Production & Daily & Annual & Cumulative & Daily & Annual & Cumulative & $\underline{\text { Daily }}$ & Annual & Cumulative \\
\hline & & $(\mathrm{BOPD})$ & (BO) & $\underline{\mathrm{BO}}$ & (BOPD) & (BO) & (BO) & $\underline{(\mathrm{BOPD})}$ & (BO) & $\underline{(\mathrm{BO})}$ \\
\hline 5 & 0 & 60,000 & 21,900 & 21,900 & 60,000 & 21,900 & 21,900 & 60,000 & 21,900 & 21,900 \\
\hline 6 & 1 & 57,000 & 20,805 & 42,705 & 57,074 & 20,832 & 42,732 & 57,000 & 20,805 & 42,705 \\
\hline 7 & 2 & 54,150 & 19,765 & 62,470 & 54,290 & 19,816 & 62,548 & 54,000 & 19,710 & 62,415 \\
\hline 8 & 3 & 51,443 & 18,777 & 81,246 & 51,642 & 18,850 & 81,397 & 51,000 & 18,615 & 81,030 \\
\hline 9 & 4 & 48,870 & 17,838 & 99,084 & 49,124 & 17,930 & 99,328 & 48,000 & 17,520 & 98,550 \\
\hline 10 & 5 & 46,427 & 16,946 & 116,030 & 46,728 & 17,056 & 116,383 & 45,000 & 16,425 & 114,975 \\
\hline 11 & 6 & 44,106 & 16,099 & 132,128 & 44,449 & 16,224 & 132,607 & 42,000 & 15,330 & 130,305 \\
\hline 12 & 7 & 41,900 & 15,294 & 147,422 & 42,281 & 15,433 & 148,040 & 39,000 & 14,235 & 144,540 \\
\hline 13 & 8 & 39,805 & 14,529 & 161,951 & 40,219 & 14,680 & 162,720 & 36,000 & 13,140 & 157,680 \\
\hline 14 & 9 & 37,815 & 13,802 & 175,753 & 38,258 & 13,964 & 176,684 & 33,000 & 12,045 & 169,725 \\
\hline 15 & 10 & 35,924 & 13,112 & 188,866 & 36,392 & 13,283 & 189,967 & 30,000 & 10,950 & 180,675 \\
\hline 16 & 11 & 34,128 & 12,457 & 201,322 & 34,617 & 12,635 & 202,602 & 27,000 & 9,855 & 190,530 \\
\hline 17 & 12 & 32,422 & 11,834 & 213,156 & 32,929 & 12,019 & 214,621 & 24,000 & 8,760 & 199,290 \\
\hline 18 & 13 & 30,801 & 11,242 & 224,398 & 31,323 & 11,433 & 226,054 & 21,000 & 7,665 & 206,955 \\
\hline 19 & 14 & 29,260 & 10,680 & 235,078 & 29,795 & 10,875 & 236,929 & 18,000 & 6,570 & 213,525 \\
\hline 20 & 15 & 27,797 & 10,146 & 245,225 & 28,342 & 10,345 & 247,274 & 15,000 & 5,475 & 219,000 \\
\hline 21 & 16 & 26,408 & 9,639 & 254,863 & 26,960 & 9,840 & 257,114 & 12,000 & 4,380 & 223,380 \\
\hline 22 & 17 & 25,087 & 9,157 & 264,020 & 25,645 & 9,360 & 266,475 & 9,000 & 3,285 & 226,665 \\
\hline 23 & 18 & 23,833 & 8,699 & 272,719 & 24,394 & 8,904 & 275,379 & 6,000 & 2,190 & 228,855 \\
\hline 24 & 19 & 22,641 & 8,264 & 280,983 & 23,204 & 8,470 & 283,848 & 3,000 & 1,095 & 229,950 \\
\hline Total & & & 280,983 & & & 283,848 & & & 229,950 & \\
\hline
\end{tabular}

Table 25 : Decline curves (Model, Harmonic and Hyperbolic Decline)

\begin{tabular}{|c|c|c|c|c|c|c|c|c|c|c|}
\hline \multicolumn{2}{|c|}{ Time (years) } & \multicolumn{3}{|c|}{ Model Decline } & \multicolumn{3}{|c|}{ Harmonic Decline } & \multicolumn{3}{|c|}{ Hyperbolic Decline } \\
\hline Cash Flow & Production & Daily & Annual & Cumulative & Daily & Annual & Cumulative & Daily & Annual & Cumulative \\
\hline & & (BOPD) & (BO) & (BO) & (BOPD) & (BO) & (BO) & (BOPD) & (BO) & (BO) \\
\hline 5 & 0 & 60,000 & 21,900 & 21,900 & 60,000 & 21,900 & 21,900 & 60,000 & 21,900 & 21,900 \\
\hline 6 & 1 & 57,000 & 20,805 & 42,705 & 57,143 & 20,857 & 42,757 & 57,109 & 20,845 & 42,745 \\
\hline 7 & 2 & 54,150 & 19,765 & 62,470 & 54,545 & 19,909 & 62,666 & 54,422 & 19,864 & 62,609 \\
\hline 8 & 3 & 51,443 & 18,777 & 81,246 & 52,174 & 19,043 & 81,710 & 51,920 & 18,951 & 81,559 \\
\hline 9 & 4 & 48,870 & 17,838 & 99,084 & 50,000 & 18,250 & 99,960 & 49,587 & 18,099 & 99,659 \\
\hline 10 & 5 & 46,427 & 16,946 & 116,030 & 48,000 & 17,520 & 117,480 & 47,407 & 17,304 & 116,962 \\
\hline 11 & 6 & 44,106 & 16,099 & 132,128 & 46,154 & 16,846 & 134,326 & 45,369 & 16,560 & 133,522 \\
\hline 12 & 7 & 41,900 & 15,294 & 147,422 & 44,444 & 16,222 & 150,548 & 43,459 & 15,862 & 149,384 \\
\hline 13 & 8 & 39,805 & 14,529 & 161,951 & 42,857 & 15,643 & 166,191 & 41,667 & 15,208 & 164,593 \\
\hline 14 & 9 & 37,815 & 13,802 & 175,753 & 41,379 & 15,103 & 181,294 & 39,983 & 14,594 & 179,187 \\
\hline 15 & 10 & 35,924 & 13,112 & 188,866 & 40,000 & 14,600 & 195,894 & 38,400 & 14,016 & 193,203 \\
\hline 16 & 11 & 34,128 & 12,457 & 201,322 & 38,710 & 14,129 & 210,023 & 36,909 & 13,472 & 206,674 \\
\hline 17 & 12 & 32,422 & 11,834 & 213,156 & 37,500 & 13,688 & 223,711 & 35,503 & 12,959 & 219,633 \\
\hline 18 & 13 & 30,801 & 11,242 & 224,398 & 36,364 & 13,273 & 236,984 & 34,176 & 12,474 & 232,107 \\
\hline 19 & 14 & 29,260 & 10,680 & 235,078 & 35,294 & 12,882 & 249,866 & 32,922 & 12,016 & 244,123 \\
\hline 20 & 15 & 27,797 & 10,146 & 245,225 & 34,286 & 12,514 & 262,380 & 31,736 & 11,583 & 255,707 \\
\hline 21 & 16 & 26,408 & 9,639 & 254,863 & 33,333 & 12,167 & 274,547 & 30,612 & 11,173 & 266,880 \\
\hline 22 & 17 & 25,087 & 9,157 & 264,020 & 32,432 & 11,838 & 286,385 & 29,548 & 10,785 & 277,665 \\
\hline 23 & 18 & 23,833 & 8,699 & 272,719 & 31,579 & 11,526 & 297,911 & 28,537 & 10,416 & 288,081 \\
\hline 24 & 19 & 22,641 & 8,264 & 280,983 & 30,769 & 11,231 & 309,142 & 27,578 & 10,066 & 298,148 \\
\hline Total & & & 280,983 & & & 309,142 & & & 298,148 & \\
\hline
\end{tabular}




\section{Appendix B- Definitions and Equations}

Cash Flow Equations: The following key equations (Petroconsultants. 1995) were used in the spreadsheet model to calculate the Net Cash Flow and the Economic Indicators:

- Net Cash Flow (NCF): is the amount of net profit that results from deducting the annual total costs from the annual total revenue. This represents the total net profit expected to be earned during the life of the project in terms of money-of-the-day. NCF is calculated using the following equation: NCF $=$ Cash Inflow - Cash Outflow $=$ Revenue - Capex - Opex

- Net Present Value (NPV): is the present value of the stream of future net cash flows. It is calculated by incorporating the assumed discount rate of $10 \%$. In other words it represents how much extra profit will be earned in terms of the present value compared to investing in a bank that offers $10 \%$ annual interest rate. NPV is calculated using the following equation:

$\mathrm{NPV}=\sum_{\mathrm{i}=1}^{\mathrm{n}} \frac{\mathrm{NCF}_{\mathrm{i}}}{(1+\mathrm{r})^{\mathrm{i}}}$ where $\mathrm{r}=$ discount rate, $\mathrm{n}=$ number of years

- Internal Rate of Return (IRR): is the interest rate the project will generate on its investment. It also means that the project will earn the same profit as a bank that will offer the same annual interest on the invested amount. Mathematically the IRR is the discount rate that yields $N P V=0$.

The IRR is determined by using a spreadsheet built-in function, by trial \& error or graphically by plotting the NPV versus discount rate.

- Payback Period (or Payout): is the amount of time required for the net cash flow projection to recover the invested amount. It is determined when the cumulative net cash flow equals 0 . 
- The Capital Productivity Index (CPI) or Return on Investment (ROI): is the amount of profit the project will earn for each dollar invested in terms of the present value. It is calculated using the following equation:

$$
\text { Capital Productivity Index }=\frac{\text { Net Present Value of Future Cash Flow }}{\text { Present Value of the Capital Costs }}
$$

Annual Oil Production: calculates the annual oil production rate in MMB @ year 5 using this equation:

Production in year $5=$ Daily production rate $\times 0.365$

From year 6 onwards annual production is calculated using the assumed exponential decline rate:

Production in year $(n)=$ production in year $(n-1) \times(1-$ decline rate $)$

Annual Gas Production: calculates the annual gas production in (BCF) using the assumed Gas/Oil Ratio:

Annual gas production in year $(n)=$ Oil production in year $(n) \times($ Gas/Oil Ratio $) \div 1000$

Annual Condensate Production: calculates the annual condensate production in (MMB) using the assumed Condensate/Gas Ratio: 
Annual condensate production in year $(\mathrm{n})=$ Gas production in year $(\mathrm{n}) \times($ Condensate $/$ Gas Ratio)

Oil Price: calculates oil selling price in $(\$ / \mathrm{bbl}$.) using the assumed oil price in year 0 and the assumed inflation rate:

Oil price in year $(n)=$ Oil price in year $(0) \times(1+\text { Inflation Rate })^{\mathrm{n}}$

Gas Price: calculates gas selling price in $(\$ / M C F)$ using the assumed gas price in year 0 and the assumed inflation rate:

Gas price in year $(\mathrm{n})=$ Gas price in year $(0) \times(1+\text { Inflation Rate })^{\mathrm{n}}$

Condensate Price: calculates condensate selling price in (\$/bbl.) using the assumed condensate price in year 0 and the assumed inflation rate:

Condensate price in year $(\mathrm{n})=$ Condensate price in year $(0) \times(1+\text { Inflation Rate })^{\mathrm{n}}$

Oil Revenue: calculates the annual oil revenue in ( $\$ M M)$ using this equation:

Oil revenue in year $(n)=$ Oil production in year $(n) \times$ Oil price in year $(n)$

Gas Revenue: calculates the annual gas revenue in ( $\$ M M)$ using this equation:

Gas revenue in year $(n)=$ Gas production in year $(n) \times$ Gas price in year $(n)$ 
Condensate Revenue: calculates the annual condensate revenue in (\$MM) using this equation:

Condensate revenue in year $(n)=$ Condensate production in year $(n) \times$ Condensate price in year ( $\mathrm{n})$

Total Revenue: calculates the total revenue in $(\$ M M)$ by summing the revenues of the individual products using this equation:

Total revenue in year $(n)=$ Oil revenue in year $(n)+$ Gas revenue in year $(n)+$ Condensate revenue in year $(\mathrm{n})$

Capex: calculates the annual capex profile from the assumed data, then calculates capex allocated for each of the first 4 years by incorporating capex percentage allocation for each year. Cost contingency and the inflation rate are then incorporated as per these equations:

Total Capex $=$ Number of wells $\times$ Cost of each well + Oil pipeline length $\times$ its diameter $\times$ Pipeline cost + Gas pipeline length $\times$ its diamter $\times$ Pipeline cost + Cost of surface facilites + Cost of camp

Capex Allocated to year $(n)=$ Total Capex $\times$ percentage of capex allocation for year $(n) \times$ $(1+\text { inflation rate })^{\mathrm{n}} \times(1+$ cost contingency $)$

Abandonment cost in year (25) = Abandoment cost in year $(0) \times(1+\text { Inflation Rate })^{25} \times$ $(1+$ contingency $)$

Opex (Fuel): calculates the annual fuel consumptions in $(\$ M M)$ by incorporating the inflation rate and using this equation: 
Fuel consumptions in year $(\mathrm{n})=$ Fuel consumption in year $(0) \times(1+\text { Inflation Rate })^{\mathrm{n}} \times$ $(1+$ contingency $)$

Opex (Spares): calculates the annual Spares costs in $(\$ M M)$ by incorporating the inflation rate and using this equation:

Spare costs in year $(\mathrm{n})=$ Spare costs in year $(0) \times(1+\text { Inflation Rate })^{\mathrm{n}} \times(1+$ contingency)

Opex (Maintenance): calculates the annual maintenance costs in $(\$ M M)$ by incorporating the inflation rate and using this equation:

Maintenance costs in year $(\mathrm{n})=$ Maintenance costs in year $(0) \times(1+\text { Inflation Rate })^{\mathrm{n}} \times$ $(1+$ contingency $)$

Opex (Salaries): calculates the annual salaries in (\$MM) by incorporating the inflation rate and using this equation:

Salaries in year $(\mathrm{n})=$ Monthly salary of each person in year $(0) \times$ numberof people $\times(1+$ Inflation Rate $)^{\mathrm{n}} \times 12 \div 1,000,000 \times(1+$ contingency $)$

Opex (Services): calculates the annual catering and services costs in (\$MM) by incorporating the inflation rate and using this equation:

Services in year $(n)=$ Services cost per person per day in year $(0) \times$ number of people $\times$ $365 \times(1+\text { Inflation Rate })^{\mathrm{n}} \div 1,000,000 \times(1+$ contingency $)$ 
Opex (O/H): calculates the annual Overhead costs in $(\$ M M)$ by incorporating the inflation rate and using this equation:

Overhead Costs in year $(\mathrm{n})=$ Overhead costs in year $(0) \times(1+\text { Inflation Rate })^{\mathrm{n}} \times(1+$ contingency)

Total Opex: calculates the total annual operating costs in $(\$ M M)$ by using this equation:

Operating Costs in year $(n)=$ Summation of individual operating costs in year(n)

Project net cash flow: is calculated using these equations:

Project Net Cash Flow in year $(\mathrm{n})=$ Cash inflow in year $(\mathrm{n})$ - Cash outflow in year $(\mathrm{n})$ Project Net Cash Flow in year (n) = Project revenue in year (n) - Capex in year (n) Opex in year (n)

Cumulative net cash flow: is calculated using the following equation:

Cumulative Net Cash Flow in year $(\mathrm{n})=\sum_{\mathrm{i}=0}^{\mathrm{i}=\mathrm{n}} \mathrm{NCF}_{\mathrm{i}}$

Payback Period: is calculated and inserted when the cumulative net cash flow (CCF) becomes positive using the following equation: 
If $\mathrm{CCF}_{n} \times \mathrm{CCF}_{n-1}$ is negative, then $\mathrm{PB}_{n}=(\mathrm{n}-1)+\mathrm{ABS}\left(\frac{\mathrm{CCF}_{n-1}}{\mathrm{NCF}_{\mathrm{n}}}\right)$, otherwise $=0$ Project Payback $=\sum_{\mathrm{i}=0}^{\mathrm{i}=25} \mathrm{~PB}_{\mathrm{i}}$

Net Cash Flow (NCF): is the amount of net profit that results from deducting the annual total costs from the annual total revenue. This represents the total net profit expected to be earned during the life of the project in terms of money-of-the-day. NCF is calculated using the following equation:

$$
\mathrm{NCF}=\text { Cash Inflow }- \text { Cash Outflow }=\text { Revenue }- \text { Capex }- \text { Opex }
$$

Net Present Value (NPV): is the present value of the stream of future net cash flows. It is calculated by incorporating the assumed discount rate of $10 \%$. In other words it represents how much extra profit will be earned in terms of the present value compared to investing in a bank that offers $10 \%$ annual interest rate. NPV is calculated using the following equation:

$$
\mathrm{NPV}=\sum_{\mathrm{i}=1}^{\mathrm{n}} \frac{\mathrm{NCF}_{\mathrm{i}}}{(1+\mathrm{r})^{\mathrm{i}}} \text {, where } \mathrm{r}=\text { discount rate, } \mathrm{n}=\text { number of years }
$$

Internal Rate of Return (IRR): is the interest rate the project will generate on its investment. It also means that the project will earn the same profit as a bank that will offer the same annual interest on the invested amount. Mathematically the IRR is the discount rate that yields $\mathrm{NPV}=0$. 
Payback Period (or Payout): is the amount of time required for the net cash flow projection to recover the invested amount. It is determined when the cumulative net cash flow equals 0 .

The Capital Productivity Index (CPI) or Return on Investment (ROI): is the amount of profit the project will earn for each dollar invested in terms of the present value. It is calculated using the following equation:

$$
\text { Capital Productivity Index }=\frac{\text { Net Present Value of Future Cash Flow }}{\text { Present Value of the Capital Costs }}
$$

Maximum Exposure (ME): is the minimum (or the maximum negative) cumulative cash flow. It normally takes place when the entire Capex is spent prior to generating any profit. It also indicates the maximum loss in case of project failure.

Second Party Abandonment Cost: is calculated for year 25 using this equation:

Second party abandonment cost in year $25=$ Inflated abandonment cost $x$ Second party share of capex $\times(1+$ contingency $)$

Cumulative Production: is calculated using this equation:

Cumulative oil production in year $(\mathrm{n})=\sum_{\mathrm{i}=0}^{\mathrm{i}=\mathrm{n}}(\text { Annual oil production })_{\mathrm{i}}$

Remaining Reserves: is calculated using this equation: 
Remaining oil reserves in year $(\mathrm{n})=$ Cumulative oil production in year $25-$ Cumulative oil production in year $(n-1)$

Second Party Inflated Abandonment Provision: is calculated using the units-ofproduction depreciation method when the "R" ratio exceeds 1 using this equation:

Second party abandonment provision in year $(\mathrm{n})=$

Remaining abandonment cost as of year $(n) \times \frac{\text { Annual oil production in year }(n)}{\text { Remaining reserves as of year }(n)}$

The calculated second party abandonment provision is inflated for year 25. To calculate its present value at the year it will be paid to the first party this equation is used:

Present value of second party abandonment provision at year $(\mathrm{n})=$

Inflated abandonment provision at year $(\mathrm{n}) \div(1+\text { Assumed discount rate })^{(25-\mathrm{n})}$

Second Party Entitled Revenue: is calculated from the total project revenue based on the second party entitled share of $15 \%$ according to EPSA-IV using this equation:

Second party entitled revenue $=$ Total project revenue $\times$ second party share

Cumulative entitled revenue in year $(\mathrm{n})=\sum_{\mathrm{i}=0}^{\mathrm{i}=\mathrm{n}}(\text { Entitled annual revenue })_{\mathrm{i}}$

The second party costs at year $\mathrm{n}$ is the summation of its share of payable Capex, Opex and its abandonment provision using this equation:

Second party costs $=$ Its share of Capex + Its share of Opex + Its abandonment provision 
Second party cumulative costs in year $(n)=$ Its past exploration costs $+\sum_{i=0}^{\mathrm{i}=\mathrm{n}}(\mathrm{its} \text { costs })_{\mathrm{i}}$

Cost Recovery: is calculated based on the annual and cumulative costs and the annual and cumulative entitled revenue. If the cumulative cost exceeds the cumulative revenue then all the entitled revenue is used for cost recovery. Otherwise only the amount of the annual cost is received from the revenue. In this case the remaining revenue is considered Profit Oil as per this equation:

Profit Oil in year $(n)=$ Second party entitled revenue in year(n) - Cost recovery in year(n)

Index "A" Factor: is calculated with the following equations:

Second party received revenue $=$ Cost recovery + its share of profit oil

Second party share of profit oil $=$ Profit oil $\times$ "A" factor $\times$ "Base" factor

"R" Ratio at year $(\mathrm{n})=\frac{\text { Second party cumulative revenue as of year }(\mathrm{n}-1)}{\text { Second party cumulative costs as of year }(\mathrm{n}-1)}$

Base "B" Factor: is calculated using this equation:

Base Factor $=\frac{\sum \text { Each segment production rate } \times \text { its designated factor }}{\text { Total field production rate }}$

A combined factor is calculated by multiplying the "A" factor with the "B" factor:

Combined Factor $=$ "A" factor $\times$ "B" factor 
Profit Oil: is calculated by deducting the Cost Recovery from second party entitled revenue as per this equation:

Profit Oil = Second party entitled revenue - its cost recovery

Second party share of Profit Oil: is calculated using this equation:

Second party share of profit oil $=$ Profit Oil $\times$ Combined factor

Second Party Net Cash Flow Profile: is calculated by deducting its cash out-flow from its cash in-flow as per the following equation:

Second party NCF $=$ Its received revenue - Its total costs

Second party NCF $=$ Cost Recovery + Its share of profit oil - Its share of Capex Its share of Opex - Its abandonment provision 